\title{
Interwediate- and High-Energy Reactions \\ of Uranium with Neon and Carbon
}

\author{
Patrick Lee McGaughey \\ Ph. D. Thesis
}

November 1982

$$
\begin{aligned}
& \text { Nuclear Sciences Division } \\
& \text { Lawrence Berkeley Laboratory } \\
& \text { University of California } \\
& \text { Berkeley, CA } 94720
\end{aligned}
$$

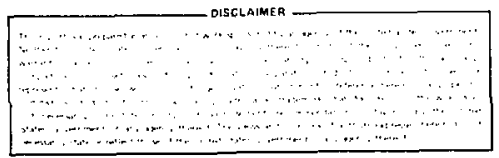

\section{NOTICE}

PORTIONS OF THIS REPORT ARE ILLEGIBLE. II

has been reproduced from the best available copy to permit the broadest possible availability.

This work was supported by the Director, Office of Energy Research, Division of Nuclear Physics of the Office of High Energy and Nuclear Physics of the U. S. Department of Energy under Contract DE-AC03-76SF00098. 


\title{
Intermedfate and High Energy Reactions \\ of Uranium wh Heon and Carbon
}

\author{
Patrick Iee HcGaughey \\ Laurence Berikeley Leboratory \\ Univerafty of california \\ Berkeley, CA 94720
}

\section{ABSTRACT}

Target fragment production from the Interactions of $1.0,3.0$, 4.8, and $12 \mathrm{GeV}{ }^{12} \mathrm{C}$ and $5.0,8.0,20$, and $42 \mathrm{GeV}{ }^{20} \mathrm{Ne}$ wth uranium has been neasured using off-line gamma-ray spectroscople techniques. The experimental charge and mass yleld distributions are gemerally cossistent with the concepts of Iimiting fragmentation and factorization at energie; of $3.0 \mathrm{GeV}$ and above. The total profectile kinetic energy was found to be the relevant scaling parameter for the comparison of reactions induced by profectiles of different sizes. Light fragments wh mass number less than 60 were found to violate limiting fragmentation, and had excitation functions that we strongly increasing with profectile energy until 8.0 to $12.0 \mathrm{GeV}$. With the $1.0 \mathrm{GeV}{ }^{12} \mathrm{C}$ beam the pattern of mass ylelds was quite different from that of all the other reactions, with the normal peak 1n the fisston masa region $(80<A<145)$, but with much lower ylelds below mass number 60 and between mass numbers 145 and 210, Indicating that these fragments are formed primarily in very energetic reactions in wich large excitation energies are transferred to and significant amounts of mass are removed from the target nucle 18.

Theoretical predictions of the intra-nuclesr cascade, nuclear fireball, and nuclear firestreak models are compared wth the 
experimental reaults. The fireball model is found to be inferior to the other two, due to its fallure to deposit large enough excitation energies whin the fragment precursora. The Intramuclear cascade and nuclear fireatreak models are both able to predict the general ahapes of the experimental distributions, with the exception of the ytelds for the lightest fragments. However, these two models are found to be incapable of reproducing the cypical sarget fragment recoll velocities, which suggests that sowe unexpected wechanism must exist for the transfer of large axcitation energies to the fragment precursors wthout the correspondingly large amounts of recoil momenta. 


\section{ACKNOWLEDGEMENTS}

I would like to take th1s opportunity to recognize the contributions of a few of those people who have assisted and encouraged me in the pursult of this thesis work. F1rat of all, let me express my gratitude to Glenn T. Seaborg, my research director, who more than anyone else made this profect posstble and enjoyable. I also wish to give thanks to my colleagues Waiter Loveland, Rfell Aleklett, Dian Lee and David Morrissey for the Invalusble assistatice which they rendered in performing the experimenta, developing the theorecical models, and for their comradery. Elnally, special thani:s are due to my friends both Inside and outgide of the scientific disciplines, and to my family, whout whom my life at Berkeley would have been much less pleasant.

This work was supported by the Director, Office of Energy Research, Division of Nuclear Physics of the Office of High Energy and Nuclear Physics of the U. S. Department of Energy under Contract DE-ACO3-76SF00098. 
I. Introduction

A. Background 1

B. Hypotheses of Fragmentation 4

1. Limiting Fragmentation

2. Factorization 5

3. Total R1netic Energy Dependence 5

C. Previous Studies of Target Fragmentation 6

$\begin{array}{ll}\text { D. Proposed Study } & 10\end{array}$

II. Experimental 11

A. Introduction 11

B. Targetry and Irrad1at1ons 12

C. Gamma-ray Spectroscopy 13

1. Measurement Systems 13

2. Calibrations $\quad 14$

D. Data Analysis 16

1. Peak Analyols 16

2. Half-11fe Analysis 17

3. Cross-section Calculation 17

4. Mass and Charge Distribution Calculation 19

III. Theoretical Models 22

A. Introduction $\quad 22$

B. Intra-nuclear Cagcade Model 24

C. Nuclear F1 reball Model 26

D. Nuclear Firestreak Model 28 
E. Statistical De-exc1tation Hodel

IV. Results and D1scusston 33

A. Experinental Results 33

1. Effects Due to Secondary-1nduced Reactions 33

2. Charge Distributions 34

3. Kase Distributions 35

4. Total Reaction Cross-sections 39

B. Theoretical Model Predictions 41

1. Theoretical Kass and Charge Distributions 41

2. Theoretical Recoll Velocity Distributions 45

3. Theoretical Total Reaction Cross-sectious 46

$\begin{array}{ll}\text { v. Conclustons } & 47\end{array}$

References $\quad 49$

Tables $\quad 53$

Figure Captions $\quad 64$

$\begin{array}{ll}\text { FHgures } & 67\end{array}$ 


\section{INTRODUCTION}

\section{A. Background}

Simultaneous wh a series of dranatic advances in accelerator technology that occurred during the $1970^{\circ}$ a, a new chapter in the study of the properties of nuclear matter was opened. During a period of only a fer years, the kinetic energies of the available composite projectiles were increased from a few $\mathrm{HeV}$ to a few GeV per nucleon. Projectiles that can presently be accelerated to relativistic energies include lons as heavy as urantum (1). Protons are now routinely accelerated to several hundred GeV. These advances have made possible the study of nuclel undergoing reactions throughout four characteristic energy ranges: the subsonic, supersonic, mesoulc, and relativistic domains. These correspond to nuclear collisions in which the center of mass energy 19 auch that the profectile is traveling at a velocity below the speed of sound in nuclear matter, above this speed, above the pion production threshold, and at relativistic velocities, respectively.

Unt1l recently only a fraction of these domains had been explored using accelerators, mainly the subsonic area and the 11ght-mass profectile part of the others. Some experimenters have used cosmic radiation to access the relativiatic reglme (2), "but this method has" severe profectile intengity 11mitations. With the upgrades of the Berkeley Bevalac, the CERN SC Bynchro-cyclotron, and varlous cyclotrons, 1t has, become posstble to access a much larger part of these energy domains.

Researchers have placed particular emphasis upon the study of relativistic heavy-1on (RHI) Induced reactions (3), In which it was 
expected that nuclear matter might be compressed to abnormally high densities and subjected to extremes of heating (4). Numerous workers have speculated upon the possible formation of nuclear shock waves, density 1somers, and pion condensates $(5,6)$. While the extstence of these phenomena have had no clear experimental confirmation, there has been subatantial recent evidence for the existence of certain anomalies in projectile fragmentation data (7). It has been bypothesized that certaln projectlle fragments (called anomalons) are formed in a small percentage of RHI-1nduced reactions and have reaction cross-8ections that are much larger than those of normal fragments.

The reactions induced by heavy-lons at high energles have been characterized as belongtng to one of two broad classes: pertpheral and central collisions (8). This classification can be made according to the Impact parameter of the collision. Peripheral collisions occur when the Impact parameter is nearly the sum of the radil of the two aucle1. In this case, only the surfaces of the two nucle1 are believed to interact, and only a few nucleons are removed from s.each nucleus during the 1nteraction. The relatively intact fragment precursors aeparate wh only modest excitation energles and momenta imparted by the reaction. Due to the reaction geometry, this process occurs th large probab1lity.

Central collisions occur when the Impact parameter is near zero, which has a much lower assoclated probability. In this scenario the two nucle1 overlap nearly completely, and the nature of the reaction 1s expected to be quite different. Since the aucleon-nucleon mean free paths are quite short in nucle1 (9), most of the nucleons in the 
projectile will suffer multiple coll1siong while traversing the target nucleus. Thus, the two nuclel are expected to undergo a violent collision wth a large amount of the incident energy being converted Into internal excltation. The result can be a violent disintegration Into a wultitude of light fragments and particles.

The obackved fragments formed in these two types of reactions have teen clanaffied as belonging to one of three categories (8): projectile fragments, traveling at near-beam velocitles in a narrow cone around zero degrees in the laboratory frame, target fragments, with near zero velocities, and intermediate products, such as various light fragments and particles, moving at velocities similar to the center of mass of the system. The relative amounts of each of these products that are isrmed are dependent upon the Impact parameter of the collision.

A varlety of experimental techniques have been employed for the detection. of various of these reaction products (3). The methods employed Include the use of emulston, mica, and plastic track detectors, streamer chambers, recoll spectrometers, particle télescopes, radiochemical techntques, etc.

Due to the previous lack of heavy-mass RHI beams, most of the work concerning heavy fragment production has been carried out by the reaction of heavy targets with IIght beams. In this work we w11 concentrate upon the production and detection of heavy target fragments in the target reference frame, remembering that the results are analogous to those observed for project1le fragments observed in the projectile rest frame. 


\section{B. Bypotheses of Fragmentation}

In the almplest view, relativistic heavy-ion physics may be conoidered to be a development of high energy particle physics to Include mulci-baryon systems. Therefore, 1t wa logical that the concepts used in hIgh energy physics be applied to RHI-1nduced fnteractions. The hypotheses of "limiting fragmencation" and "factorization" [of cross-sections] $(10,11)$, which were firat invoked 1n the deacription of single-particle inclusive spectra, may have some value for these more complicated reactions. Due to the complex nature of the profectile, a question of the relevancy of discussing fragmentation in terms of the total incident projectile kinetic energy or of the energy per nucleon (a velocity dependence) naturally arises. A third hypothesis has been Introduced (12), which states that the nature of the reaction 1 s determined by the total kinetic energy of the projectile.

\section{Limieing Fragmentation}

Earlier studies of target fragmentation at relativistic projectlle energles have demonstrated that the target fragments formed range in mass from that of the target all the way down to light nucle1 such as ${ }^{7} \mathrm{Be}(13)$, with recoll klnetic energles varylng from near zero to fisslon energies (approximately $1 \mathrm{MeV} / \mathrm{u}$ ) (14). The hypothesis of "Iimfting fragmentation" states that the distributions of products and their energles, in the respective target or projectile rest frame, approach limiting forms as the bombarding energy increases. This limiting behavior can be qualitatively understood as being due to the fact that as the projectile velocity approaches the speed of light, 
the profectile-target interaction time approaches a constant value. Thus, 1t may be expected that the fragment production cross-sections and kinematical properties may become Insensitive to further increases In the beam energy.

\section{Factorization}

The hypothesis of "factor1zation" of cross-gections 1s operative in the region where Jimiting fragmentation is valid, and states thst the yleld of a particular target (projectile) fragment is independent of the bombarding projectile (target) nucleus, except for a geometric factor due to the size of the bombarding nucleus. For the case of target fragmentation, the yleld $Y$ for fragment $F$ from target $T$ and beam B, may be expressed as (15):

$$
\mathbf{Y}_{T, B}^{\mathbf{F}}=\mathrm{G}_{T}^{\mathbf{F}} \mathrm{G}_{\mathrm{B}}
$$

where $G_{T} F$ depends on the target and the fragment formed, and $G_{B}$ is dependent only upon the geometry. The effect of factorization is to scale the magnitude of the obgerved product ylelds, but not to change the shapes of the distributions. The geometry factor may be expressed as (16):

$$
G_{B}=\pi r_{0}^{2}\left(A_{T}^{1 / 3}+A_{B}^{1 / 3}-d\right)
$$

where $A_{T}$ and $A_{P}$ are the target and projectile mass number, respectively, $r_{0}$ is the nuclear radius constant, and $d$ is the overlap parameter.

3. Total K1netic Energy Dependence

In the energy range below that in which the concept of limiting 
fragmentatico 1s applicable, fragment ylelds and spectra will vary with the profectile energy. For the comparison of different reactions, It is valuable to know whether the physics of the Interaction 18 dependent upon the total kinetic energy of the projectile or the energy per nucleon (velocity dependent). With the exceptiou of products with mass number near to that of the target and of some fisaion fragments, most products are formed by reaction of the target with a algnificant number of nucleons from the projectile. If the Interaction proceeda mainly by a collective cascade of nucleons, it might be expected that it is the total kinetic energy of the projectile that is sensed by the target nucleus. This shall be the hypothes1s of cholce.

C. Previous Studies of Target Fragmentation

A gubstantial mount of experimental data concerning target fragmentation Induced by relativistic heavy-ions and protons has become avallable in the past few years. Cumming, et al. have studied the reaction of nat $\mathrm{Cu}$ with $\mathrm{P},{ }^{4} \mathrm{He},{ }^{12} \mathrm{C},{ }^{14} \mathrm{~N}$, and $40 \mathrm{Ar}$ at energies ranging from 0.18 to $28 \mathrm{GeV}$ per nucleon $(13,17,18)$. The onset of limiting fragmentation for the mass yields of all but the lightest fragmenta was observed at approximately $3 \mathrm{GeV}$ total projectile kinetic energy. The 1sobarlc charge distributions for these products were Invarlant above $3 \mathrm{GeV}$, further indicating the validity of this hypothes1s. At lower energles the mass yleld results scaled with the total profectile kinetic energy, not the velocity. The shapes of the mass yield curves were found to be correlated with the total kinetic energy, providing a sort of temperature measurement. 
Factorization of the fragment yields seemed to hold for projectiles with simflar total energy and for those with energies in the range of limiting fragnentation. The factorization ratios were found to be consistent wh factors based upon olmple geometry. The fallure of limiting fragmentution for the lightest fragments was attributed to the possibility that these were formed only in the most central collistons, where their formation cross-sections would be enhanced by increasing the projectile size and energy.

Recoll momenta measurements of the target fragments, deduced from thick-target, thick-catcher experiments by use of the two-step vector mode1, demonstrated that while the Inferred esitation energies of the fragment precursors we constant above approximately 3 GeV beam energy, the recoll momenta we varying strongly with projectile energy up to gearly $30 \mathrm{GeV}$. Also, the size of the projectile seemed important, for at the same total projectile kinetic energy the fragments produced with heavy-1ons had larger recoll energles than those formed with protons.

Porile, et al. have studied the fragmentation of nat Ag by $p$ and ${ }^{12} \mathrm{C}(19)$, and confirmed the validity of the factorization hypothesis for the mass yield and charge distributions, again with the exception of the 11ghtest fragments. The wass distributions for heavy-ion Induced reactions re moderately well reproduced using both an abrasion-ablation and an intra-nuclear cascade model calculation. However, the models falled to reproduce the proton-1nduced reaction results.

Heavy-ion and proton-induced reactions with 181 Ta have been studled by many groups. Morr1ssey, et al. reported that the observed fragment production crosg-sections scaled with the total projectile 
kinetic energy (12). A significant enhancement of light fragment production with heavy-1ons, relative to protons, was noted. For the first tiee it was observed that a fraction of the heavy residues must have been forned in central collialons. A comparison of the mass yield curve with the results of the Intra-nuclear cascade and abrasion-ablation model calculations Indicated that while both models reproduced the general shapes of the distribution, neither could predict the yielda of the lightest fragments.

Recoll properties of these fragments were measured by Loveland, et 1 . (20). These workers found that while the exc1tation energies of the fragment precursors were simflar for protons and for heavylons, the recoll momenta we much larger wh heavy-ions. Dertel has confirmed that jimiting fragmentation is observed in the mass yield curves and 1sotopic distributions obtained with a variety of projectiles at energles between 5 and $42 \mathrm{GeV}$ (21), again noting the exception of the light fragments. He also decermined factorization to be valid for the ratio of total reaction cross-sections of heavy-ions versus protons.

Kaufman, et al. have examined the interaction of protons and heavy-ions with 197 Au $(22,23)$. Thelr conclusions were similar to those obtalned wth the Ta targets, with limiting fragmentation being observed for the fragment production cross-sections, but not for the recoll momenta. These authors also confirmed the total energy hypothes1s. Aleklett, et al, have measured the cross-sections for the production of gold in the reaction of heavy-ions with ${ }^{209} 9_{B 1}(24)$. They reported that the observed relative ylelds of the gold 1sotopes showed a stmilar dependence upon the1r mass number, regardless of the 
projectile-energy combination, wth the conclusion that the Inferred excltation energies of the primary residues remain approximately constant.

A substantial body of data has been published concerning the fragmencation of uranim by relativistic protons. Yu has shown that the charge distibutions for target fragments with mas in the fission mass region consiat of both neutron deficlent and neutron excessive species (25). The neutron excessive fragment mass distribution peaiked near mass 110 and was understood to be the resuli of low-excitationenergy fleston of a uranium-like nucleus. The neutron deficient fragment distribution was rather flat and has been attributed to being formed by a deep-spallation process. These conclusions have been confirmed by coincident particle detection measurements made by Wilk1ns, et al. (26) and Warwlck, et al (27).

Recoll properties and formation cross-gections for these fragments have been reported by Portle, et al. (28), Biswas and Porile (29), and Lagarde-Simonoff and Simonoff (30). In general, it was found that the neutron deficlent fragment spectra and formation crosssections vary differently with proton energy than do those of the neutron excessive fragments. The latter have excitation functions that decrease wth increasing beam energy and have recoll energy spectra that are 1ndependent of the beam energy, while ths former have fncreasing excitation functions and recoll energy distributions that decrease sharply above $3 \mathrm{GeV}$ proton kinetlc energy. Th1s reluforces the evidence for the existence of different production machenisms for these two classes of fragments.

Relative production cross-sections for fragments formed in the Inceraction of $25 \mathrm{GeV}{ }^{12} \mathrm{C}$ wtth ${ }^{238} \mathrm{v}$ have been reported by Loveland, et 
al. (31). They observed a large enhancement of the heavy-mass yields, relative to the proton Induced reaction, exceeding that expected due to simple factorization. Cole and Porlle have Investigated the 18.5 Gev ${ }^{12} \mathrm{C}$ Induced reaction (32). Bere it was noted that the 1 ight Eragments were enhanced relative to those produced with protong, with the very 11ghtest fragments befng wost atrongly affected.

\section{Proposed study}

In this atudy we w11l examine the varlation of target fragment yields as a function of projectile energy and size for the reaction of intermediate and relativigtic-energy heavy-ions with uranium. The method of cholce will be gamma-ray radio-analytical measurement of the target fragment production cross-sections. Comparioon of these mass yields and charge diatributions wh those obtained from protonInduced reactions wil be used to examine the validity of the three hypotheses of fragmentation. Careful examination of the light fragment yields should provide insight into the underlying reason for their known fallure to be subject to limiting fragmentation and factorization. Theoratical calculacione of the experimental observables will be performed to help elucidate the mechanisms of fragment formation. 


\section{EXPERIMENTAL}

\section{A. Introduction}

Target fragment yielda have traditionally been measured using the radio-analytical method, which currently rematns in use at several laboratories throughout the world. The method is comprised of the Irradiation of an elemental foll with the chosen beam, following which the Induced radioactivities are surveyed using a gamm-ra: spectrometer. Individual nuclides produced in the Interactions are Identified by their characteristic gamma-ray decay energies and half11ves. This technique offers the advantage of sensitivity to several orders of magnitude in cross-section and has the benefitg of providing for absolute charge and zass determination. Varlations of this technique have been employed for the measurement of fragment angular distributions and recoll energy spectra.

Disadvantages of this type of off-11ne measurement include the 1nabllity to measure fragment wultiplicities and the necessity for the reaction products to have half-lives of at least a few minutes, so that their decays may be observed. Unfortunetely ; $1:$ is how from flssion and high-energy studies that many of the products typically formed In a nuclear reaction have quite short beta-decay half-lives (33). Thus, 1t was expected that the experimentally observed product ylelds would be an admixture of directly formed products, and those that sumped up part of their loobarlc beta-decay chain.

The terms "independent" and "cumulative" yields have been used to categorize products that have been formed directly, wh no feeding by radloactive decay of a parent, and those that have bian formed by both paths, respectively. As a result of this admixing of different types 
of $y$ ields, It wes neceasary to correct the group of ylelds measured from each reaction. This was accomplished by fitring the measured yields to charge dispersion curves using an iterative procedure, wth the Independent gielda serving as a guide. from the calculated 1sotopic and 1sobaric ylelds, the pre-beta-decay mass and charge distributione were constructed.

\section{Targetry and Irradiations}

The self-supporting targets uatd in the bombardments consisted of natural or depleted uranien of 25 to $120 \mathrm{mg} / \mathrm{cm}^{2}$ thlckness, surrounded by mylar or aluminum catcher foils, which contained the recolling fragments. At the beam energies used in this work, there was negligible energy loss in target stacks of these thicknesses (34). In most of the experiments targets of more than one thickness were 1rradiated. This was to provide for the possibility cf extrapolating the fragment production cross-sections to zero target thickness, thereby eliminating any effects due to secondary-partiale-induced reactions, which are known to give a significant contribution to the yields at large target thicknesses (13). Depleted urantum was the preferred target, since it has much less background activity. However, the prohtbitively high cost of this material prevented its general use.

Table I lists the accelerator, beam fon, energy, flux, and length of Irradiation together with the target thickness(es) and catcher material used in each experiment. All of the irradiatlons, other than with the $1.0 \mathrm{GeV}{ }^{12} \mathrm{C}$ beam, were performed at the Bevalac accelerator fac1l1ty located at the Lawrence Berkeley Laboratory. This facility 
consiata of the Superirlac 11near accelerator 1njecting the Bevatron ayachrotron. A schenatic dlagram of a typical Bevalac target arrangement is shown in Figure 1. The beam exite through a Kapton window at the end of the beam pipe, and then passeg through a wre chaber, an Ion chamber, the target assemblies, and a final wre chamber. Theae high-energy beamo loat very little energy in any of the objects in the beam pat' and no vacuum chamber was required.

The wre chambers served the purpose of facilitating the focussing and aligment of the beam throughout the target stack. Generally, the beam focus was approximately one half inch in diameter, and remained unchanged in size and position during the irradiations. An Ion collection chamber filled wth argon and carbon dioxide (807 Ar, $207 \mathrm{CO}_{2}, 800 \mathrm{~mm}$ pressure) was used to measure the beam flux.

The CERN SC synchro-cyclotron accelerator, located near Geneva, was used to provide the $1.0 \mathrm{GeV}^{12} \mathrm{C}$ beam. At this low energy, the 1rradiations we performed Inside a small fast-access vacuum chamber. The beam flux measurewent was obtained wh the use of an aluminum monitor foll. The flux was calculated from the induced ${ }^{24}$ Na activity by assuming that the cross-section for the reaction ${ }^{27} \mathrm{Al}\left({ }^{12} \mathrm{C}, \mathrm{X}\right){ }^{24} \mathrm{Na}$ was 24.5 millibarns (35). Because the $f l u x$ and $d E / d X$ of the beam were so much iarger at this energy, it was necessary to use aluminin catcher folls, Instead of mylar, to prevent their thermal destruction.

\section{c. Gamma-ray Spectroscopy}

1. Heasurement Systems

Following the end of each Irradiation, the gamma-ray activities Induced in the target-catcher foll assemblies were measured with 
gamma-ray spectrometers for a perlod of up to six weeks. Each sample asgembly was mounted on an aluminum counting card, which was rigidly held In place by a Lucite rack at calibrated distances from the face of the gamis-ray detector. Ten or more ample positions were avallable to allow for tive adjustment of the detector dead time. All measurements were made using Ortec coaxial lithium-drifted and Intrinalc-germanium diode detectors.

Each detector was DC coupled to a charge senaitive pre-amplifier, which wa connected to a high-rate linear amplifier with matching signal rimetime. The amplifier outputs were AC coupled with analog to digital converters (ADCs) using active baseline restoration for good peak resolution at high counting rates. The ADr; outputs we re in turn connected to pulse helght analysis systems, which recorded the gamaray spectra on magnetic tape or floppy-disc media. A schematic diagram of a spectrometer system is given 1n Flgure 2. Each oystem was programmed to collect a 4096 channel spectrum covering the energy rang. of about 80 to $2000 \mathrm{keV}$. Corrections for detector dead times were made by automatically increasing the data acquisition time.

\section{Callbraclons}

Each detectiom system was calibrated for absolute efficiency and energy using standard techniques (36). This was performed usiag mixed gamma-ray atandard sources supplied by the National Bureau of Standards and by Amersham Corporation. Spectra from these sources were recorded at each detector position used during the experimeats. To perform the energy calibration, the ceatrold channel numbers of the gamma-ray peaks we fitted to a cublc equation: 


$$
E=a_{1}+a_{2} c+a_{3} c^{2}+a_{4} c^{3}
$$

where $E$ is the actual energy of a peak, and $C$ is the centroid channel number. The coefficients $\left(a_{1}{ }^{\prime}\right)^{\prime}$ were determined using a least squares fit of the know peak energies to the channel numbers. The calibration for each detection aystem was found to be quite inear, wth negligible higher order coefficients.

The detector efficlencles we re computad by comparison of the known emission rates of the standard sourcas with their measured gamma-ray photopeak areas. From the calculated efficlencles, the energy dependence of the detector efficluncy was determined using a least squares fit to an equation of the form:

$$
F=p_{1}\left[E^{-p_{2}}-p_{3} \exp \left(-p_{4} E\right)\right]
$$

where $F$ is the detection efficlency for a particular peak, E is the peak energy, and the $P_{1}{ }^{\prime}$ are the coefficlents. This fitting procedure was performed for each counting position of the detectors. The resulting efflclency fits were found to match the measured efficlencles to within the errors associated with the source intengities and those due to measurement atatistics.

An Important measure of the quality of a detection sygtem 18 its experimental resolution. This is especially significant for the spectroscopy of RHI-Induced reactions, where hundreds of peaks are observed in a oingle spectrum, many of which overlap. Therefore, each detection aystem was set up to provide the best possible resolution by careful adjugtment of the amplifier risetime and pre-amplifier compensation, together wth the use of active signal baseline restoration and extengive grounding aystems. The full-width half- 
maximum resclution of each spectrometer was found to be less than or equal to $2.2 \mathrm{keV}$ for the ${ }^{60} \mathrm{co} 1332.5 \mathrm{keV}$ gamma-ray. Using the standard sources, the IIne-shape for each peak was measured and subsequentiy fit by least squares methods to a shape consisting of a gausalan function with an exponential tail smoothly jolned on each side. Thia $f$ In of line-ghape was found fit the peak-shapes of each detector to high accuracy.

\section{Data Analyaia}

\section{Peak Analygis}

Each gamma-ray spectrum collected during the four to six week perfod following the end of an irradiation was analyzed using a sequence of computer programs previously developed for this purpose (36). A flowchart for this procedure is given tn Flgure 3. The first operation was to search out and $f 1 t$ the gamma-ray photopeaks. This was done ualng a modified version of the SAMPO computer code (37). Using the energy, efficlency, and line-shape calibrationg peeviously determined for each detector, this program de-convoluted each spectrum into Individusl photopeaks superimposed upon a smoothly varying polynomial background. The accuracy of the fitting procedure was usually good, but the program tended to m1ss gmall peaks, and was often unable to resolve superpositions of peaks.

Following the completion of the SAMPO analysis, the resulting tables of gamma-ray activities were sorted by sample name and photopeak energy in preperation for decay curve construction. This was done by searching each sample measurement for the presence of gamma-rays of energy whin an interval centered about an earlier 
observed peak's wean energy. The size of the interval was energy dependent. wth the form:

$$
\text { D. } 2 \log _{10} E_{m}-3.0 \quad[5]
$$

where $D$ is the width of the energy Interval $1 \mathrm{keV}$ and $E_{m}$ is the mean gamma-ray energy. In this way, a table of gamma-ray 1ntensities and associated errors, sorted as a function of time, was generated for each sample.

2. Half-life Analysis

In the next step of the data reduction, an interactive decay curve analysis program (TAU2) was used to construct decay curves for the gamma-rays observed in each sample. These decay curves rere sequentially presented on a graphics terminal, together with a section of a table of nuclides with gamma-ray energieg bracketing the observed energy. The data comprising thlo abridged table were taken from the work of Binder, et al. (38). From the fnteractive terminal the Investigator was able to choose from a varlety of different least Bquare fitg to the decay curves, including aingle or multiple components, growth and decay, and background activities. This flexibility made it possible to fit most decay curves correctly and rapidly. After the fit to each decay curve was completed, the program recorded the nuclidic identifications, half-1ives, calculated end-of-bombardment activities, and the assoclated statistical errors.

3. Cross-section Calculation

Using the activity and nuclidic half-life values determined by this method, the cross-sect1ons for each component of the decay curves 
were calculated using another computer code. Since large beam fluctuations usually occurred during an irradiation, the form of the usual equation used for the calculation was expanded about a number of short intervals, $n$, during which there was a relatively constant beam Elux:

$$
Y-A_{0} /\left[N \sum_{1=1}^{n} \phi_{1}\left(1-\exp \left(-\lambda t_{b 1}\right)\right) \exp \left(-\lambda \sum_{j=1+1}^{n} t_{b_{j}}\right)\right]
$$

where $Y 18$ the cross-section, N 18 the number of target atoms, $\phi_{1} 18$ the beam flux during the $1^{\prime}$ th interval, $\lambda$ is the decay constant, $A_{0}{ }^{1 s}$ the activity ai the end-of-bombardment, and the $t_{b k}$ 's are the length of the $k^{\prime}$ th flux interval. The final output of this computer code was an 1sotope-ordered list of nuclidfc cross-sections, which were computed from the welghted averages of all gamm-rays observed for each particular nuclide in the sample.

It was found to be necessary to review the nuclidic assignments, to ensure that consistent 1dentifications had been made. This screening was done using the following criterla:

(a) The energtes of the observed gamma-ray transitions wer within $0.5 \mathrm{keV}$ of the literature values.

(b) Each decay curve was resolved into a single unique combination of nuclidic identifications.

(c) The cross-sections calculated for each difterent transition of a particular nucilde re self-consistent.

(d) All of the gammo-ray lines from a glven nuclide with branching rat10s larger than the wakest observed zransition were found to be present, unless they were masked by another more 
Intange ganma-ray.

Thio screening procedure eliminated most incorrect Identifications; the few that remained were removed in the charge dispersion fitting process to be described later.

An attempt was made to correct the nuclidic cross-sections for the possible effects due to secondary-1nduced reactions. At relativiatic energies, large fluxes of light particles wh Intermediate energles are created in the mare central collisions (39). To permit an Investigation of this effect, targcts of more than one thicknet, were arradlaced in most. uf the experiments. By fitting the nuclidic cross-sections to a linear function of target thickness, and extrapolating to zero thickness, the size of the effect could be determined and the approprtate corrections made.

4. Mass and Charge Distribution Calculation

The experimentally measured cross-sections included both Independent and cumulative yields; protucts which we re formed directly by particle evaporation and those formed as a result of beta-decay Eollowing particle emission. However, the data of interest were the 1ndependent nuclidic and isobaric yields. For this reason it was necessury to correct the measurements for the effects resulting frum precursor beta-decay. The procedure used was to iteratively fit the experimental nuclidic ylelds to Gaussian charge distributions (40), functions which represent the distribution of lsobaric cross-section among the members of the 1sobar. For a Gaussian distribution, the independent yield $\mathrm{Y}(\mathrm{Z}, \mathrm{A})$ can be expressed as a function of the mass yleld $Y(A)$ by: 
$Y(Z, A)=Y(A)\left[\left(2 \pi C_{z}(a)^{2}\right)^{-1 / 2} \exp \left(-\left(2-Z_{m p}(A)\right)^{2} / 2 C_{z}(A){ }^{2}\right]\right.$

where $C_{z}(A) 18$ the Gausalan width parameter and $Z_{m p}(A)$ is the centrold atomlc number value.

Thua, if three Independent ylelds had been measured for each 1oobar, It would have been possible to uniquely determine each of the three unknosns in this equation. Unfortunately, this was not possible, since there are no known 1sobars contalning more than two nuclides which are shielded from feeding by beta-decay. In fact, generally very few members of any particular 1sobartc multiplet ere observed in the experiments. The solution to this problem was to assume that the values of the lsobaric yleld, gaussian widh, and centrold position vary slowly and regularly as a function of product mass number. This sas expected to be a poor assumption for products with mass number near to that of the target, where the mass yield changes rapidly with mass number. Ising this approach, the data from each experiment were grouped by similar mass number, and then a single charge distribution was constructed for each group.

A computer code named MASSY has been written by ot to to perform these calculations (41). From a set of 1nput parameters for $2_{\text {mp }}(A)$ and $C_{2}(A)$, the code constructed sets of charge distributions for each grouplag of the data. Using these distributions, together with the half-1ives of the members of each isobaric multiplet, the amount of beta-decay feeding to each observed nuclide was computed. Then, the Independent yields were calculated, and their distributions were compared to those generated by the original cholces for the widths and centers of the charge distributions. A set of parameters that gave reasonable fits to the calculated independent ylelds were found by 
iteration. From the independent yields, the mass (1sobaric) y1elds were calculated using equation 7. 
III. THEORETICAL MODELS

\section{A. Introduction}

At relativiatic energies heavy-ions may undergo two basic types of Interactions, which can be classified as peripheral and central colliglons. Peripheral events are reactions in which there is only a small overlap of nuclear density. Thus, only a small transfer of momentum and energy occurs. The profectile fragments contiaue forward within a narrow fragmentation cone (1n the laboratory frame) at velocities close to that of the incldent beam. The slowly recolling target fragments evaporace particles 1sotroplcally and may fission if sufficiently heavy. Central collision events correspond to those reactions in which a nearly complete overlap of the two nucle1 takes place. In these events fragmentation products are emitted with large velocities over all forward angles and are no longer of traceable parentage. The high charge multiplicities of these fast fragments Indicate that an "explosion" of the colliding system may have occurred. Of course, these scenariog represent the two extreme cases of reactions, and in reality 1 t 18 expected that all manner of collisions wh thtermediate character w11 take place.

To ald in the understanding of the mechantsm(s) Involved in these two types of interactions, it is important to compsre the predictions of current theoretical models with the results of the experimental measurements. Three theoretical models of high-energy heavy-1onInduced reactions wil be considered: the Intra-nuclear cascade model (42), the nuclear fireball (abraston-ablation model) (43), and the nuclear firestreak model (44). These chree represent somewhat limiting views of relativistic nuclear collisions, with the intra- 
nuclear cascade model plcturing the interaction as consisting of uncorrelated collisions between individual nucleons from the tro nucle1, whle the nuclear fireball and firestreak models assume that the Interaction 1s localized to collective inelastic collisions of the nucleons within the overlap region, with little effect on the nonoverlapping regions of the two nuclei.

Each if these models is based upon the common underlying assumption wat the nuclear reaction occurs as a two step process, as or1glnally proposed by Serber (42). During the first step, the fast profectile-target interaction occurs, In which the excited primary projectile and target remuants are formed. The second step consists of a slow statistical de-excitation of these remants by particle emission and by fission.

There have been alternate theoretical approaches suggested to model these high energy reactions. Campl and Hufner have had some success in fitting experimental data by treating the first step of the reaction wh Glauber theory and the second by solution of the Master equation (45). Their results are quite simflar to those predicted by the use of the intra-nuclear cascade model. Most recently, fragmentation processes have been approximated using a relacivistic hydrodynamic model (46), which views the reaction as being completely collective in nature. However, this work has not yet been applied to quantitatively predict the formation of large target fragments. 
B. Intra-nuclear Cascade Model

The first realistic calculations of the interaction of high energy particles with complex nucle1 we done wthin the framework of the intra-nuclear cascade (INC) model (42), which approximates the nuclear reaction as consisting of a sequence of single nucleon-nucleon collistono taking place between the Incident particles and the nucleons in the target nucleus. Struck nucleons in the target are imilarly alluved to Interact wh the remaining undisturbed nucleons, unt1 the tine at wich all the "participant" nucleons have elther escaped frow the target remnant or have been slowed to energies below the Dermi energy in the target. This eype of calculation is particularly well sulted to computation using Monte-Carlo simulation rechniques on a mainframe computer.

As a representative example of this type of calculation, the Yariv and Fraenkel version of the INC model, named ISABEL (47), was chosen for this work. This computer code has been well described previously; here only the main sssumptions used th the calculation w11 be noted:

(a) The target and projectlle nuclel were assumed to behave as cold Fermi gases contained in potential wells. Thetr nuclear density distributions were approxfmated by $a$ step function consisting of eight constant density reglons. These regions were obtalned by fits to folded Yukawa sharp-cutoff density distributions.

(b) The reaction kinematics we treated with1n the framework of relativiatic classical mechanics, with all calculations being performed in the target rest frame, where the projectlle 
was Lorentz contracted.

(c) Within the computation, the multiple collision process was handled in stepwise time fashion. Interactiong between cascade particlea were not allowed; hence nucleon-nucleon correlations were diaregarded.

(d) Plon production and absorption was included and occurred via the delta $(3,3)$ resonance :

$$
\begin{aligned}
& N+N=\Delta_{3,3}+N \\
& \Delta_{3,3}=\pi+N
\end{aligned}
$$

where $N$ is a nucleon, and $\pi$ is a pion.

Nucleon-nucleon and pion-nucleon scattering cross-sections were Interpreted from on-mass-shell, free-particle data.

(e) Effects of the Pauli principle were included.

(f) During the development of the cascade process, the densities of the nuclear Ferml seas were depleted, and no further Interactions were allowed in the holes created. Each cagcade particle was followed until it left the nucleus or until its energy fell below the cutoff for escaping.

Typically, 500 or more complete cascades were performed, with randomly chosen impact parametera. A complete record of the residual mass, charge, excitation energy, recoll momentum, and angular momentum of the projectile and target remnants was kept for each collision. Af ter the computation of the fast cascade process was completed, the target remnants formed in the primary interaction were de-excited using the Monte-Carlo statistical evaporation code described at the end of this chapter. 
c. Nuclear Plrebull Hodel

The nuclear fireball model, as originally proposed by Westfall, et al. (43), was developed to account for intermediate velocity nucleon emigeion resulting from central and near central collisions. It was based upon the geometrical concepta of the abrasion-ablation model of Bowmen, et al. (48) and Included the use of a relativistic atatiaticul thermodynamic treatment of the participant nucleons. The model may be stated as follows: When the target and projectile collide, the two nuclel make a clean cut chrough each other. The Interaction is localized to the region of overlap, wth the nonoverlapping regions (spectatora) being unaffected. Nucleons in the region of overlap transfer the1r momenta and energies to the center of mass of the "fireball" that they form, which travels forward at an Interaed late velocity.

Th18 "firebal1" contalns internal excitation energies which are far in excess of normal nuclear binding energles, and is assumed to decay as a non-rotating thermally equilibrated relativistic 1deal gas. After undergoing an isotrople expansion in its rest frame, the reaulting fast particles have a Maxwellian kinetic energy distribution. In contrast co this, the target and projectile remnants are assumed to have rather low excitation energles and will decay by statistical particle emission and by fission.

A computer code written by Morr1s8ey, et al. named wOOPS (49), was used to perform the fireball model calculations of target fragmentation. In this computation the target and profectile were assumed to be sharp spheres with untform density distributions, and 
made a cylindrical cut through each other during the primary 1nteraction. The number of nucleons removed from the target nucleus at each Impact parameter was calculated by numerical integration of the Intersection volume. By having weighted each impact parameter by 1ta geonetrical probatility, the crosa-sections for each fragment mass were evaluated. The average ratio of che number of removed neutrons to protons was assumed to be equal to the ratio present in the original target nucleus.

Excitation energies for each target remant produced in the primary encounter were assigned by assuming that the only forn of excltation energy present was that due to auclear deformation of the remnant. This has been referred to as the "clean cut" approximation. The excitation energy was taken to be the product of the nuclear surface energy coefficlent $\left(.95 \mathrm{MeV} / \mathrm{fm}^{2}\right)$ and the increase in nuclear surface area of the deformed fragment relative to that of a spherical nucleus of Identical volume. This was also computed by numerical 1ntegration. As a result of the "clean cut" approximation, the linear and angular momentum transferred to the fragments we re assumed to be negligible and the results of the reaction are independent of the projectile energy. Oliveira, et al. have previously shown that this method of calculating the excitation energleg of the fragments gives values which are too low to account for the experimental results $(50)$. To generate the charge distributions for the primary carget remnants, it was necessary to consider realistic neutron-proton fluctuations. Morr 1ssey, et al. have proposed that these fluctuations could be related to zero polnt vibrations of the giant dipole resonance (GDR) of the target nucleus (49). This resonance has been postulated to be a collective vibration of neutrons against protons in 
a nucleus. Uo1ng KyerB, et el. treatment of the GDR In terms of the nuclear droplet model (51), these workers were able to treat the fluctuations by expresaing them in terms of a Gausian distribution with with based upon the classical turning point of a simple harmonic oscillator. Thls approach was found to give better fits to experimeatal tragmentation data than by the asoumption that there existed a prreiy statisticai distribution of protons and neutrons throughout the target nu: leus before the interaction took place.

Once the calculation for the formation of the pidmary remnants was complete, these romnants we re de-excited using the same model used wth the Intra-nuclear sascade model calculation.

D. Nuclear Firestreak Model

The rather simple nuclear fireball model suffers from some aerlous 11mitarions when uged for target fragmentation calculations. Specifically, it is expected that the actual amount of excitation energy deposited during the abrasion step must be much larger than that which nuclear deformation alone can supply. In addition, the simple "clean cut" geometry is an over-simplification, since there is significant momentum transfer to most target fragments and there exists some profectile energy dependence of the fragment ylelds.

In order to retain the collective nature of the nuclear inceraction, but to eliminate the unrealistic assumptions of the nuclear fireball model, we have extended the nuclear firestreak model of Hyers (44) to include a calculation of the primary projectile and target remnant production in these reactions. Gosset, et al. have previously employed the nuclear firestreak model for the calculation 
of the spectra of plons, protans, and light nuclel produced in RHIInduce collisions (52).

Under this newer model'a formallam, the colliding nuclet are assumed to have diffuse surfaces, which were generated by folding a short-range (Yukawa) function into the conventional sharp-sphere density diatribution. It was assumed that during the collision the Interaction was localized to the overlap region, where collinear tubes of nuclear matter from the target and projectile underwent completely Ibelastic collisions. A transparency function, based upon a fixed nucleon-nucleon acatering cross-gection of 30 millibarns, was lacluded to prevent collisions from occurring between tubes containing an Insufficlent density of nucleons.

Once two tubes had collided, they fused and equilibrated their kinetic and thermal energies. If the resulting kinetic energy of a fused tube was less than its binding energy in the target remnant, then it was retained and contributed directly to the remnant's energy, mass, and momenta, which we explicitly conserved during the 1nteraction. Additional excitation energy, due to the surface deformation of the remnant, was 1ncluded. Charge distributions for the primary remnants we re computed using the GDR model mentioned previously. Projectile fragmentation can be calculated in analogous fashion with this code, by reversing the assigments of the projectile and target nucle1. The de-excitation step of the reaction was handled In Identical fashion to those of the previously described reaction models and is described in the following section. 


\section{E. Statiatical De-excitation kodel}

Eech of the previously described reaction models required the use of atatistical de-excitation calculation for the second step of the reaction. In this etep the exclted primary fragments were assumed to decay by particle emission and by fission Into the nuclides (and their beta-decay precursora) that were actually observed in the experiments. So as not to obscure any differences in the results of the three primary reaction modela, the Identical de-excitation calculation was performed for each.

We have adapted the DFF computer code of Dostrovsky, et a1. (53) for this calculation. The DFF code is the original stepuse MonteCarlo treatment of the de-excitation of nuelel by particle emission and flssion. The computation was performed according to the following points :

(a) De-excitation was simulated by statistical evaporation of neutrons, protons, deuterons, tritons, ${ }^{3} \mathrm{He}$, and alpha particles in competition wh fission.

(b) Fermi-gas level densities wh pairing correction and level density parameter of a $=\$ / 20$ were used.

(c) Ef fects due to angular momentum were excluded.

In order to obtain a more realistic treatment of fission competition, have replaced the fission section of the code. In this new section, the excitation energy dependence of the ratio of figsion to particle emiseion width la given by (54): 


$$
\begin{aligned}
& \Gamma_{f}^{\prime} \Gamma_{\mathrm{ll}}=4 A^{2 / 3} a_{f}\left(E^{*}-B_{n}\right) \exp \left[2 a_{n}^{1 / 2}\left(E^{\star}-B_{n}\right)-2 a_{E}^{1 / 2}\left(E^{\star}-E_{E}\right){ }^{1 / 2}\right] \\
& K_{0} a_{a}\left[2 a_{f}^{1 / 2}\left(E^{*}-E_{f}\right)^{1 / 2}-1\right]
\end{aligned}
$$

where $I_{f}$ and $\Gamma_{\mathrm{a}}$ are the figsion and neutron emission widths, respectively, A 18 the mass number of the nucleus, $E^{\star}$ is the excitation energy, $B_{n}$ is the neut on binding energy, $E_{f}$ is the fission barrier helght, and $k_{0}$ is the profection of the neutron angular momentum upon the nuclesr symmetry axis.

The ratio of the level denalty parameter at the fission andle point, $a_{f}$, to that at the equilibrium deformation, $a_{n}$, was arbitrarily set using the relation:

$$
a_{f} / a_{n}-\left[1+0.1 / \log _{10}\left(E^{*}-E_{f}\right)\right]
$$

The fission barrier heights were chosen using the approximate formulae from Cohen and Swlatecki (5S):

$$
\begin{array}{ll}
E_{f}=0.38(0.75-X) E_{g}^{0} & \text { for } 1 / 3 \leq X \leq 2 /, \\
E_{f}=0.83(1.0-X)^{3} E_{g}^{0} & \text { for } 2 / 3 \leq X \leq 1
\end{array}
$$

for which the fisslonability parameter, $X$, is given by:

$$
x=z^{2} /\left(50.88 \mathrm{~A}\left(1-1.7826[(A-2 Z) / A]^{2}\right)\right]
$$

and w1 th

$$
E_{s}^{0}=17.80 \mathrm{~A}^{2 / 3}
$$

The variation of the widh of tive fission mass distribution as a function of the mass, charge, and excitation energy of the fisstoning 
system was deterwined using the liquid drop theoretical inethod of Nix (56).

Several thourand de-excitation chains we followed for each model calculation. The averaged results of these simulations are the theoretical analogs of the experimental mass and charge distributions, which are all compared in the next gection. 


\section{RESULTS AND DISCUSSION}

\section{A. Experimental Results \\ 1. Effects Due to Secondary-induced Reactions}

In each experiment in which more than one thickness of target was 1rradiated, the dependence of the fragment production cross-sections upon target thickness was examined. In general it was found that no consistent, statiatically significant effect was observed for 1ndividual nuclides produced in any particular reaction. To enhance the statistics obtained from the fitting of the observed ylelds to the target thicknesses, the nuclides observed in each experiment re separated Into flue groups consisting of fragments that were expected to be produced by similar types of reactions: light fragments with mass number $A=80$, nentron deficient fragments with $80<A<145$, neutron excessive fragments in the same mass range, heavy fragments with $145 \leq A \leq 210$, and near-target fragments with $A \geq 230$.

Within each group, the results from the fltting procedure were averaged to give an approximate correction factor for secondary Induced reactions in each grouf of yields. Even with th1s rather extreme measure, the statistical errors in the calculated seconciary effects were st11l usually larger than their values, or the calculated effects were smalier than the uncertalnties present in the original data. The only group in which there was any hint of a secondary effect being present was the one consisting of neutron excessive fission fragments. Therefore, it was assumed that there was to significant dependence of the target fragment production crosssections upon the target thicknesses in any of the experiments 
performed. The resulta for the directly measured ylelds were simply averaged over the various different target thickneases.

\section{Charge D1stributions}

For the purpose of obtaining the Indeppndent and 18obartc yields, the averaged nuclidic ylelds were placed into one of sixteen groups according to the mass number of the nuclide and its position with respect to the line of nuclear stabllity. Each member of a particular group was fitted to a Gausslan-shaped Independent yleld distribution, as described previously. The nuclidic grouplags, together with the centers and widhs of the Gaussian distributions, are glven in Table II. With the exception of the $1.0 \mathrm{GeV}{ }^{12} \mathrm{C}$ Induced reaction, the parameters for each group's fitted distributions are nearly the same in each experiment, Indicating that identical fragments were initially formed In each of these reactions wh generally similar excitation energ 1es.

The most probable atomlc number values ( $Z_{m p}$ ) used for the centers of the charge distributions are consistent with those determined by Yu for the 11-29 GeV proton-1nduced reaction (25), the two sets being within less than 1.52 units of each other for all of the mass regions. The $z_{\text {mp }}$ values obtalned from the $1.0 \mathrm{GeV}{ }^{12} \mathrm{C} 1$ nduced reaction are within 1.52 units of those reported by de Saint Simon, et al. (57), who have measured the mass distributlons of Rb and Cs from the reaction of $77 \mathrm{~A} \mathrm{MeV}{ }^{12} \mathrm{C}$ with ${ }^{238} \mathrm{U}$.

Representative charge distributions from the reaction of $3.0 \mathrm{GeV}$ ${ }^{12} \mathrm{c}$ with ${ }^{238} \mathrm{U}$ are shown in Figures 4 through 19 . The distributions measured In each of the other reactions are quite simflar, wh the masn differences being only those due to overall changes in the 
1sobaric glelds. In the fission mass region $(80<A<145)$, the charge distributions were found to be composed of two separate distributions, one neutron excessive and the other neutron deficient. These diatritutions have a separation of from less than two units of atomic number at mass number 90 to approximately four units at mass number 135. Th1s behavior has also been noted $1 \mathrm{n}$ the work of Yu (25) and de Saint simon et al. (57). Warwck, et al. (27) have suggegted that these two distinct digtributions are formed as a consequence of this mass region being populated by two separate reaction mechanisms, one being deep-spallation and the other medium-energy fission.

\section{Mass Distributions}

Presented in Figures 20 through 27 and In Table III are the glelds for each 1sobar produced in the various reactions, obtalned by Integration of the charge distrtbutions. Outside of the fission wass range, these are the 1sobaric yields. Inside this range, they are the lsobaric yields of the neutron deficlent and neutron excessive distributions. The solid curves shown in the figures represent an approximate fit to the total 1sobaric ylelds. The error bars on the measured points reflect only the measurement statistcs and do not take Into account any errors due to uncertainties in the absolute beam flux or those introduced in the charge distribution curve fitting process. Morrissey, et al. (12) have suggested that ind lvidual ylelds may have systematic uncertainties of approximately 25 percent. The observed scatter in the ylelds Indicates that this may be an underestimate. Since it 13 expected that the mass yield changes Blowly over a narrow range of mass (except near the target mass), it 
Is belleved that this scater 16 not algnificant, and the averaged values may be used as the 1sobaric gields.

All of the experimental mass yleld curves have some features in comon. Most of the Isobartc yleld lies in the neutron excessive fragmenta found in the flesion mass region, which are formed as the result of fission of arantum-like nucleus. These fragments are Identical to those that are formed In low-energy proton or alphaparticle-1nduced fission of uranium. A large part of the remaining Isobaric yleld is also contained in this wass regton, and consists of neutron deficlent yields. These may have been produced both in highexcitation-energy fission events and by deep-spallation processes. This possibllity is indicated by the fact these ylelds are generally larger than those for the fragments wth larger mass, which are expected to be purely spallation ylelds. In all of the reactions studied a strong increase in the mass yields is observed for the neartarget products, as expected, since these are most likely formed in peripheral reactions, which should have large cross-sectlons.

The energy dependence of the fragmentation of uranium by heavy10ns is demonstrated in Figure 28, In which the isobaric yield curves for the four energies of ${ }^{12} \mathrm{C}$ are supertmposed, and likewise in Figure 29 for the four energies of ${ }^{20} \mathrm{Ne}$. In the case of the $1.0 \mathrm{GeV}{ }^{12} \mathrm{C}$ projectile there is a large peak in the flssion mass region, with rather low yields everywhere else except near to the target mass. The seutron defictent yields in the fission mass region are much larger than the spallation ylelds at larger mass, Indicating that most of the formet are produced by the figsion of a highly exclted system.

As the ${ }^{12} \mathrm{C}$ boubarding energy Increases, two dramatic changes in the yleld patterns are apparent. of greater significance, a large 
increase in the production of the light fragmeats (A<60) is observed, wth the very lightest fragments showing the largest effect. Th1s 1ncrease continues up to the highest energy of $12 \mathrm{GeV}$, suggesting that the aechanism for the formation of these fragments is quite energy Intensive. Gutbrod, et al. (58) have suggested that the formation of the lightest fragments can be accounted for by assuming that they are emitted from a highly exc1ted thermal source. If this 1s the case, then the probabilities for their formation are related to their size and to the temperature of the sources, which are directly depeadent upon the beam energy. The shapes of the light fragment yleld distributions measured in this work seem to be exponential up to about mass number 50, as would be expected if they were produced the rmally.

A large change 13 also observed in the yields of the heavy fragmentg $(145 \leq A \leq 210)$. These increase sharply as the projectile energy Increages from 1.0 to $3.0 \mathrm{GeV}$ and then seem to become relatively constant at higher energles. The bump observed at mass number 175 1a the y1eld curve from the experiment performed at $12 \mathrm{GeV}$ may not be algnificant, since there are few experimental points in this region. No evidence is seen for a very large peak in the yields of mass number 160 to 180 fragments, as orfginally reported by Loveland, et a1. for the reaction of $25.2 \mathrm{GeV}{ }^{12} \mathrm{c}$ with ${ }^{238} \mathrm{v}$ (31). A re-analysis of that work has determined that the fitting of the Independent yields to the charge distributions may have been performed 1ncorrectly, resulting in abnormally large ylelds (59). The yfelds of fragments in the fission mass region seem to be nearly independent of the projectile energy. While there appears to be some increase in 
these ylelds going up in energy from 1.0 to $3.0 \mathrm{GeV}$, this could simply be due to the cholce of the monitor cross-section that was used to calculate the beam flux for the $1.0 \mathrm{GeV}$ experiment being somewhat too Iarge.

Much less variation of the ylelds wth projectile energy 13 observed with $20 \mathrm{Ne}$, as expected, aince Its lowest total kinetic energy was $5.0 \mathrm{GeV}$. With this projectile the wass yleld curves are all quite almilar, except for a problem with the overall helght of the ylelds obtalned from the reaction induced at $5.0 \mathrm{GeV}$. Apparently, in this experiment there was an undlagnosed difficulty with the Ion chamber and the associated electronics that were used to measure the beam flux, with the result belng that an erroneougly small flux was recorded. This problem is clearly demonstrated in the table of total reaction cross-sections to be introduced in the following section. If the height of this yleld curve is normalized to that of the others, an Increase in light fragment production is observed as the energy Increases frow 5.0 to $8.0 \mathrm{GeV}$. At higher energles little further change 18 apparent. The heavy element yields are all stmilar, with the Increase at $20 \mathrm{GeV}$ again probably belng due to the scarcity of data in this region. Yields of the fission mass products are relatively constant at all these energies.

With the confirwation of limiting fragmentation for all but the 11ghtest fragment's ylelds at spproximately $3.0 \mathrm{GeV}$, it is of 1nterest to make some tests for factorization. In Flgure 30 the isobaric yields for the $4.8 \mathrm{GeV}{ }^{12} \mathrm{C}$ and $5.0 \mathrm{GeV}{ }^{20} \mathrm{Ne-1}$ nduced reactions are compared. Again with some vartation in the heavy mass region, the yield patterns are nearly identical. The good agreement for even the Ifghtest fragments confirms the viability of both the factorization 
and the total energy hypotheses.

Heavy-1on and proton-1nduced reactions are compared in Figure 31. The two 1sobaric yleld curves are for the reactions of $29 \mathrm{GeV}$ protong and $20 \mathrm{GeV}{ }^{20}$ Ne with ${ }^{238} \mathrm{U}$. The proton data were taken from the work of Chu, et al. (60). The variation of loobaric yleld with product mass number 18 aimilar for both reactions, except for the flatness at the top of the Elssion bump from the proton-1nduced reaction. Yu has re-analyzed these proton data (25) and concluded that there should be a peak in this region, which would be in better agreement with the heavy-ion data. Heavy fragment yields, which we re not reported in the original proton work, have since been measured by Jacak, et al. (61). These workers observed cross-sections of about 5 to 10 millibarns for fragments of mass numbers 150 to 200 , which are 10 agreement with those seen in this work, keeping in mind the difference in total reaction cross-sections.

4. Total Reaction Crosg-sections

In order to further check the various hypotheses of fragmentation, it is useful to examine the total reaction and total fission cross-sections. These re determited by integrating the mass yleld curves according to the following points:

(a) The lower limit of the Integrat1on was get at mass number 40 . The origin of fragments wth lower mass 18 uncertain and thus their multiplicities are unknown. In some cases these fragments may have even been formed in conjunction with a heavy fragment.

(b) All of the fragmente from within the fiselon mass region ( $B 0$ $<A<145$ ) were assumed to have been produced by binary fisston. 
Therefore, their yields were divided by two before Integration. While aome of the aeutron deficient products in this group may have been produced by spallation, most were probably of binary $\operatorname{orIg1a.}$

(c) The upper limit of the integration was mass number 230 . This cholce helped to elfminate fragments that were formed in the most peripherel reaction,, such as coulomb excitation, from making large and uncertain contributions to the total reaction crosssections.

The total reaction and fission cross-sections obtained in this uanner are presented in Table IV. The experimental values are expected to have errors of approximately 25 percent. These data show that the total reaction cross-section for a RHI-induced reaction of uranium is generally invariant as the total projectile kinetic energy Is varied from 3.0 to $42 \mathrm{GeV}$. The devlations observed for the $1.0 \mathrm{GeV}$ ${ }^{12} \mathrm{C}$ and $5.0 \mathrm{GeV}{ }^{20} \mathrm{Ne-1}$ nduced reactions have been previously discussed. Excluding these two measurements, the values of the total reaction cross-sections for ${ }^{12} \mathrm{C}$ and ${ }^{20} \mathrm{Ne}$ with ${ }^{238} \mathrm{U}$ agree rather well with the respective geometric values of 3.75 and 4.16 barns. The latter values were calculated using Equation 2, taking the parameters $r_{0}$ and $d$ to be 1.37 and $5.1 \mathrm{fm}$, respectively, as suggested in the work of Heckman, et al. (62). The average experimental cross-section ratio for $20 \mathrm{Ne}$ relative to ${ }^{12} \mathrm{C} 18 \mathrm{1.22}$, wich is well within the error of the ratio of 1.11 for the geometric cross-gections. No evidence is seen in the experimental total reaction cross-sections for any effects due to nuclear transparency. Since the free nucleon-nucleon scattering croas-sections vary dramatically with kinetic energy (63), there 
existed the possibility that the total reaction cross-sections would be energy dependent, but this appears not to be the case.

The fraction of total reaction cross-section going into the fission channel seems to be relatively congtant at all but the lowest energy, wt th an average value of about .56 at energles above $1.0 \mathrm{GeV}$. Th1s is nearly identical to the value of .58 , which was calculated in a aimilar manner from the results presented by Yu for 11-29 GeV protons (25). Track detector meavurements of total fission crosssections from the resction of various encrgies of ${ }^{14} \mathrm{~N}$ with uranium have been made by Katcoff and lud1s (64), and match nicely those obtained from the ${ }^{12} \mathrm{C}-1$ nduced reaction.

B. Theoretical Model Predictions

1. Theoretical Mass and Charge Distributions

In Figures 32 through 39 the mass yfeld distributions predicted by the Intra-nuclear cascade (INC), nuclear firestreak, and nuclear fireball models are presented, together with the experimental results previously described. Since the nuclear fireball model includes no projectile energy dependence, 1ts results are shown only once for each cholce of projectile. From an examination of Flgures 35 and $38,1 \mathrm{t}$ is evident that this model drastically overestimates the ylelds of the heavy fragments and underestimates those of the fission mass fragments. Th1s 18 primarily due to the very low excitacion energies which are deposited during the first step of the model reaction, which are in turn the consequence of the "clean cut" assumption. As earlier noted, Olivelra, et al. have come to this same conclugion (50). Of course, by altering the $a_{f} / a_{n}$ ratio used in the de-excitation 
calculation, it would be possible to allow more fiaston to occur. However, even for larger values of this ratio, too few of the heavy residues will finsion before loaing their excitation energy by particle emfasion.

In contrast to the predictions of the nuclear fireball model, both the puclear firestreak and INC modela reproduce the experimental yield curves with falr accuracy. For the $1.0 \mathrm{GeV}{ }^{12} \mathrm{c}$ experiment these two calculations follow the shape and approximate size of the fission mass distribution but underestimate the heavy fragment yields for mass numbers 175 to 210 . Of course, it should be kept in mind that the theoretical yields in this region are quite sensitive to the choice of the $a_{f} / a_{n}$ ratio. A the projectile energy increasea to $3.0 \mathrm{GeV}$, the calculations begin to fill in the yields of the heavy fragments, so that they approach the experimental values. Eurther increases in projectile energy have little effect upon the theoretical ylelds of these fragments, but do result in ylelds that become too large for fragmenta of mass numbers 50 to 80 . Netther model is capable of predicting the turn-up in the yields for fragments with mass numbers less than 50, which is apparent in the experimental data. This fallure can be attributed to the possibility that these fragments are not formed in binary fission, which is their assumed mechanism of formation in the model calculations.

Two primary differences between the nuclear firestreak and INC model results can be noted. The nuclear firestreak calculation generally predicta somewhat larger yields for the mass numbers at and below the lower end of the fission region. This is due to the larger excitation energies that are deposited during the first step of the reaction, which result in larger numbers of particles being emitted in 
the de-excitation step. The other difference between the model calculations is the appareut lack of large near-target yields that is predicted by the firestreak model at most profectile energies. Th1s 1s simply an artifact of the interpolation process that was used in the calculation to predict the average excltation energy for each primary fragment mass that was formed during the primary resction. A correction could be made for this by the use of a discrete distribution of excitation energies for the near-target primary fragments.

It is of some 1nterest to examine the charge distributions that are predicted by the varfous models. However, the widths and centers of these distributions tura out to be much more dependent upon the parameters used 1n the de-excitation model, than upon the cholce of fragmentation model, except possibly for products wt th mass near to that of the target. This has been noted prevlously by Morrissey, et al. (65). Hence, a comparison of the predicted charge distributions wth those determined in the experiments can serve best as a test of the accuracy of the de-excitation model. In Figure 40 the predicted charge distribution for products with mass numbers 40 to 60 , which was calculated through use of the Intra-nuclear cascade model, is compared wth the experimental independent ylelds for the reaction of $3.0 \mathrm{GeV}$ ${ }^{12} \mathrm{C}$ with ${ }^{238} \mathrm{U}$. The center and width of the theoretical distribution are similar to those of the experimental data, wh the former being centered somewhat more nentron excessive. Throughout the non-fission mass reglons the theoretical centers of the distributions are generally within less than $1.5 \mathrm{Z}$ units of those obtained from the experimencs. For fiasion mass products the calculations give single 
brond charge distributions, which superimpose over the tops of the twin narrow distributions of neutron excessive and deficlent fragments which are observed in the experiments.

It 1 s somewhat surpriaing that two models as conceptually dissimilar as the Intra-nuclear cascade and nuclear firestreak models ahould give such almilar results. This can be interpreted as heing due to the following factors: Frat, many of the features of RHIInduced reactions are simply dependent upon the geometry of the collision, which is treated nearly identically in both models. Second, the mean free path of cascade nucleon in a nucleus is short enough at these energies so that its interaction is quite lnelagtic, giving results which approach those obtalned as a consequence of the assumption of a completely inelastic interaction, which is inherent in the nuclear firestreak model. Flnally, it is the de-exc1tation proceas which takes place in the common second step of the reaction that generates the general shape of the mass yleld distribution. As long as the excitation energies deposited in the first step are comparable, the resulting shapes of the yleld distributions will be quite similar.

While the intra-nuclear cascade and nuclear firestreak model results reproduce much of the character of the experimental data for these reactions, nelther model accurately satisfles the hypothesis of limiting fragmentation. This is a consequence of the fact that both models predict that the excitation energies of the fragment precursors continue to increase throughout this projectile energy range. Yet these models do demodstrate the validity of the concepts of factorization and a dependence upon the total kinetic energy for the results of the reactions. 
2. Theoretical Recoll Velocity Distributions

As a parallel to this study, we have previously reported the target fragment energies and momenta measured in the reactions of 4.8 GeV ${ }^{12} \mathrm{C}$ and $5.0 \mathrm{GeV}^{20} \mathrm{Ne}$ whth urantum (66). A comparison of the recoll velocities for neutron deficient fragments produced in the 4.8 GeV ${ }^{12} \mathrm{c}-1$ induced reaction with the velocities predicted by the nuclear firestreak and INC models 18 shown in Figure 41 . The selection of neutron deficient fragments was made to eliminate the products of lowexcltation-energy flasion and to emphasize fragments produced in deepspallation type reactions. The lines of recoll velocity shown for the model calculations were determined by allowing the target remnants produced In the first step of the reaction to de-exclte by particle emission only. A cursory examination of this figure reveals a rather dramatic fallure of the models; except for the near-target fragments, both modele grossiy overestimate the recoll velocities that are imparted to the fragments. Th1s fallure is especlally significant at nasa numbers above 150, ince these fragments are expected to be formed only by a deep-gpallation type of mechanism.

It is difficult to understand the behavior of the experimental recoll velocity distributions in terms of conventional theory. The recoll veloctiles are nearly identical for all fragments of mass numbers 100 through 200 . This is hard to reconcile with the supposition that these fragments are formed by de-excitation of primary remants that were given widely different amounts of excitation energy during the fast abrasion step of the reaction. Apparently, some mechanism exists which allows for the transfer of 
large amounts of excitation energy to the fragments, without the transfer of correspondingly large amounts of linear momentum. Crespo, et al. have proposed that the primary remants could have emitted large pre-equilibrium fragments such as Na (67), whlch carried off large amounts of momenta before the statistical de-exc1tation took place. Th1s mechantam could therefore account for the large recoll velocities of these 11ght fragments, as well as the1r strongly energy dependent excltation functions.

3. Theoretical Total Reaction Cross-sections

The total reaction cross-sections predicted by the intra-nuclear cascade and nuclear firestreak models are given together wh the experimental values in Table IV. Both calculations predict a general 1nviriance of reaction crossmection with beam energy. They match the exp=rlmental values reasonebly weli, except for the measurements with the $1.0 \mathrm{GeV}{ }^{12} \mathrm{C}$ and $5.0 \mathrm{GeV}{ }^{20}$ Ne beams, which are somewhat ouspect, as discussed earlier. This general agreement is simply the tesult of the ge onetrical assumptions inherent in the two models. 


\section{v. CONGLUSIONS}

Several conclusions can be drawn frow the results presented in the previous section. Clear evidence for the validity of the concepts of limiting fragmentation and factorization is seen in the experimental mass yield and charge distributions. Limiting fragmentation is observed in the yields of all but the light fragments $(A<60)$ for energies beginning at approximately $3.0 \mathrm{GeV}$. At $1.0 \mathrm{reV}$ the fisston wass rields are simflar to those at higher energies, but the yields of the heavy fragments (145 $\leq A \leq 210)$ are sirongly Buppressed. This is conslstent with the origin of the latter fragments arising from deep-spallation reactions, which can only take place if large energies were deposited during the primary interaction. The light fragment producticn cross-gections are otrongly 1ncreasing with energy unt1 8 to $12 \mathrm{GeV}$. Th1s is ind tcative of the possibility that the fe fragments are formed in "explosive events" or are emitted from thermal sources, both of which woudd require large profectile energies. Comparisons of the mass yields from the ${ }^{12} \mathrm{C}$ and the ${ }^{20}$ Ne-1nduced reactions wh those previously published for proton and $14 \mathrm{~N}$ profectiles of simflar energy confirm that the tocal projectlle kinetic energy is a good parameter for describing the results of the reactions.

The theoretical model calculations give ingight into the probable mechaniam of formation of the varioug target fragments. The heavy fragments are produced by deep-spallation, in which a highly excited primary remnant evaporates a multitude of light particles. Neutron excessive fragments of ffssion mass $(80<A<145)$ are produced by fission of moderately-exclted near-target apecies. Neutron defictent 
fragments of this mass region are produced by fission of highlyexclted heavy species and to smaller degree by deep-spallation processes.

of the three theoretical nodels, only the nuclear fireball model is clearly inferior in Its predictions fo.: the mass yield distributions, which 18 due to the inability of this mechanism to deposit large enough excitation energles within the fragment precursora. The nuclear firestreak and intra-nuclear cascade models both produce air predictions for the shapes of the experimental mass and charge distributions, with the exception of the yields for the lightest fragments. This fallure can be attributed to the lack of any mechanism within the de-excltation model, other than that of fission, which can populate this mass reglon. The two reaction models are both found to be incapable of predicting target fragment recoll velocities which are close to the previously measured values. This suggests that some other mechanism must exist for the transfer of large excltation energles to the target fragments, whout the correspondingly large amounts of recoll momenta. 


\section{REFERENCES}

1. J.R. Alonso, R.T. Avery, T. Elloff, R.J. Force, H.A. Grunder, H.D. Lancaster, E.J. Lofgren, J.R. Mereghett1, P.B. Selph, R.R. Stevenson, and R. B. Yourd, Sclence 217, 1135 (1982).

2. G. B. Yodh, Proceedings of the lat Workshop on gltra-Relativist1c Nuclesr Collisiona, Lawrence Berkeley Laboratory Report LBL-8957, p. 139 (1979). See also Ref. 3.

3. A.S. Goldhaber and H.H. Hecloman, Ann. Rev. Mucl. Part. Se1. 28, 161 (1978).

4. G. F. Chapline, M.H. Johnson, E. Teller, and M.S. We1ss, Phys. Rev. D8, 4302 (1973).

5. C.Y. Wong and T.A. Welton, Phys. Lett. 49B, 243 (1974).

6. R.F. Sawyer, Phys. Rev. Lett. 29, 382 (1972).

7. E.M. Frledlander, R.W. Gimpel, H.H. Heckman, Y.J. Karant, B. Judek, and E. Ganssauge, Phys. Rev. Lett. 45, 1084 (1980).

8. H. L. Bradt and B. Peters, Phys. Rev. 75, 1779 (1949).

9. R.M. DeVries and J.C. Peng, Phys. Rev. C22, 1055 (1980).

10. J. Benecke, T.T. Chou, C.N. Yang, and E. Yen, Phys. Rev. 188,2159 (1969).

11. V.N. Gr1bov and I. Ya. Poweranchuk, Phys. Rev. Lett. $\underline{8}, 343$ (1962).

12. D.J. Morrissey, W. Loveland, M. de Salnt Simon, and G.T. Seaborg, Phys. Rev. C21, 1783 (1980).

13. J.B. Cumming, R.W. Stcenner, and P.E. Haustein, Phys. Rev. Cl4, $1554(1976)$.

14. S.B. Kaufman, E.P. Stelnberg, and M.W. Welstield, Phys. Rev. Cl8, 1349 (1978).

15. P.J. Lindstrom, D.E. Greiner, H. H. Heckman, B. Cork, and F.S. Bleser, Law ence Berkeley Laboratory Report LBL-3650 (1975).

16. G.D. Westfall, L.W. WIIson, P.J. LIndstrom, H.J. Crawford, D.E. Greiner and H.H. Heckman, Phys. Rev. C19, 1309 (1979).

17. J. B. Cumming, P.E. Hausteln, and R.W. Stoenner, Phys. Rev- ClO, 739 (1974).

18. J.B. Cumming, P.E. Hauste1n, T.J. Ruth, and G. Virtes, Phys. Rev. C17, 1632 (1978). Ste also J.B. Cumming, P.E. Heuste1n, and H.C. Hseuh, Phys. Rev. C19, 2288 (1979). 
19. H.T. Porile, G.D. Cole, C.R. Rudy, Phys, Rev. C19, 2288 (1979).

20. W. Loveland, D.J. Morribaey, K. Aleklett, G.T. Seaborg, S.B. Raufman, E.P. Stelnberg, B.D. Wilkins, J.B. Cumming, P.E. Hauste1n, and H. C. Hseuh, Phys. Rev. C23, 253 (1981).

21. C.P. Dertel, Target Fragmentation In the Interaction of Relativistic Heavy-Ions and Protons wth Ta, $H_{*}$ s. thesis, Oregon State UnIveralty, Sept. 1981.

22. S.B. Kaufman, E.P. Stelaberg, and M.W. Welsfleld, Phys. Rev. C18, 1349 (1978).

23. S. B. Kaufman, E.P. Stelnberg, B.D. Wllk1ns, and D.J. Henderson, Phys. Rev. C22, 1897 (1980).

24. K. Aleklett, D. J. Korrissey, W. Loveland, P.L. McGaughey, and G.T. Seaborg, Phys. Rev. C23, 1044 (1981).

25. Yu-Wen Yu, Phys. Rev. C22, 933 (1980).

26. B.D. Wilkins, E.P. Steinberg, and S.B. Kaufman, Phys. Rev. C19, $856(1979)$.

27. A.I. Warwlek, A. Baden, H.H. Gutbrod, M.R. Ma1er, J. Péter, H.G. Rutter, H. Stelzer, H.H. Wieman, F. We1k, M. Freedman, D.J. Henderson, S.B. Kaufman, E.P. Stelnberg, and B.D. Wilk1ns, Phys. Rev. Lett. 48,1719 (1982).

28. N.T. Por $¥$ le, S. Pandian, H. Klonk, C.R. Rudy, and E.P. Stelnberg, Phys. Rev. C19, 1832 (1979).

29. S. B1swas and N.I. Porile, Phys. Rev. C20, 1467 (1979).

30. M. Lagarde-Simonoff and G.N. S1monoff, Phys. Rev. C20, 1498 (1979).

31. W. Loveland, R.J. Otto, D.J. Morrissey, and G.T. Seaborg, Phys. Rev. Lett. 39, 320 (1977).

32. G. D. Cole and N.T. Por1le, Phys. Rev. C24, 2038 (1981).

33. See, for example, any chart of the nucl1des.

34. L. C. Northcliffe and R.F Schilling, Nucl. Data Tables A7, 233 (1970).

35. T. Lund, private communtcation (1981).

36. D.J. Morr1ssey, D. Lee, R.J. Ot to, and G.T. Seaborg, Nuc l. Ingt. Keth. 158, 499 (1979).

37. J.T. Routt1 and S.G. Prussin, Rucl. Inst. Meth. 72, 125 (1969). 
38. I. Binder, R. Rraua, R. Klein, D. Lee, and M.M. Fowler, Laurence Berkeley Laboratory Report LBL-6515 (1977).

39. J. Gosset, H.H. Gutbrod, W.G. Meyer, A.M. Poskanzer, A. Sandoval, R. Stock, and G.D. Weatfall, Phys. Rev. C16, 629 (1977).

40. D.J. Horr1agey, Study of the Role of Complete Fuaion in the

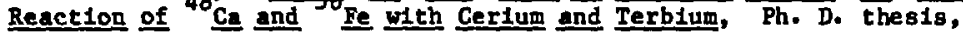
Lawreace Berkeley Laboratory Report LBL-7713 (1978).

41. R.J. Otto, private comunication (1978).

42. R. Serber, Phys. Rev. 22, 1114 (1947).

43. G.D. Weatfa11, J. Gosset, P.J. Johansen, A.M. Poskanzer, W.G. Heyer, H.H. Gutbrod, A. Sandoval, and R. Stock, Phys. Rev. Lett. 37. $1202(1976)$.

44. W.D. Myers, Nuc 1. Phys. A296, 177 (1978).

45. X. Camp1 and J. F. Hufner, Phys. Rev. C24, 2199 (1981).

46. H. Stocker, J.A. Maruhn, and W. Greiner, Phys. Rev. Lett. 44, 725 (1980).

47. Y. Yariv and 2. Fraenkel, Phys. Rev. C20, 2227 (1979).

48. J.D. Bowman, W.J. Swlateck1, and C.F. Tsang, Lawrence Berkeley Laboratory Report LBL-2908 (1973).

49. D.J. Morrissey, W.R. Marsh, R.J. Otto, W. Loveland and G.T. Seaborg, Phys. Rev. C18, 1267 (1978).

50. L. F. Oliveira, R. Donangelo, and J.0. Rasmussen, Phys. Rev. C19, $826(1979)$.

51. W.D. Myers, W.J. Swiateck1, T. Kodama, L.J. El-Jaick, and E.R. H1If, Phys. Rev. C15, 2032 (1977).

52. J. Gosset, J.I. Kapusta, and G.D. Westfall, Phys. Rev. C18, 844 (1978).

53. I. Dostrovsky, 2. Fraenkel, and G. Friedlander, Phys. Rev. 116, 683 (1959).

54. R. Vandenbosch and J.R. Huizenga, Nuclear Flssion (Academ1c: New York, 1973) P. 233.

55. S. Cohen and W.J. Swlateck1, Ann. Phys. 22, 406 (1963).

56. J.R. N1x, Nucl. Phys. Al30, 241 (1969).

57. M. de Salnt Simon, S. Haan, G. Aud1, A. Coc, M. Epherre, P. Guimbal, M. Langevin, A.C. Mueller, C. Thlbault, and F. Touchard,

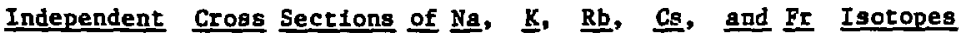


Produced 1a Ta and $\mathrm{g}$ Targets Bombarded by ${ }^{12} \mathrm{c}$ Ions up to $\underline{77}$ MeV/u , submitted to Physe. Rev. C (1982).

58. H.H. Gutbrod, A.I. Warwick and H. Wleman, Lawrence Berkeley Laboratory Report LBL-14059 (1982).

59. W.D. Loveland, private communication (1982).

60. Y.Y. Chu, E.M. Pranz, G. Frledlander, and P.J. Karol, Phys. Rev C4. 2202 (1971).

61. B.V. Jacak, W. Loveland, D.J. Morrissey, P.L. KcGaughey, and G.T. Seabor8, Eeavy Target Fragment Yielde in the Interaction of $28 \mathrm{GeV}$ Protone with t, Can. J. Chem., to be published (1982).

62. H.H. Becloman, D.E. Greiner, P.J. Lindstrom, and B. Shue, Plys. Rev. C17, 1735 (1978).

63. T.A. Lasingke, A. Barbaro-Galtiert, R.L. Re1ly, A. Rittenberg, A.I. Rosenfeld, T.G. Trippe, N. Barash-Schmidt, C. Brifman, V. Chaloupka, P. Soding and M. Roos, Rev. Kod. Phys. 45, S40 (1973).

64. S. Ratcoff and J. Hud 18, Phyt. Rev. C14, 628 (1976).

65. D. J. Morrissey, L. F. Ollvelra, J.0. Rasmussen, G. T. Seaborg, Y. Yar1v, and 2. Fraenkel, Phys. Rev. Lett. 43, 1139 (1979).

66. W. Loveland, C. Luo, P.L. McGaughey, D.J. Morr1sgey, and G.T. Seaborg, Phys. Rev. C24, 464 (1981).

67. V.P. Crespo, J.B. Cumming, and J.M. Alexander, Phys. Rev. C2, 1777 (1970). 
TABLE I.

Irradiation Conditions

\begin{tabular}{|c|c|c|c|c|c|c|c|}
\hline Accel. & Beam & Ion & $\begin{array}{l}\text { Total } \\
\text { linetic } \\
\text { energy }\end{array}$ & $\begin{array}{l}\text { Total } \\
\text { flux } \\
\text { particles }\end{array}$ & $\begin{array}{l}\text { Irrad. } \\
\text { period } \\
\text { min. }\end{array}$ & $\begin{array}{l}\text { Target } \\
\text { tnickpess } \\
\text { mg/cm }\end{array}$ & $\begin{array}{l}\text { Catcher } \\
\text { materlal }\end{array}$ \\
\hline
\end{tabular}

CERN SC $\quad{ }^{12} \mathrm{c}^{4+} \quad 1.0 \mathrm{GeV} \quad 4.3410^{15} \quad 120 . \quad 46.8 \quad$ Aluminum

Bevalac $\quad{ }^{12} \mathrm{c}^{6+} \quad 3.0 \mathrm{GeV} \quad 8.3810^{13} \quad 1605 . \quad 37.4,46.0$ Mylar

Bevalac $\quad{ }^{12} c^{6+} \quad 4.8 \mathrm{GeV} \quad 6.2310^{13} \quad 821.5 \quad 56.1 \quad$ Mylar

Bevalac $\quad{ }^{12} \mathrm{C}^{6+} \quad 12 \mathrm{GeV} \quad 9.1310^{12} \quad 750 . \quad 37.1,44.8$ Mylar

Bevalac $\quad 20 \mathrm{Ne}^{10+} \quad 5.0 \mathrm{GeV} \quad 1.01 \quad 10^{13} \quad 639.8 \quad 37.2,45.8$, Mylar Bevalac $\quad 20 \mathrm{Ne}^{10+} \quad 8.0 \mathrm{GeV} \quad 3.7610^{13} \quad 1074 . \quad 33.5 \quad 116.29$ Mylar Bevalac $20 \mathrm{Ne}^{10+} 20 \mathrm{GeV} \quad 1.0910^{13}$ 859. 25.3,63.7, Mylar Bevalac $20 \mathrm{Ne}^{10+} 42 \mathrm{GeV} \quad 1.9310^{12}$ 545. 36.0,44.6, Mylar

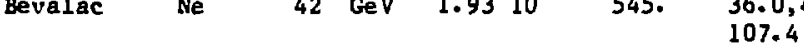


TABLE II.

Charge Dispera10n Parameters

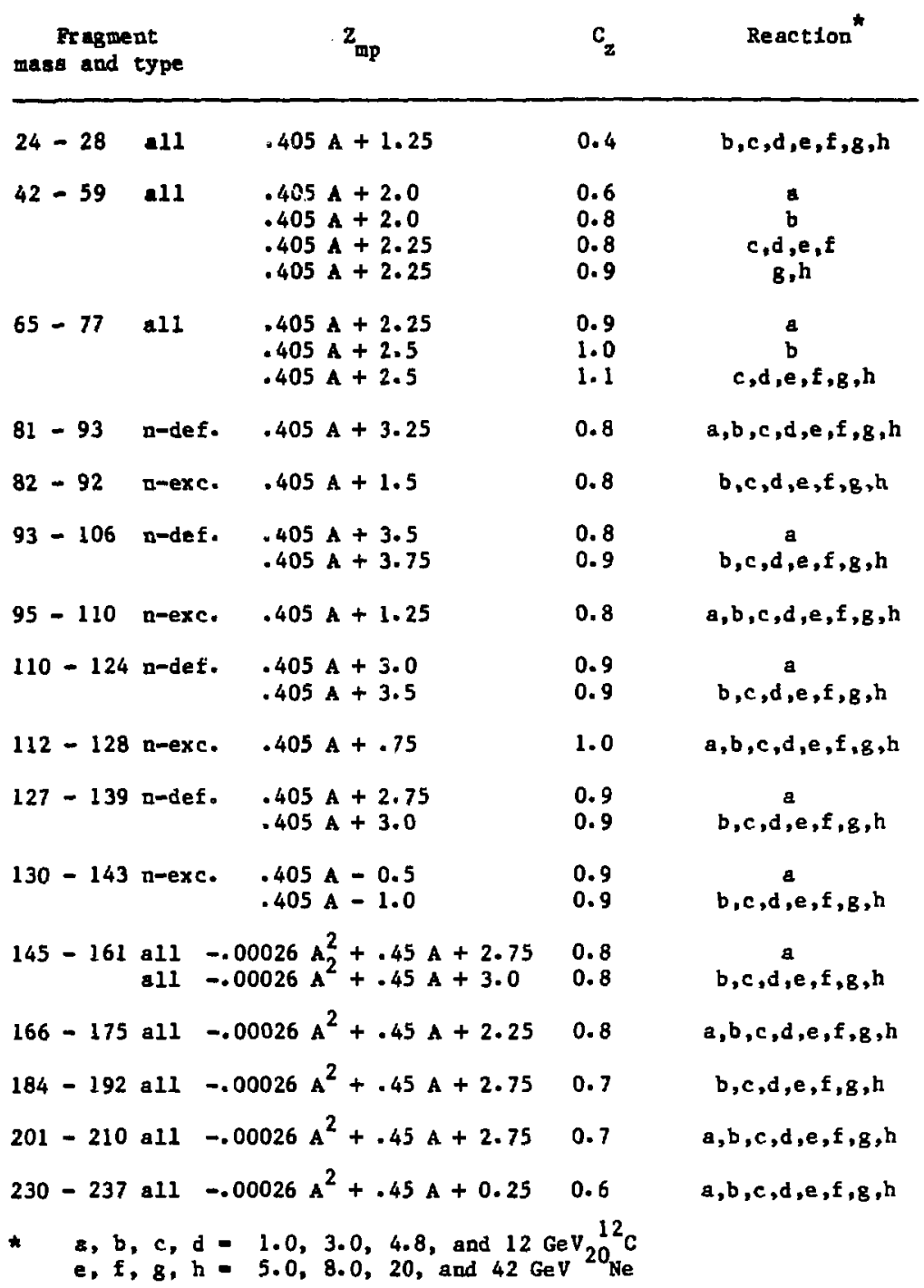


TABLE III.

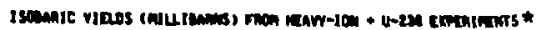

\begin{tabular}{|c|c|c|c|c|c|c|c|c|}
\hline \multirow{2}{*}{ ach 10} & \multicolumn{8}{|c|}{ MOSEetILE } \\
\hline & $1 \in \mathbb{C}<-12$ & $3 \in \mathbb{E}(-12$ & $4.1 \mathrm{ar} c-12$ & $12 \leq x<-12$ & $\operatorname{sar} \in=-20$ & - E⿸厂 ter $<-20$ & $20 \mathrm{erV}=-20$ & $42 \operatorname{cev} v e-20$ \\
\hline$m$ & & 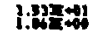 & 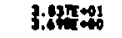 & 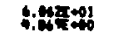 & E:775 & 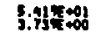 & 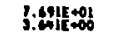 & 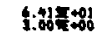 \\
\hline$\approx 10$ & & tisfort:이 & 1. & 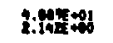 & 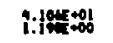 & 1.7345+0.01 & i:34teop? & 3:13: \\
\hline 192 & & i: 740 & 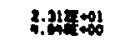 & & 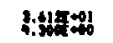 & 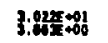 & 1. Afte+ol & 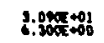 \\
\hline$n$ & & & 1. & & E:4t: & $1: t+x+\infty 11$ & Hitirto이 & \\
\hline$x+m$ & 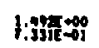 & & & 1.34 & 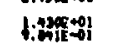 & $1: 34=0+01$ & & \\
\hline$x \operatorname{sen}$ & & 1:AE+ol & 2.190 & & & & 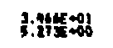 & $2,59 \pi+0.0615$ \\
\hline 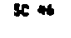 & $3: 4+4=0$ & 1:417n & 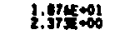 & f:4te+ol & 2.:日us & 1:40: & $3: 54=+90$ & \\
\hline en $n$ & 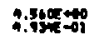 & $1: 72 \pi 10+\infty$ & 1:Ax & 1.2705001 & 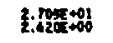 & 2.037 090 & & 1.48x+ot \\
\hline sc 4 & & & 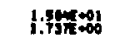 & f:47x+ol & 1.2utze+ol & & & 3. \\
\hline se 48 & 2.41: & 1:20 $20=000$ & $1: 11$ = +201 & 1:. 11: & 2:30e+os & 2. $3: 155$ & 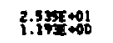 & 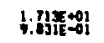 \\
\hline$v$ & $3 . \operatorname{sen} x=00$ & :Heti & $1:=04000$ & $2: 197 \%+01$ & 1. & 2.060 35001 & 2. & 2. $304 x+010$ \\
\hline$m 32$ & & 1: & $1.47 \pi+\infty 101$ & 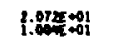 & 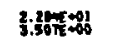 & 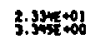 & $\frac{2.210 x+01}{2.720}+400$ & 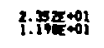 \\
\hline an 36 & & 1.519E+100 & 1.35xtod & 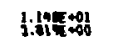 & 2.4. & $\frac{1}{3} \cdot x^{2}= \pm 01$ & 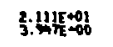 & 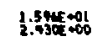 \\
\hline re s9 & 3. & 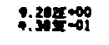 & 1:40x: & 1:73: & 2.128:+0! & 1:4206:01 & 3. & \\
\hline$D$ A S & 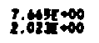 & & & & & & & \\
\hline as $n$ & & 1.225: & 2:16x+ol & $5.4015 \div 201$ & & & 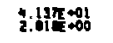 & 2. $4 x=0$ \\
\hline$m n$ & 1. $10 x+010$ & $2.798+010$ & 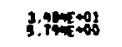 & $7.55 x+001$ & $3.27=01$ & & $\because \because$ A the $=01$ & $2,4350+01$ \\
\hline$\omega n$ & & 1:I & 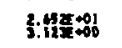 & $3.30 \pi+01$ & 3. & I.ZIE & $\frac{3}{3}: 410 \times+01$ & 2.4 $45=+01$ \\
\hline
\end{tabular}




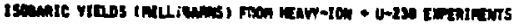

\begin{tabular}{|c|c|c|c|c|c|c|c|c|}
\hline $\operatorname{aratax}$ & & & & mos & 7145 & & & \\
\hline$m n$ & 1 tar t-12 & 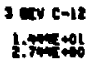 & 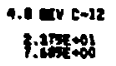 & 12 Ex $E-12$ & 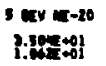 & 1: av ur-20 & 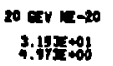 & 4 Eev $u=-20$ \\
\hline 50 & & 1:4th & $1: 2 x+21$ & 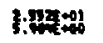 & 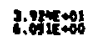 & f:Fute+el & & 2.:47215001 \\
\hline as $n$ & 1.futud & 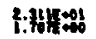 & 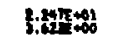 & f.4titiol & 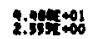 & J:23nt+d & 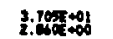 & 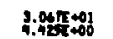 \\
\hline$x n$ & 1:네에 & 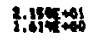 & & 1:40yit & 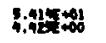 & 3: $315=01$ & 1. $114 x+\infty=0$ & \\
\hline as ro & & E:15y & l:14:40 & 1) 340 & 7:18: & i: $14+400$ & 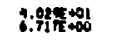 & 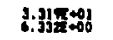 \\
\hline$\pi$ & 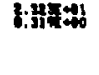 & 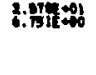 & f:11:4에 & 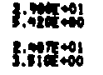 & 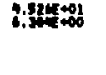 & $2: 15+\infty$ & 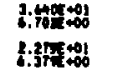 & 7; \\
\hline 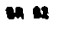 & 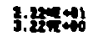 & 1:20 & 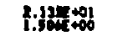 & 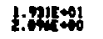 & 3:켜ำ & 2.:4t: & 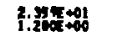 & 1.:185+o1 \\
\hline 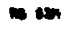 & & 1:77 & 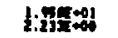 & $1: 27=+\infty$ & 1.2y & 1.237t+ol & 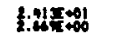 & 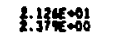 \\
\hline$m$ & 1.230 & 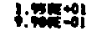 & 1.375. & 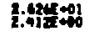 & 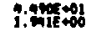 & 2:000 & & \\
\hline 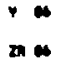 & & 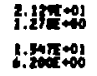 & 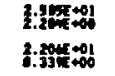 & 2.195.01 & 4: & 1:14:=018 & 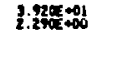 & 2.97EE+901 \\
\hline a 97 & & 1.281te+ol & & & 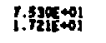 & & & 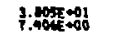 \\
\hline $\begin{array}{l}\text { Y ot } \\
\text { in on }\end{array}$ & 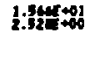 & 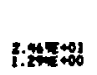 & 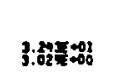 & 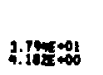 & 3. & 9.7458 & & \\
\hline$\omega$ & & 3.944 tool & l:metol & 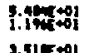 & 1:106 & i: & 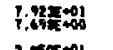 & 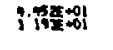 \\
\hline to & 1: $: \operatorname{lor} 4+\infty$ & 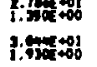 & $2.11=+\infty$ & $3.15=0+06$ & $7: 30=+\infty$ & 3. & 2,4185 & \\
\hline
\end{tabular}




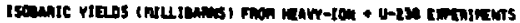

\begin{tabular}{|c|c|c|c|c|c|c|c|c|}
\hline \multirow{2}{*}{ anctiot } & \multicolumn{8}{|c|}{ mostetiu } \\
\hline & 1 ex $c-12$ & J $x v c-12$ & 4,0 E $c-12$ & 12 ex $[-12$ & 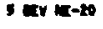 & $10 x y=-20$ & $x \in v \in-20$ & $42 \mathrm{EEV}$ Me -20 \\
\hline at & 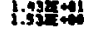 & 2.15itat & 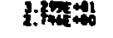 & $3:+401$ & $2: 325 \div 24$ & 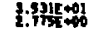 & i.64te+ot & 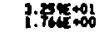 \\
\hline $1 m$ & & S.1575 & B.sfotof & titst & 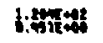 & 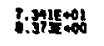 & 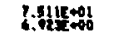 & 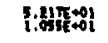 \\
\hline $\operatorname{sen}$ & & 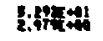 & 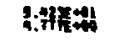 & 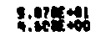 & 8.4ny & 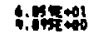 & $4: 24=0$ & 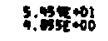 \\
\hline$m$ & & 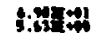 & 7:47: & I:120 & i:2415:402 & i.24e+set & 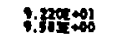 & 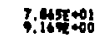 \\
\hline & & s:10x+ol & 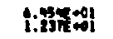 & 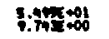 & & $8.9745+000$ & 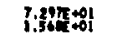 & \\
\hline דים & & I.:Intopt & 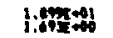 & 2; $37 \pi+\infty$ & 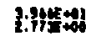 & 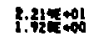 & 2.:fre+ol & $1: 1,120+201$ \\
\hline & & s.7neteol & & & 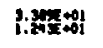 & 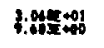 & 3: $1070 \pm 0.01$ & 2.4metifil \\
\hline & & & 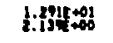 & & & & 2.2. $2185+010$ & $1: y=010$ \\
\hline & 2. 27x & 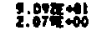 & 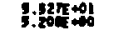 & 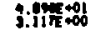 & f:mute+ol & 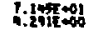 & 3:04: & 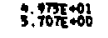 \\
\hline & & 1:1ㅣ페에 & 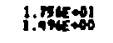 & 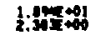 & 3: & 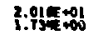 & $2.345+010$ & 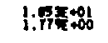 \\
\hline & 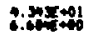 & Silntirat & 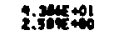 & 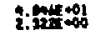 & 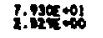 & 5.8372 & 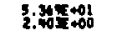 & \\
\hline 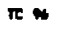 & 1. AuEtol & 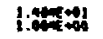 & 1:45: & 1.4.45 & 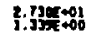 & 2:.03ete+21 & $1: 21 x+210$ & $1: 21=0$ \\
\hline & & 8:4 & 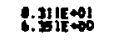 & 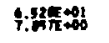 & $6: \frac{22 \pi}{350+02}$ & 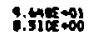 & $8: 040=010$ & 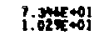 \\
\hline & 2:4015 & 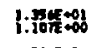 & & 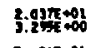 & 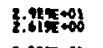 & 2.31) & 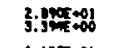 & $\begin{array}{l}2.07 \times 0+01 \\
2.054=00\end{array}$ \\
\hline & 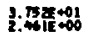 & i.tTr +01 & 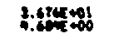 & s.t45:+ol & 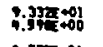 & 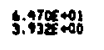 & E:Herestos & 5. HFE \\
\hline & & & & 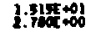 & 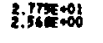 & & & \\
\hline & & & & & & 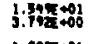 & & \\
\hline$m$ & 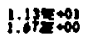 & 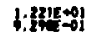 & 1:30315+401 & 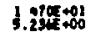 & 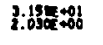 & 1:20=010 & 2.2315+ol & 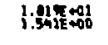 \\
\hline
\end{tabular}




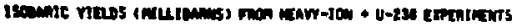

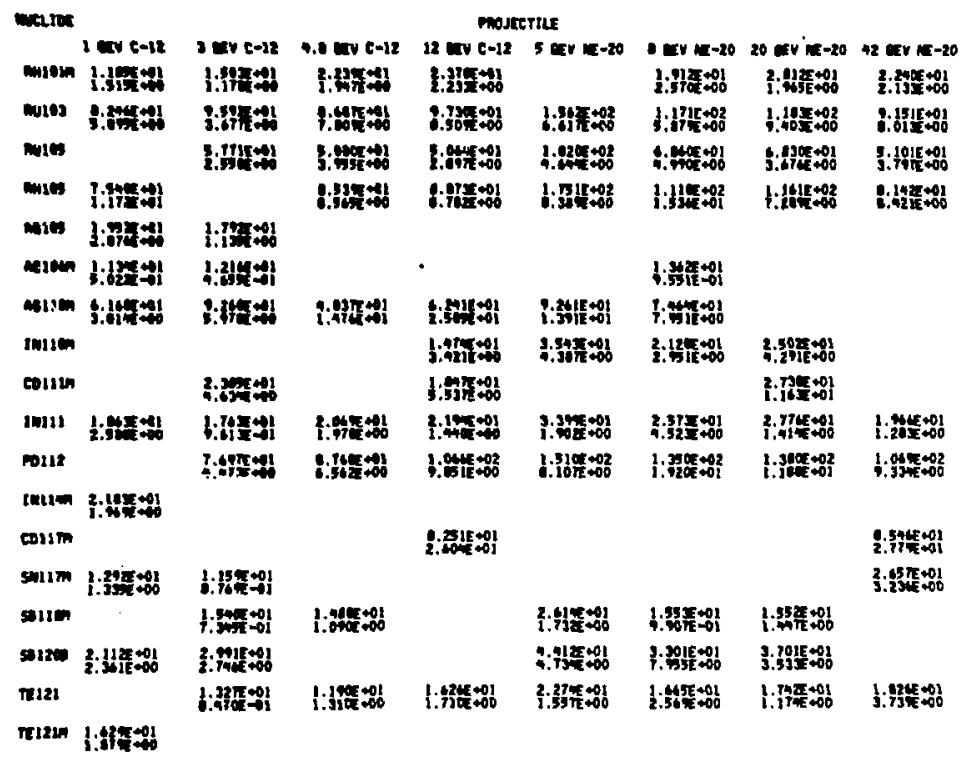




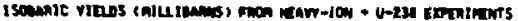

\begin{tabular}{|c|c|c|c|c|c|c|c|c|}
\hline \multirow{2}{*}{ werles } & \multicolumn{8}{|c|}{ moJectIL } \\
\hline & $104 c-11$ & $30=-12$ & $0.1<x<-12$ & $12 \mathrm{er} e-12$ & $\operatorname{ser} \mid \in-20$ & $0 \leq r \leq-20$ & $20 \mathrm{Fr} \in=-20$ & 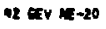 \\
\hline 112 & & 2:137x+ot & 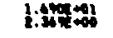 & $3: F=0$ & 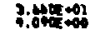 & $\int: 41 E+000$ & & 1:70: \\
\hline $\mathbf{m 1 2}$ & 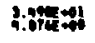 & 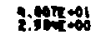 & 1: $\rightarrow x=+40$ & 3:39nt+ol & $4: 4 x=00$ & $1: 730$ & 3.411E+이 & 3.: $45 \pi+\infty$ \\
\hline 125 & tistertor & & & & & & & \\
\hline I II & & 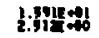 & $1.21=0+01$ & 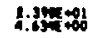 & 3. 개t我 & 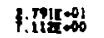 & 2. $30 x+01$ & 2.38x 4.010 \\
\hline & $1: 40+2010$ & 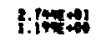 & E.47xक्य & 2. Burtoll & 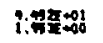 & i.4utesesol & 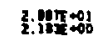 & \\
\hline 18 & 1.tentor & i: $1:+1$ & $1.70+\infty$ & 1.t.textos & 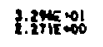 & 2. $2.12=0100$ & 2. $0.99+0.01$ & $1.445+013$ \\
\hline & 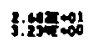 & 2. 가래 & 1.25 & & i.ffritol & 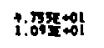 & & \\
\hline & 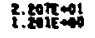 & 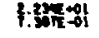 & 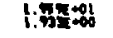 & & 1.145e+01 & 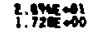 & 2.2015+02 & \\
\hline & 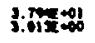 & 2.t2uted & 3.415000 & 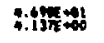 & 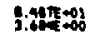 & f:114te+ol & f: & $40210+01$ \\
\hline & 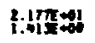 & 1.001 & & $1: x=0=01$ & 3:3737 & 2.: & & \\
\hline & & & 2:14:-00 & 2.237 2091 & 3:97t & & j:H类地 & \\
\hline A12e & & 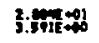 & 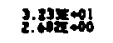 & 2. $z=2 x+010$ & 1. $13=0$ & $2: 20+001$ & 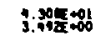 & 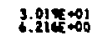 \\
\hline \$120 & 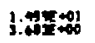 & 1: $50=0$ & 1.:43: & 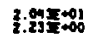 & 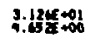 & 2. & 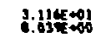 & \\
\hline 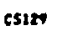 & & 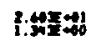 & $2.164 x+01$ & 2. & $+4 x+x=0.00$ & 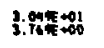 & 3. $328 x+001$ & \\
\hline 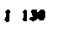 & & 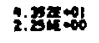 & 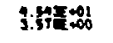 & 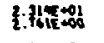 & : $15 x+\infty$ & 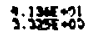 & $4.900 x=0006$ & 3. \\
\hline & & 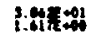 & 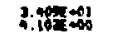 & 3. $1415+20 \%$ & $\frac{5}{2} \cdot 425=+092$ & $3: 0000+000$ & $3.24 x=010$ & 3. $137 x+000$ \\
\hline & & i. $56 t=01$ & $1: x^{2}=+\infty$ & 1.:130e+ol & S.tick & I:Int) & $\frac{2}{2.73 x}=010$ & \\
\hline anz & 2.73tited & $f: y=0$ & 2. $20=001$ & $1.857+02$ & 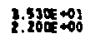 & 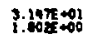 & $\begin{array}{l}3.428+001 \\
1.600\end{array}$ & 2. $20115+010$ \\
\hline
\end{tabular}




\begin{tabular}{|c|c|c|c|c|c|c|c|c|}
\hline waside & \multicolumn{8}{|c|}{ mosrtule } \\
\hline 112 & 1 are $5-12$ & 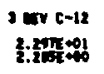 & 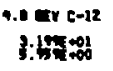 & 12 eev $5-12$ & 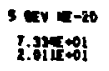 & 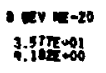 & 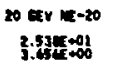 & 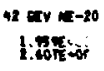 \\
\hline $\tan$ & & $3.1 \mathrm{mx}+6$ & & & & $3.2217=01$ & & \\
\hline 1133 & & $1.420+0+\infty$ & 1:41:-010 & 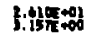 & 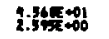 & 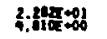 & 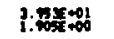 & 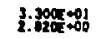 \\
\hline at3 & & 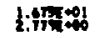 & 1:70x-101 & 1. $439 \pi+91$ & H: & $4.140+\infty$ & $9.14=010$ & 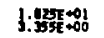 \\
\hline $\begin{array}{l}\text { I } 19 \\
\text { esin }\end{array}$ & 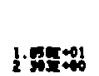 & $9.4 x+1$ & & & I:A2: & 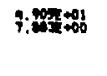 & $3: 325 \times 000$ & 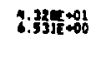 \\
\hline $\begin{array}{l}118 \\
218\end{array}$ & & 1.21 & 1:20 & 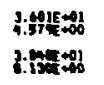 & 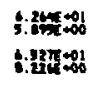 & 3. $2 x=010$ & $3.22 \times 12+\infty$ & 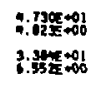 \\
\hline$[\times 13$ & & 1.:ํㅏㄹㅐ & 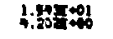 & it: & 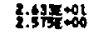 & 1,415 & i. ipte+ol & 1:3450 \\
\hline $\begin{array}{l}\operatorname{csi3} \\
\operatorname{sis} 139\end{array}$ & 6.215: & 3: & 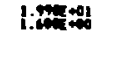 & 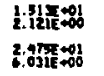 & 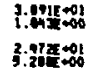 & 2.931: & 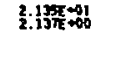 & 2.0145 409 \\
\hline tris & 1: & & & & & & & \\
\hline $\begin{array}{l}\text { Lal40 } \\
\text { La142 }\end{array}$ & $1: 14=01$ & 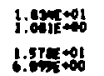 & & $\begin{array}{l}2.142=0 \\
1.274=+\infty\end{array}$ & 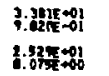 & 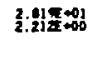 & 2:120=010 & 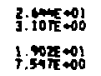 \\
\hline trtes & 1:5entolos & $1: \operatorname{lom}^{2} \neq 0+1$ & 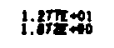 & 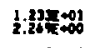 & 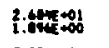 & 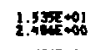 & 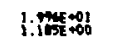 & 1. $4=0$ \\
\hline $\begin{array}{l}\text { Evin } \\
\text { Evint }\end{array}$ & 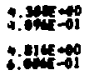 & 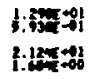 & 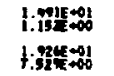 & 1:2 $2 x=+\infty$ & 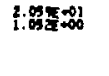 & 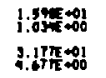 & $\begin{array}{l}\text { 1. } 11=+\infty 1 \\
\text { 3. } 40=+01 \\
\text { 1. } 40=+6 !\end{array}$ & \\
\hline$\omega$ & & 1. & $1.4007+\infty 109$ & 1. $120 \times 0+\infty$ & 1.72715:019 & 1:满:000 & 3.37t: & $1.04=01$ \\
\hline
\end{tabular}




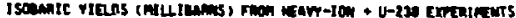

\begin{tabular}{|c|c|c|c|c|c|c|c|c|}
\hline \multirow{2}{*}{ matio: } & \multicolumn{8}{|c|}{ mosetils } \\
\hline & 1 are $[-12$ & 3 are c-12 & $4.10 \mathrm{E}[-12$ & $12 \approx x<-32$ & $3 \in=-20$ & I aty a & 20 $\operatorname{cec} \in-20$ & 42 aty ke -20 \\
\hline EU140 & A.dictot & & & & & & & \\
\hline D140 & 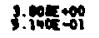 & 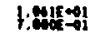 & $1 \cdot 4+4000$ & 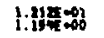 & 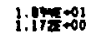 & 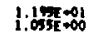 & & \\
\hline nisi & & 2. & 1.:21 $210+\infty$ & & 3: & 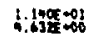 & 3. $14=001$ & 2.1415-01 \\
\hline Dיז15 & & & & $3.15 x+\infty 00$ & 1.:4דrat & & 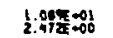 & \\
\hline molss & & 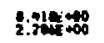 & & & & & 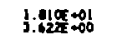 & \\
\hline oris7 & & 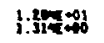 & 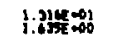 & 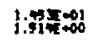 & 2. $197 \pi \neq 000$ & 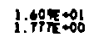 & 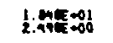 & $1: 735=010$ \\
\hline 20101 & & 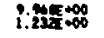 & & 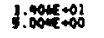 & & & 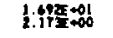 & 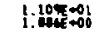 \\
\hline nian & 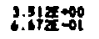 & 1.4702001 & 1. $3015=001$ & $3.420=010$ & 2. $4705+\infty 01$ & & 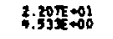 & 1.30 30+01 \\
\hline nise & 2. & t.2h: & & & $1:+10=010$ & 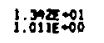 & & \\
\hline cuts! & & 1:1:037 & & & & & 2. $24= \pm 01$ & \\
\hline Luiro & & 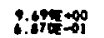 & & & & 1.230 & & \\
\hline$=170$ & & & 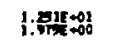 & 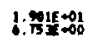 & $2.85+01$ & & $\begin{array}{l}2.325+01 \\
2.53+400\end{array}$ & 1. $550=0010$ \\
\hline เU1 $\pi$ & & & 1. & $2.0211+01010$ & 2.515=01 & 2: 41 EE & 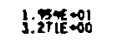 & \\
\hline 613 & & b. $200 x=000$ & $1: 085=+010$ & 3. ${ }^{423}+2000$ & & 1:0306+ol & $1 \cdot 1+4=0601$ & \\
\hline-13 & 1. $20 \pi+400$ & & & & & & & \\
\hline insen & & $1.1350+\infty$ & & & & & & 2. $4.42 \pi=000$ \\
\hline w192 & & & & & & $1 \cdot 36 \mathrm{E}$ & 2. $2000 \times+\infty$ & \\
\hline$m 12$ & & $1.08=00$ & $1: 490+000$ & 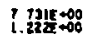 & $1.3199+0100$ & 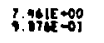 & $\begin{array}{l}1.1245=01 \\
3.515=00\end{array}$ & \\
\hline
\end{tabular}




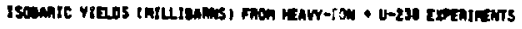

\begin{tabular}{|c|c|c|c|c|c|c|c|c|}
\hline weLIdoe & \multicolumn{8}{|c|}{ mosketile } \\
\hline n201 & 1 axe $c-12$ & 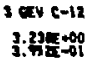 & 1. Ex t-12 & 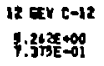 & 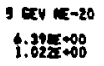 & C GEY $\mathrm{kE-20}$ & 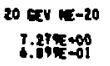 & 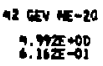 \\
\hline 01802 & & 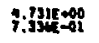 & i.76tet+os & 1.:19ux & 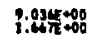 & 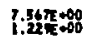 & $\frac{1}{2.92 \pi+201}$ & $1.318 \pi+400$ \\
\hline mess & & & 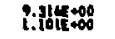 & & i: Mage & 7:24:-4000 & & \\
\hline mew & & $3 ; 6 z^{2}=010$ & bit3 & $9: 494=00$ & 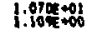 & 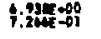 & 1:300=00\% & 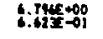 \\
\hline 01205 & 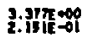 & ;:11: & 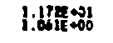 & & i:lite & 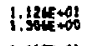 & 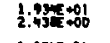 & \\
\hline 11206 & & & & & & $\frac{1}{2}: 14 x^{2}+01$ & 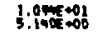 & \\
\hline pores & $\frac{2.24}{2,7 x+00}$ & 1.:4txtap & 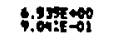 & 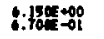 & 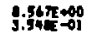 & 1.94tege & 1:905E+0! & 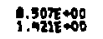 \\
\hline pror & & $i \cdot \cos x=00$ & 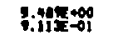 & & 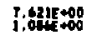 & $1: 4018+000$ & & $1: 2810+000$ \\
\hline Ar204 & & 7:해 & 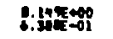 & 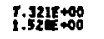 & $1: 45=+00$ & $\frac{1}{1: 21<x+201}$ & 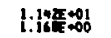 & 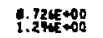 \\
\hline A7210 & & 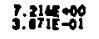 & t: & $1: 0050+\infty$ & 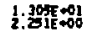 & 1:05: & 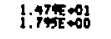 & 1:.02 $30 \pm 0.00$ \\
\hline P19230 & 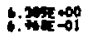 & 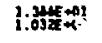 & & & 1.C5R & 4.9mento & & \\
\hline 4232 & 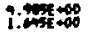 & 1:Athe+ol & $\frac{1}{2: 0150+00}$ & 1) & 2.73: & $\frac{2}{2: 325 x+\infty 10}$ & 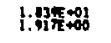 & 2. $1.04=0010$ \\
\hline cones3 & 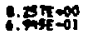 & 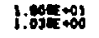 & 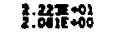 & 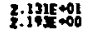 & 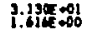 & $\frac{2}{2.906 \pi+000}$ & $\begin{array}{l}\frac{2}{2.625}+2.210 \\
2.26 t=000\end{array}$ & 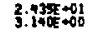 \\
\hline menem & & $3.24+5+010$ & & 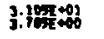 & 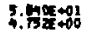 & 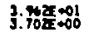 & 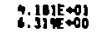 & 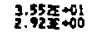 \\
\hline U 237 & 1.51ZE+e2 & 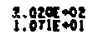 & 2.2.24:-002 & 3: & 1:2070 2002 & & 3. & 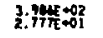 \\
\hline
\end{tabular}


TABLE IV.

Total Reaction and Hssion Crass-sections

for Beavy-1ons and Protons with $238_{\mathrm{U}}$

(barns)

\begin{tabular}{|c|c|c|c|c|c|}
\hline Project1le & reaction & fission & Fraction & $\begin{array}{c}\text { INC } \\
\text { reaction }\end{array}$ & $\begin{array}{l}\text { FI restreak } \\
\text { reaction }\end{array}$ \\
\hline $1.0 \mathrm{GeV}^{12} \mathrm{c}$ & 2.31 & 1.65 & .71 & 3.34 & 3.15 \\
\hline 3.0 & 3.33 & 2.03 & .61 & 3.36 & 3.41 \\
\hline 4.8 & 3.71 & 2.00 & .54 & 3.44 & 3.51 \\
\hline 12. & 4.08 & 2.18 & .53 & 3.54 & 3.71 \\
\hline $5.0 \mathrm{GeV}{ }^{20} \mathrm{Ne}$ & 6.36 & 3.59 & .56 & 3.52 & 3.84 \\
\hline 8.0 & 4.33 & 2.65 & .61 & 3.86 & 3.96 \\
\hline 20. & 5.02 & 2.76 & .55 & 3.96 & 4.15 \\
\hline 42. & 4.24 & 2.26 & .53 & $-\infty$ & 4.35 \\
\hline $11-29 \mathrm{GeV} p$ & 1.84 & 1.06 & .58 & & \\
\hline $2.0 \mathrm{GeV}{ }^{14} \mathrm{~N}$ & $-\infty$ & 2.84 & $-\infty$ & & \\
\hline 3.9 & $-\infty$ & 2.39 & -- & & \\
\hline 29. & --- & 2.13 & - & & \\
\hline
\end{tabular}

The values shown for $11-29 \mathrm{GeV}$ protong were computed using the data from Reference 25. The fission cross-sections for the $14 \mathrm{~N}$-1aduced reactions were taken from Refereace 64. 


\section{FIGURE CAPTIONS}

(1) A typical Bevalac targetry arrangement.

(2) The schematic diagram of a conventional gamma-ray spectroscopy aystem.

(3A-3B) The flowchart dlagram for the sequence of computer operations used In the analysis of the gamma-ray spectra.

(4-19) The Independent yleld distributions from the reaction of 3.0 GeV ${ }^{12} \mathrm{C}$ wth ${ }^{238} \mathrm{U}$. The plotted points are the experimental values and the solid lines are the fitted Gaussian charge distributions.

(20-27) The mass y1eld distributions for the elght reactions studied. The open circles are the total (1sobaric) y1elds, while the triangles are the total neutron excessive ylelds and the squares are the total neutron deficlent ylelds. The solid lines are the fitted 1sobaric yleld curves.

(28)

A comparison of the mass yield curves for ${ }^{12} \mathrm{C}$ induced reactions. The curves A, B, C, and D represent total projectile k1netic energles of $1.0,3.0,4.8$ and $12 \mathrm{GeV}$, respectively.

(29) A comparison of the mass yleld curves for 20 Ne induced reactiong. The curves A, B, C, and D represent total projectile kinetic energies of $5.0,8.0,20$, and $42 \mathrm{GeV}$, respectively. 
$5.0 \mathrm{GeV} 2{ }^{20}$ induced reactions, labeled as $A$ and $B$, respectively.

(31) A comparison of the mass yleld curves for the $28 \mathrm{GeV}$ proton and $20 \mathrm{GeV} 20 \mathrm{Ne}$ induced reactions, labeled as $A$ and $B$, respectively. The data for the proton induced reaction were taken from Reference 60 .

(32-38) The mass yield distributions predicted by the various theoretical models are compared with the experimental results. The solid lines are the experimental curves, while the curves labeled as $A, B$, and C correspond to the intranuclear cascade, nuclear firestreak, and nuclear fireball model calculations.

(39) A comparison of the experimeatal and theoretical mass yieid curves for the reaction of $42 \mathrm{GeV}{ }^{20} \mathrm{Ne}$ wh ${ }^{238} \mathrm{v}$. The solid curve is the experimental data and the curve labeled $A$ is the nuclear firestreak model prediction.

(40) A comparison of the independent ylelds for fragments with mass numbers 30 to 50 , produced in the reaction of $3.0 \mathrm{GeV}$ ${ }^{12} \mathrm{C}$ with ${ }^{238} \mathrm{U}$, and the charge distributions predicted by the Intra-nuclear cascade model. The plotted points are the experimeatal data and the solid curve is the result of the model calculation.

(41) A comparison of the theoretical and experimental rarget fragment longitudinal velocities imparted during the reaction of $4.8 \mathrm{GeV}{ }^{12} \mathrm{C}$ wth ${ }^{238} \mathrm{U}$. The plotted polnts are the 
66

experimental data for the neutron deficient fragments, which were taken from Reference 66 . The solid curves are the velocities for the fragments not arising from fission, as predicted by the Intranuclear cascade and nuclear firestreak model calculations. 

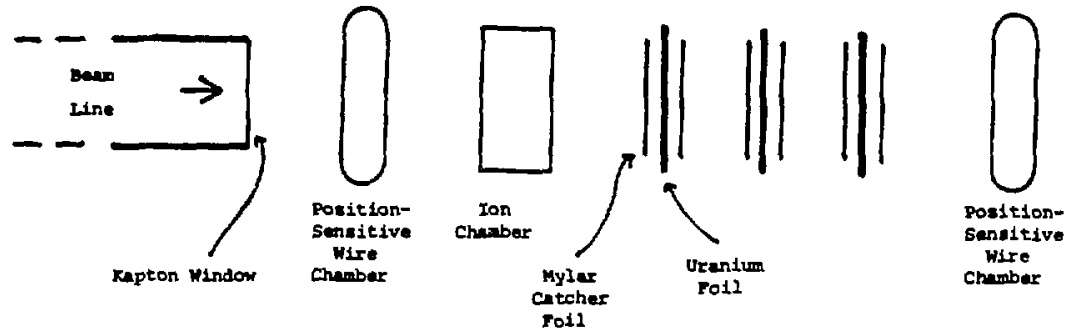

Figure 1. 


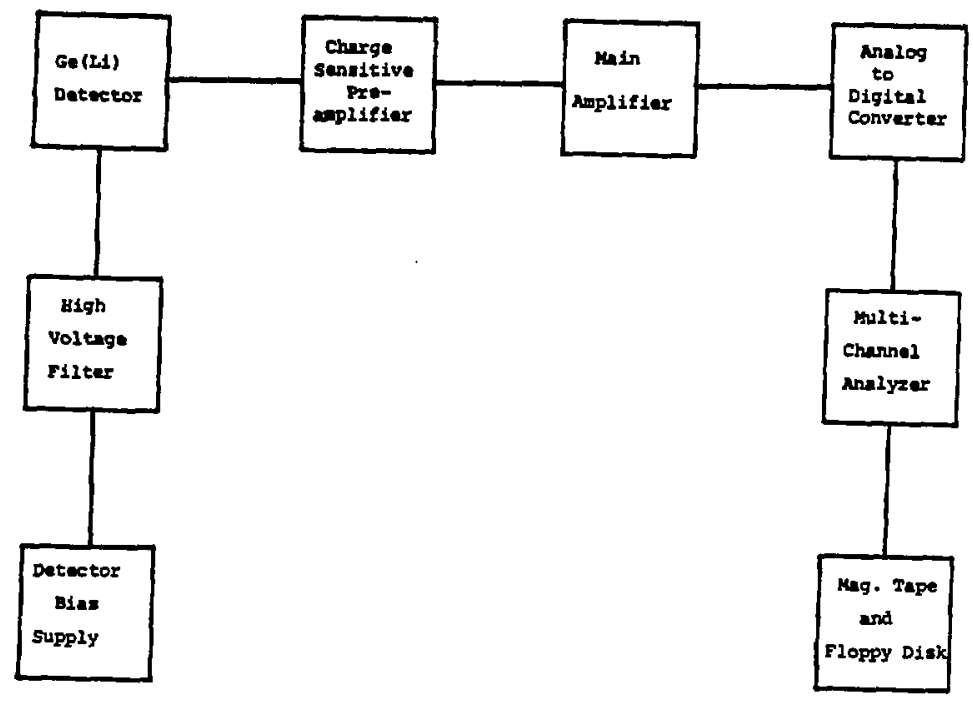

Figure 2. 


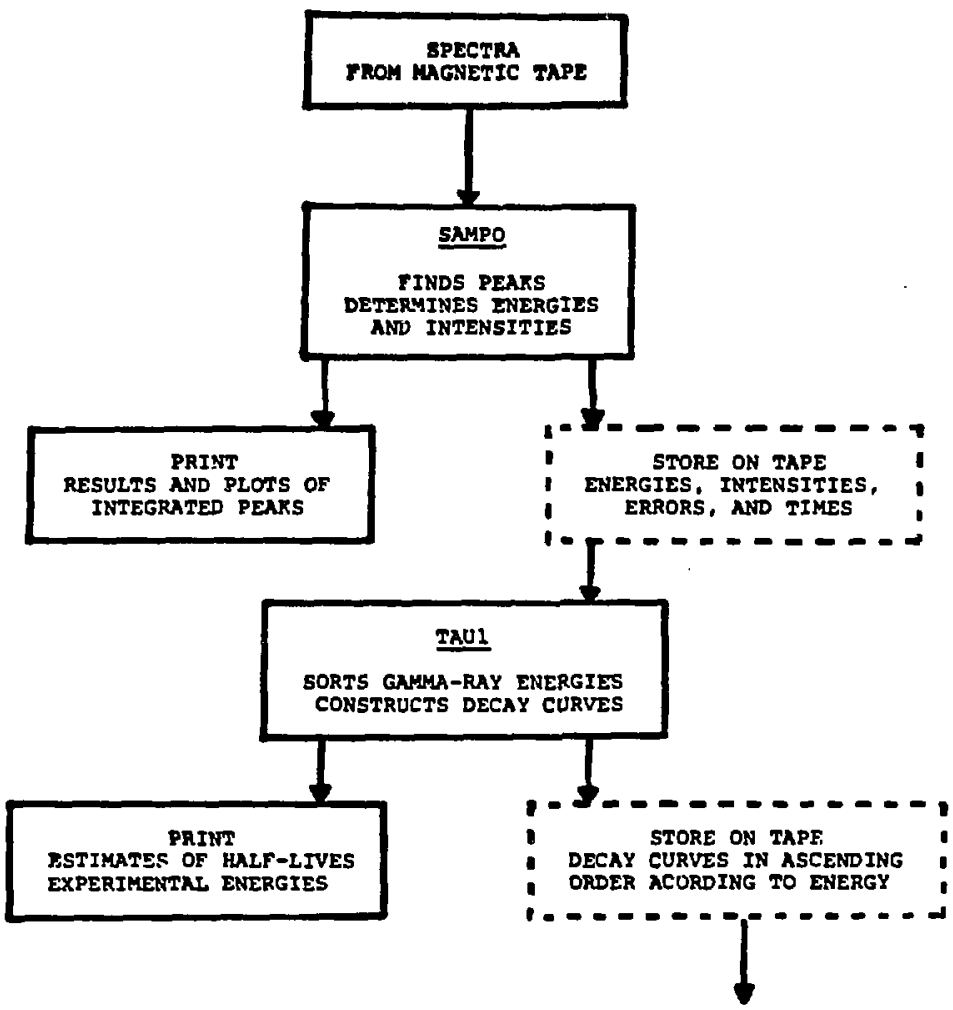

(A) AUTOMATIC MODE: PHOTOPEAK ANALYSIS, AND DECAY CURVE CONSTRUCTION FIGURE $3 A$. 


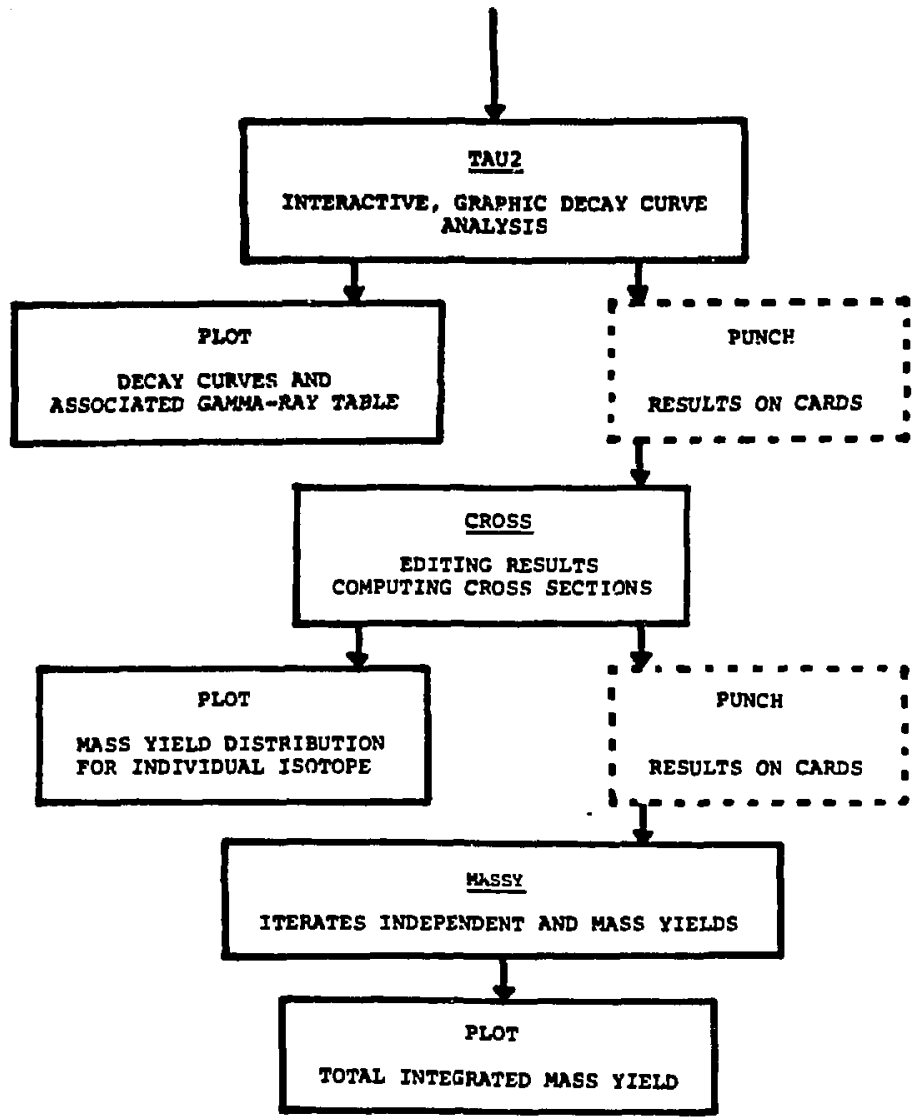

(B) INTERACTIVE MODE: DECAY CURVE ANALYSIS, AND A TOTAL

CROSS SECTIONAR YIELD CALCULATION

FIGURE $3 B$. 


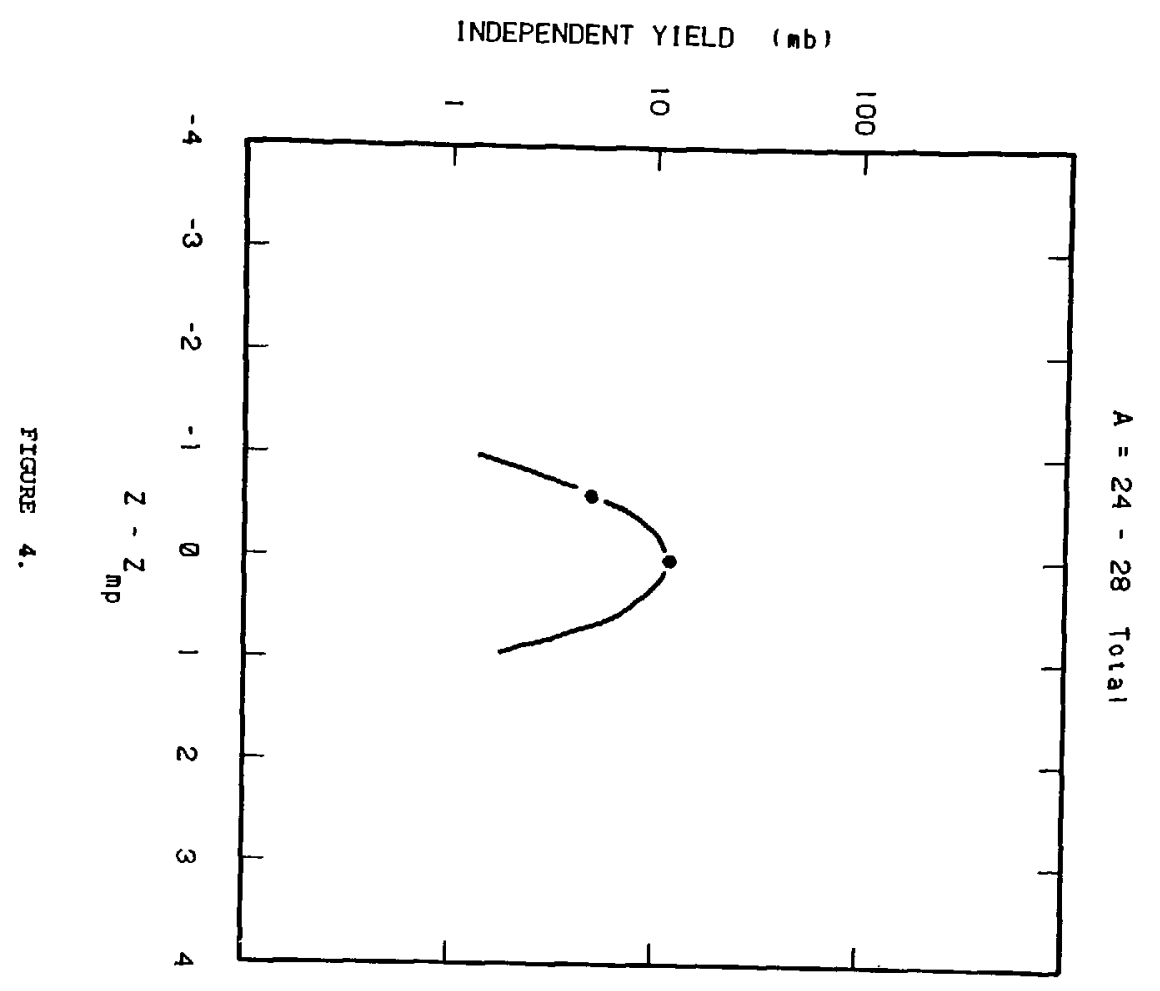




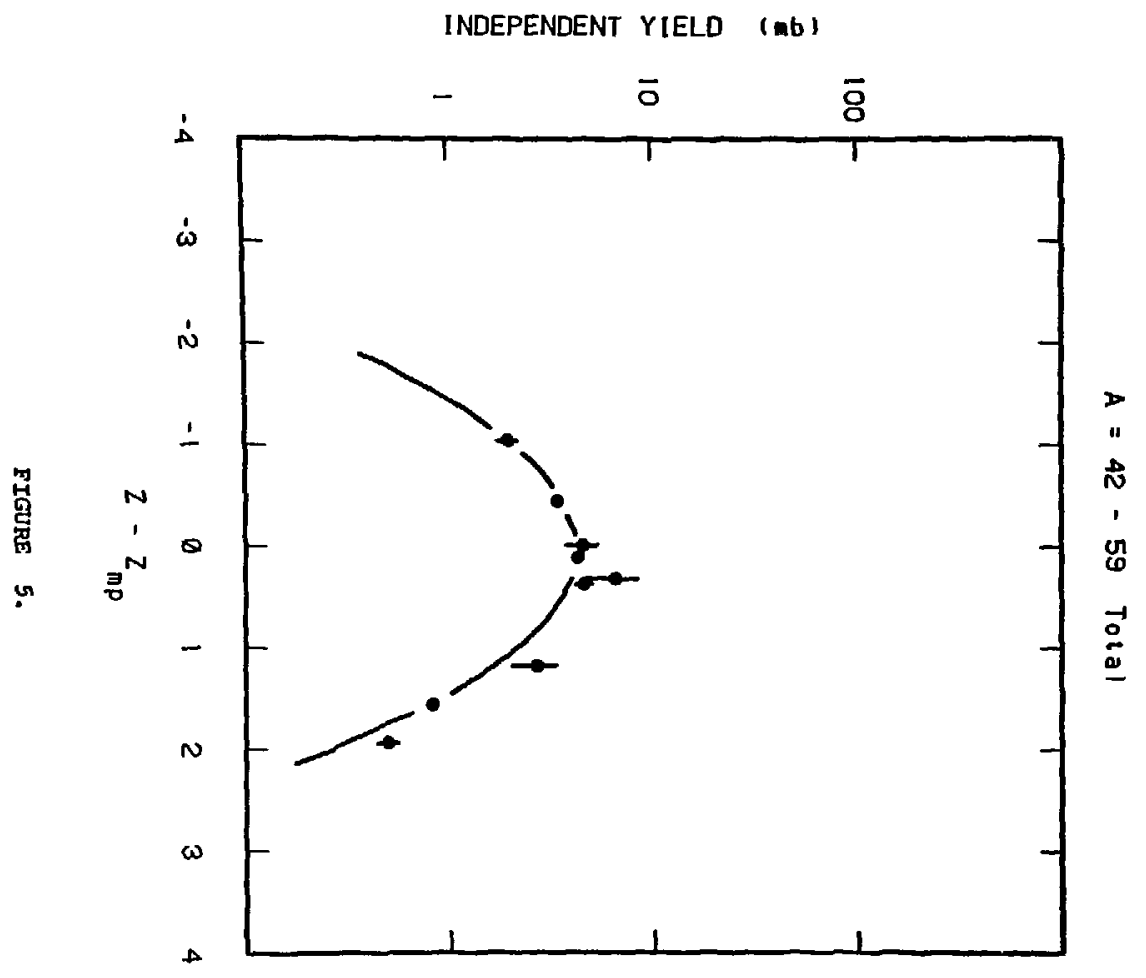




$$
2
$$




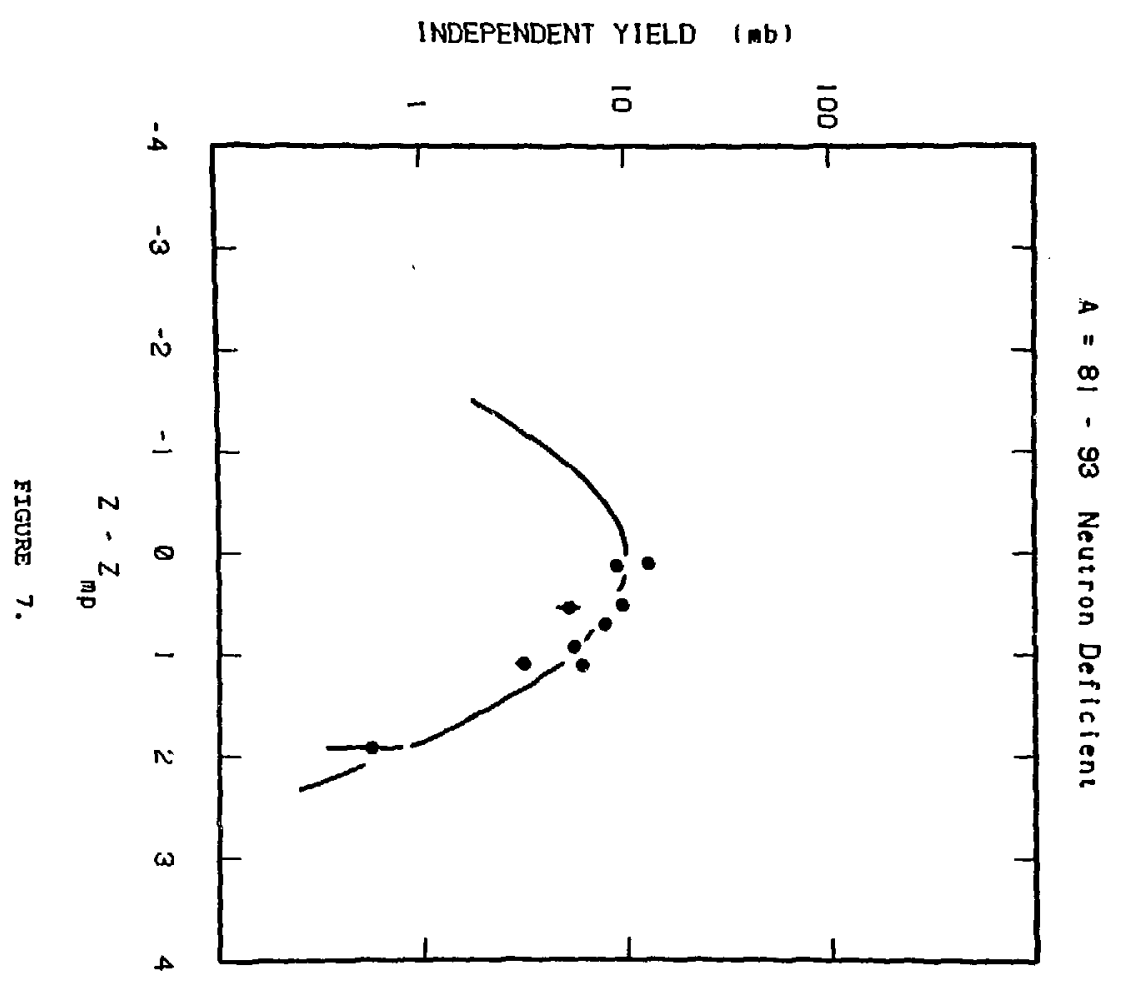




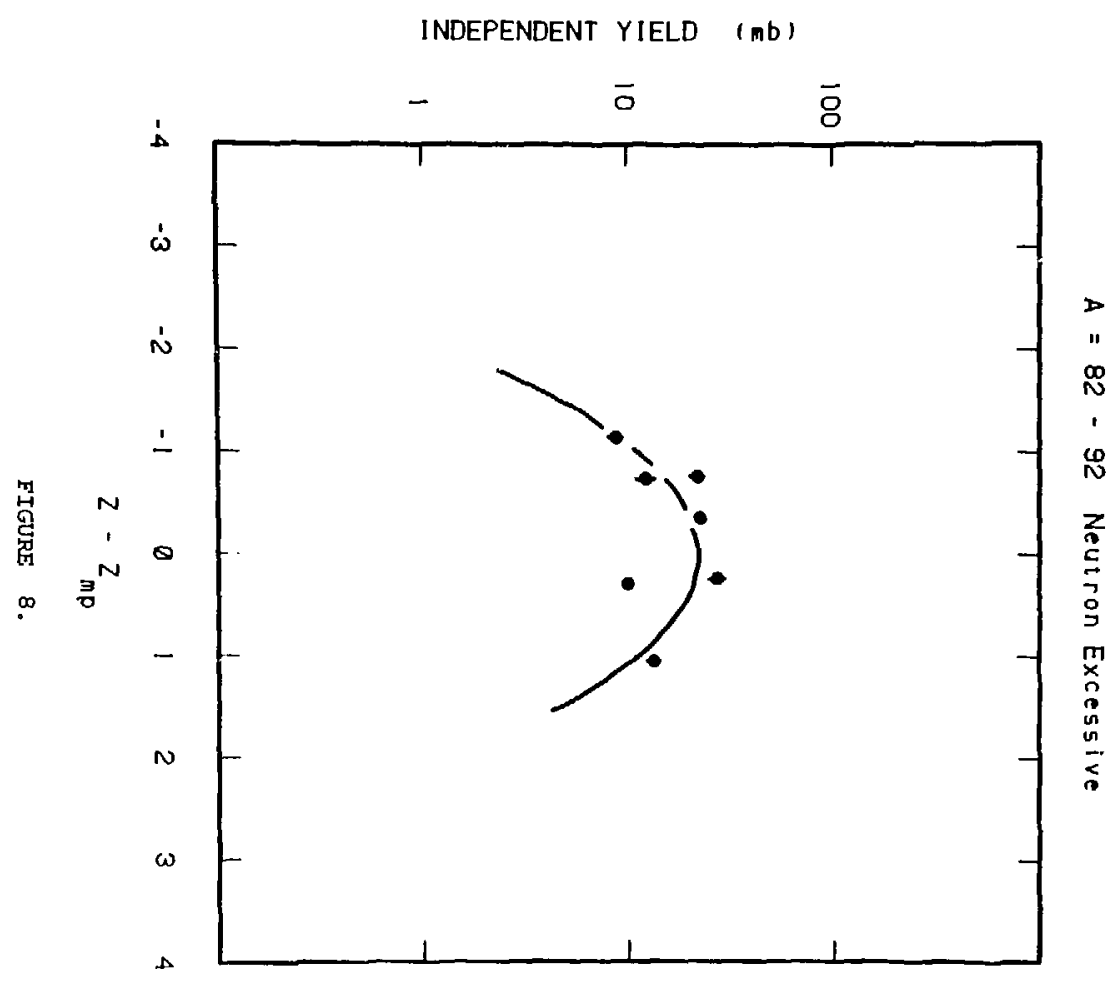




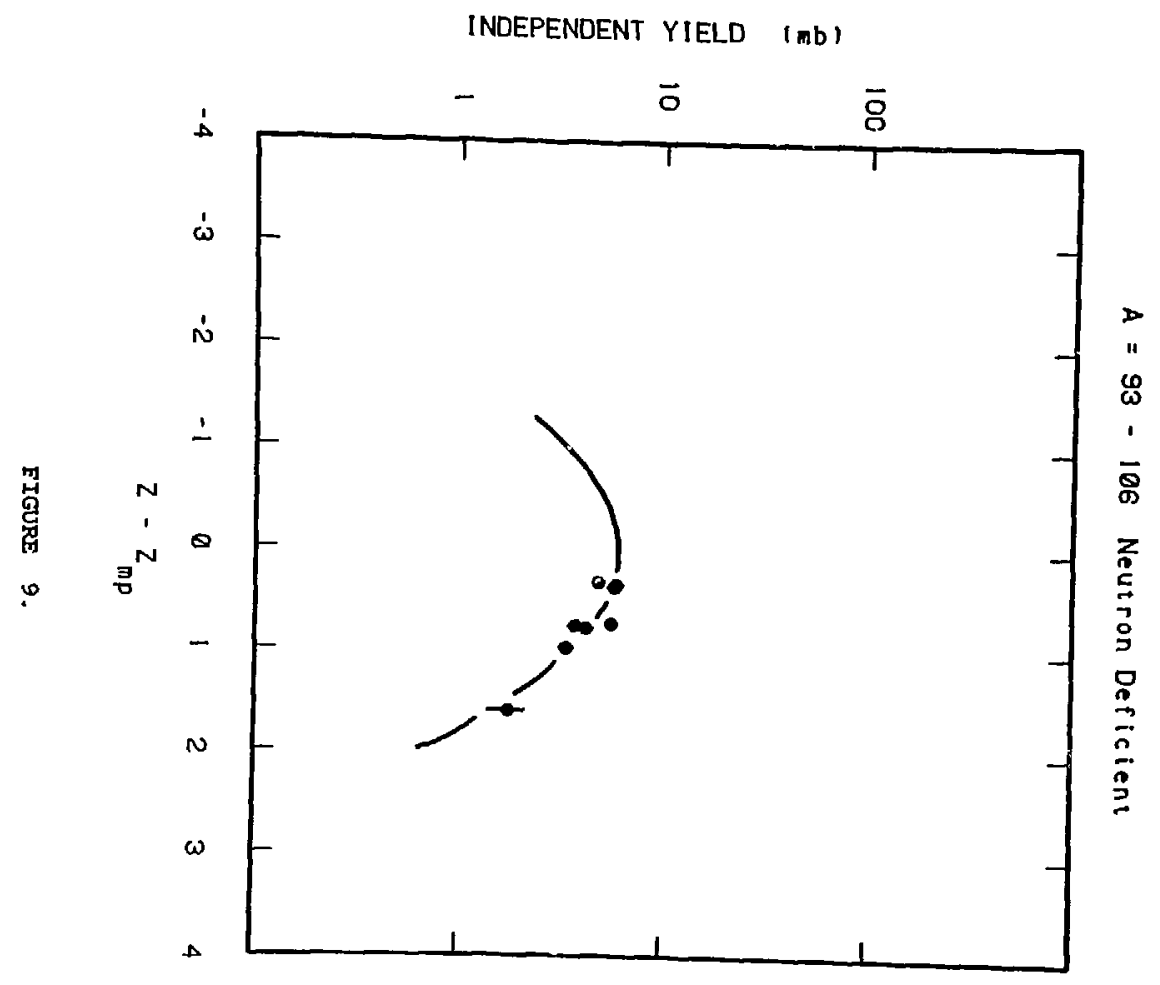




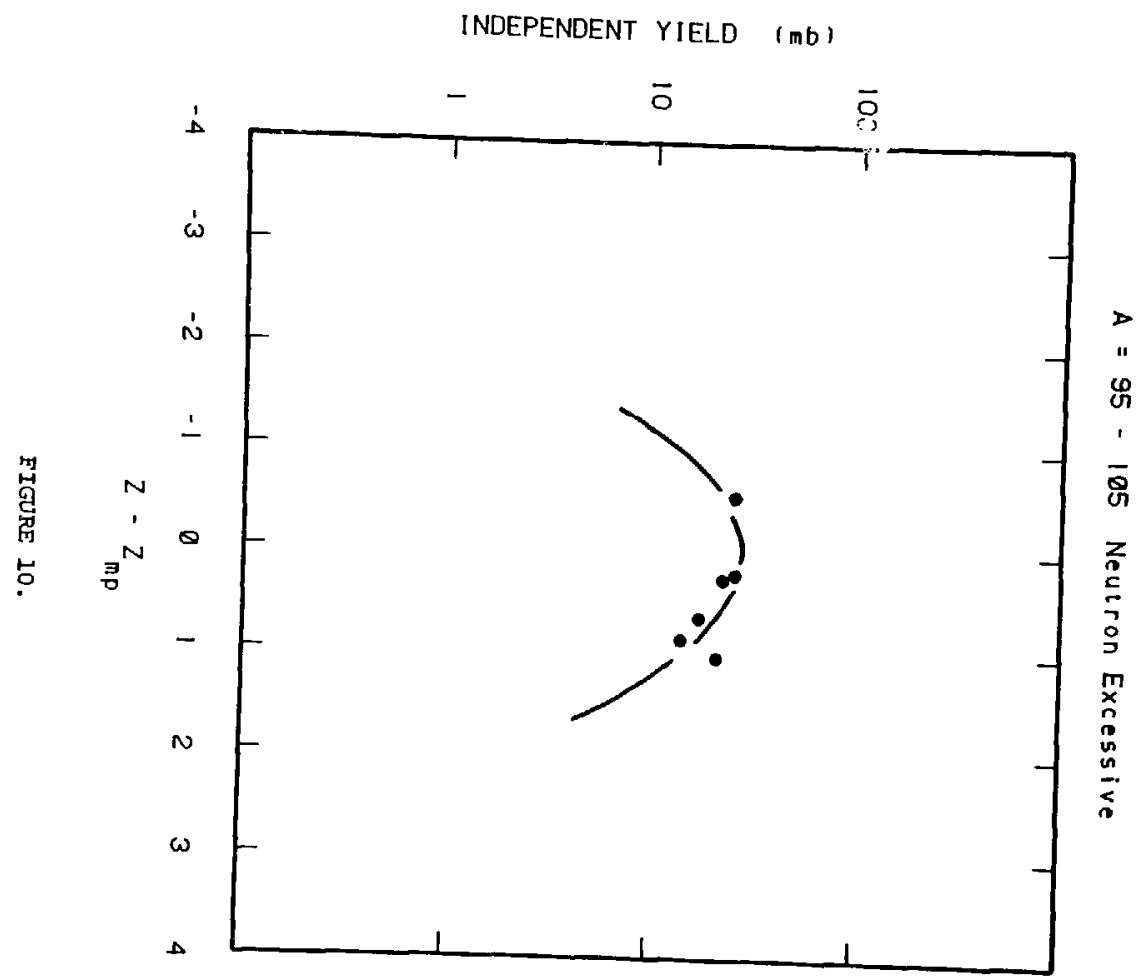




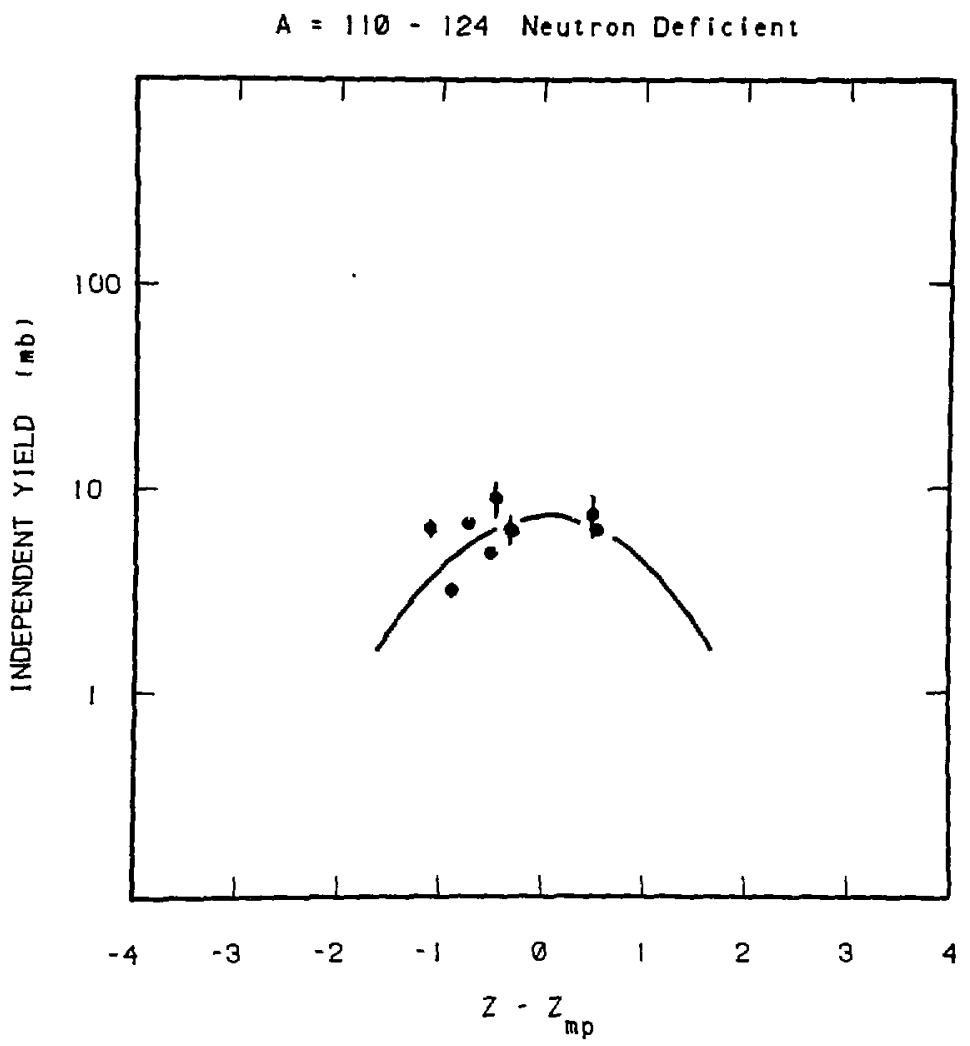

FIGURE 11. 


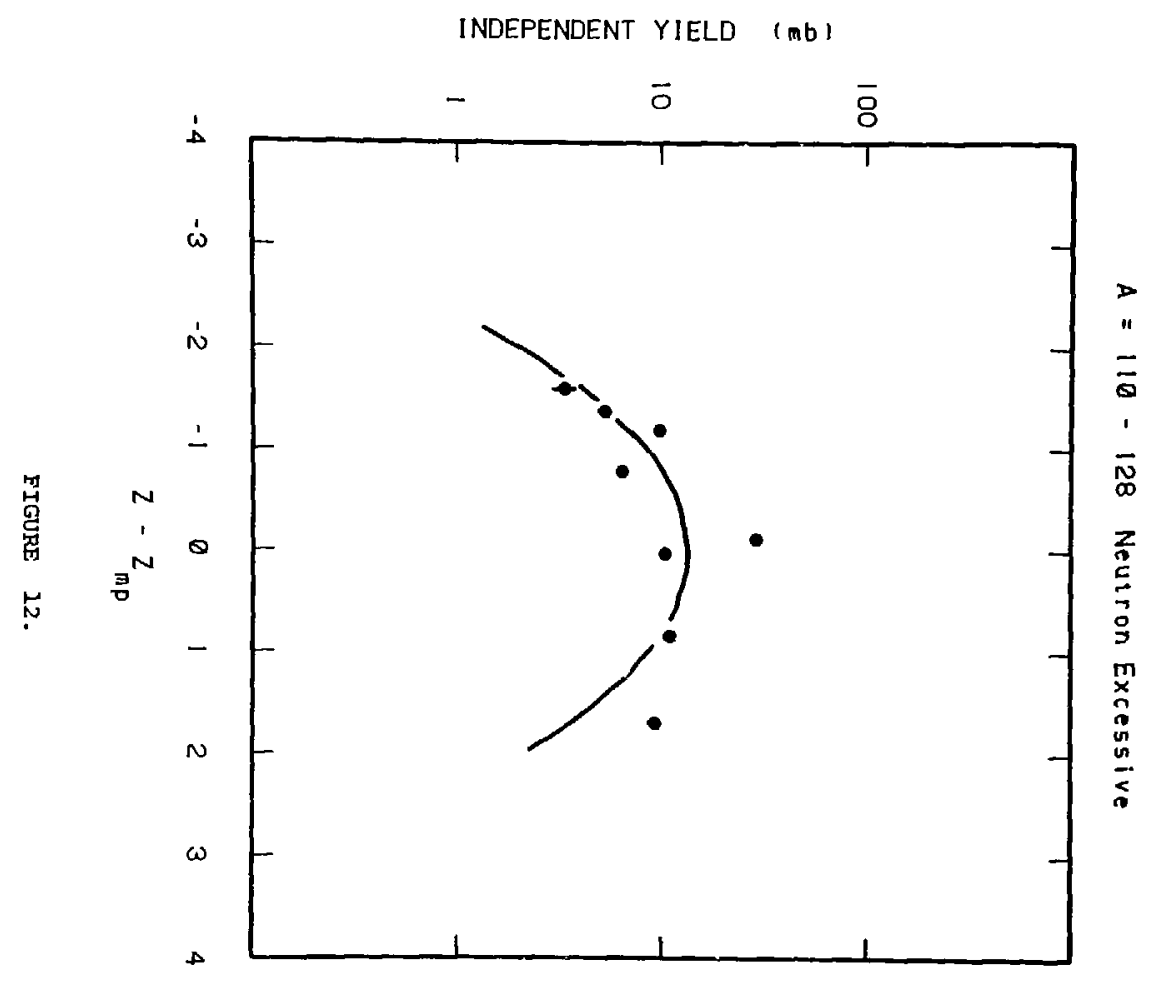




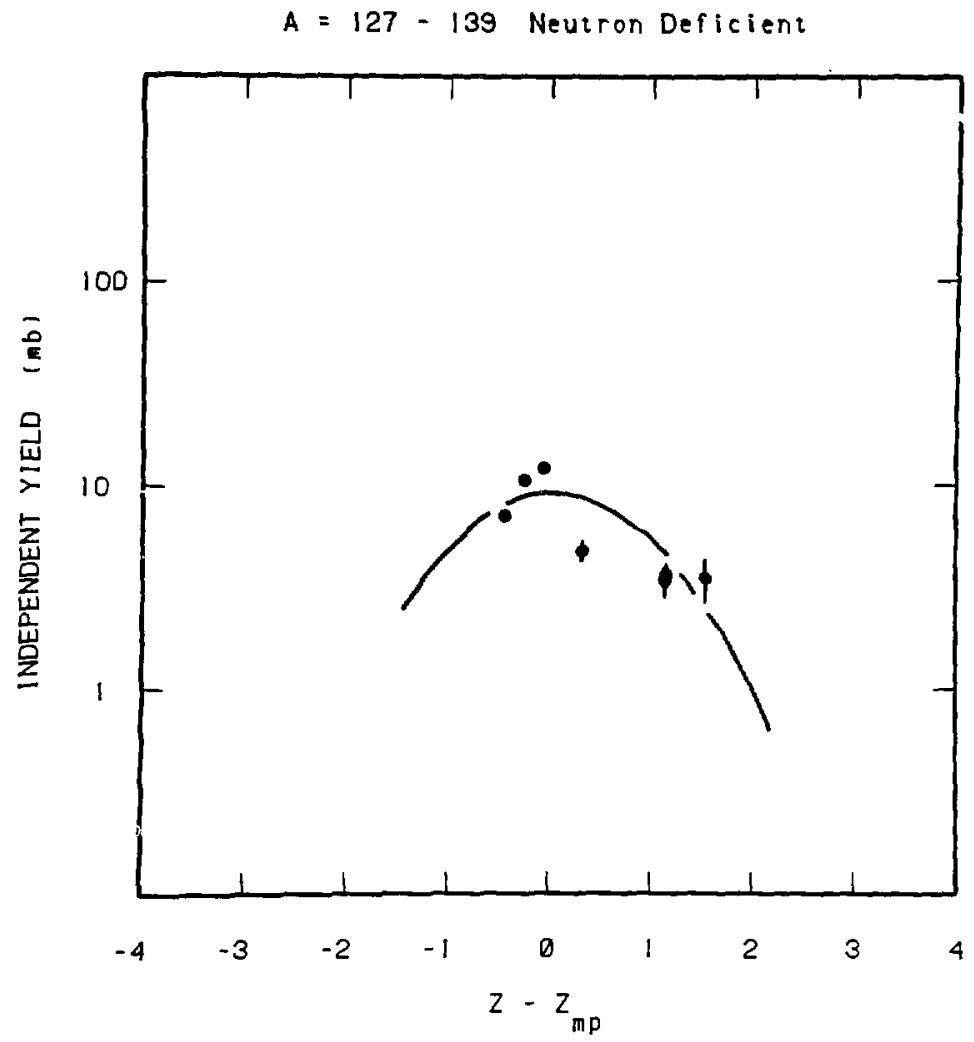

FIGURE 13. 


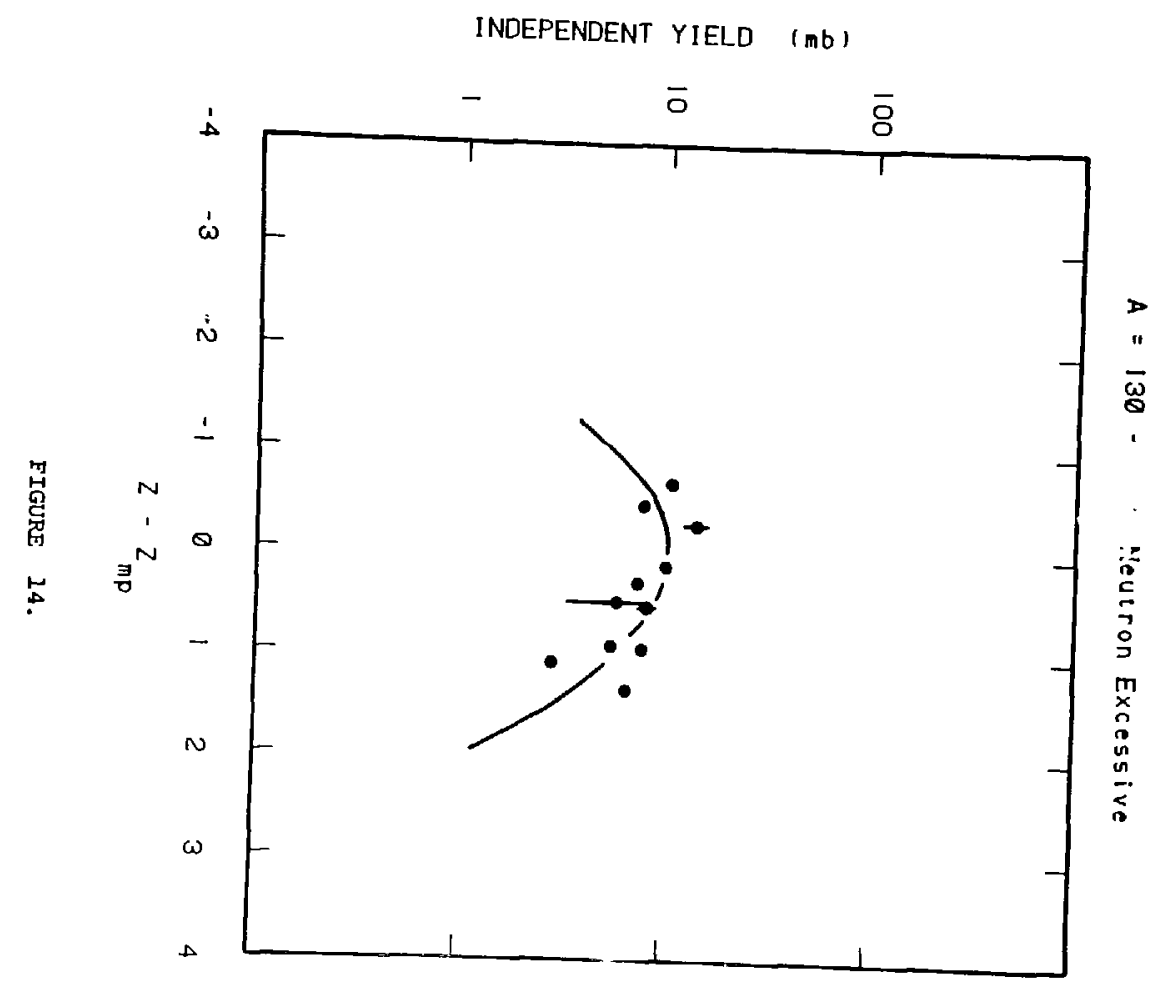




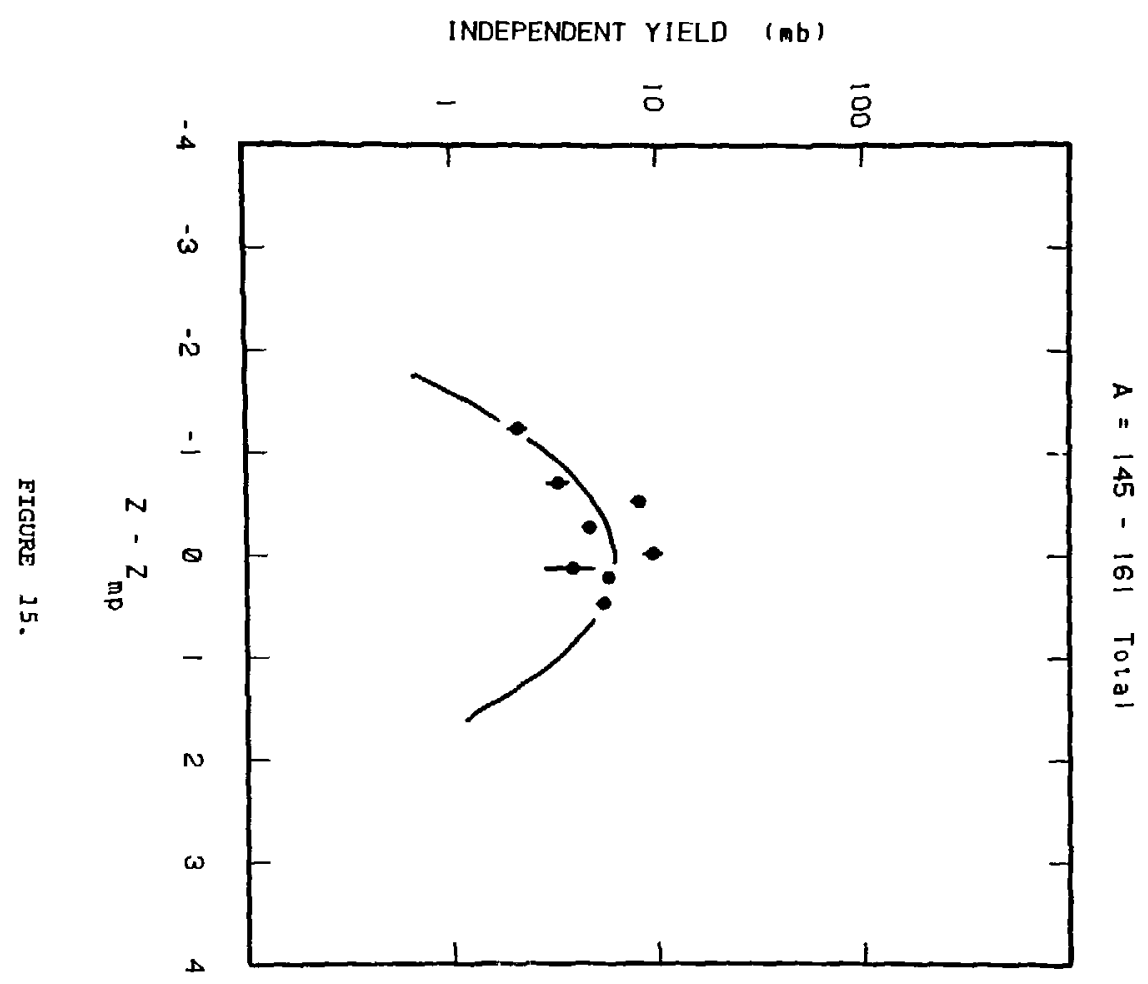




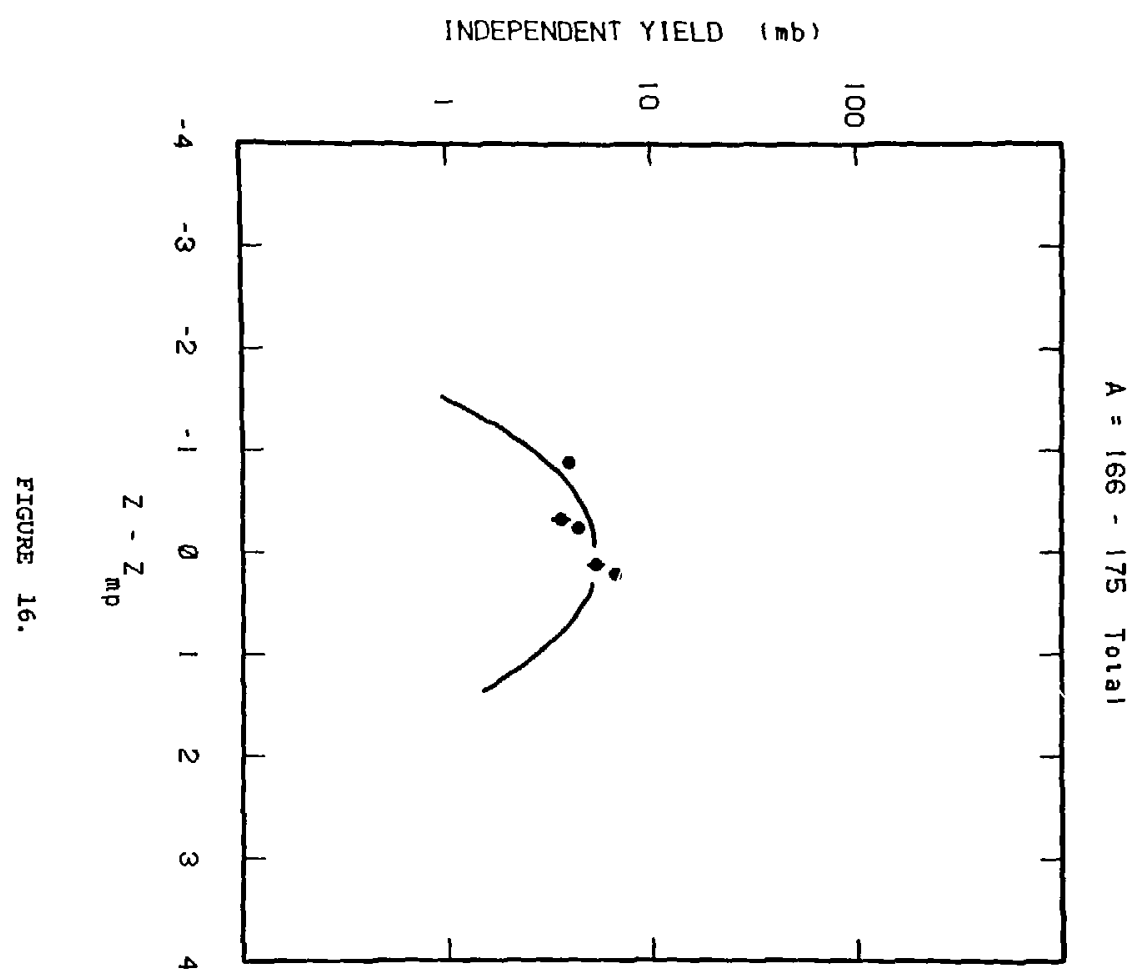




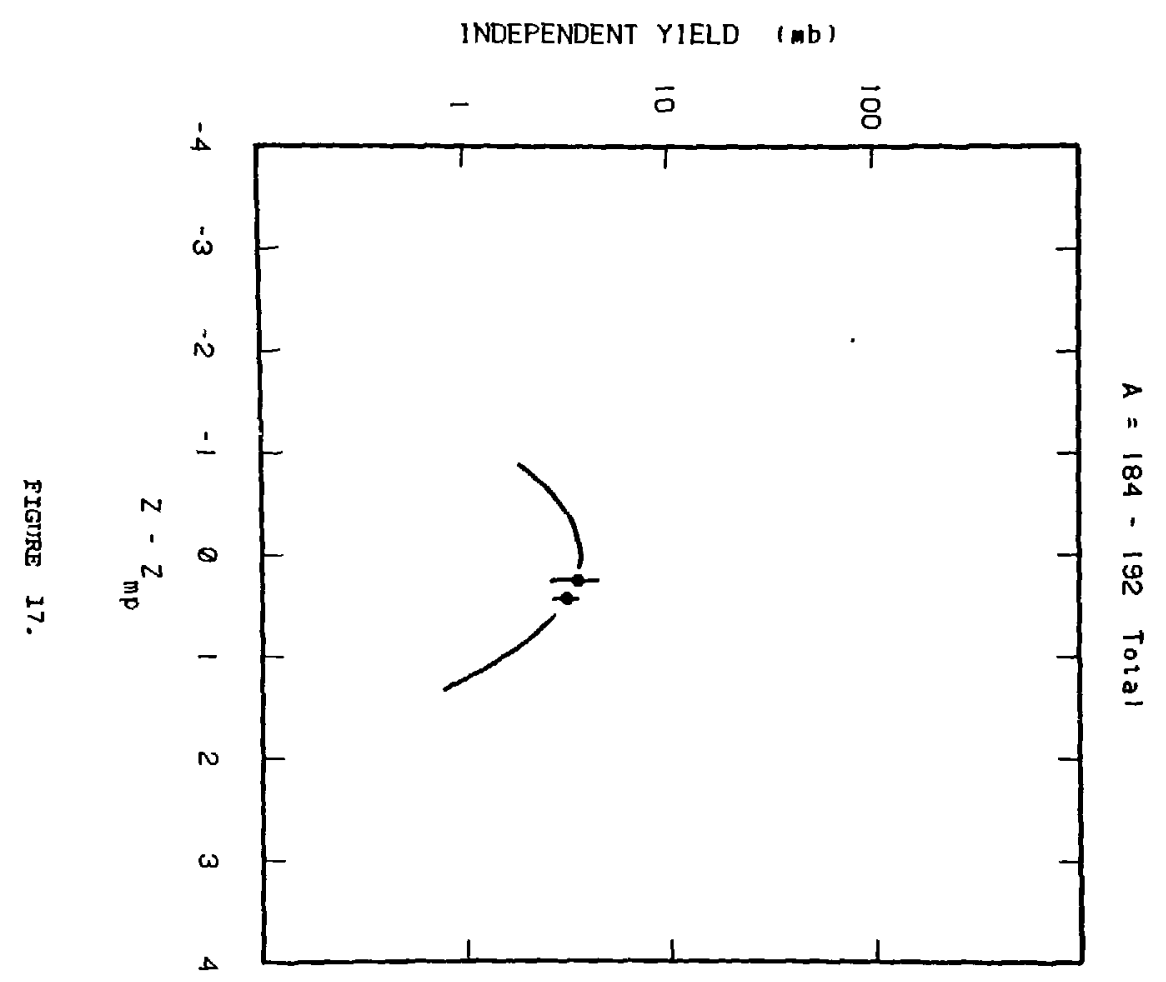




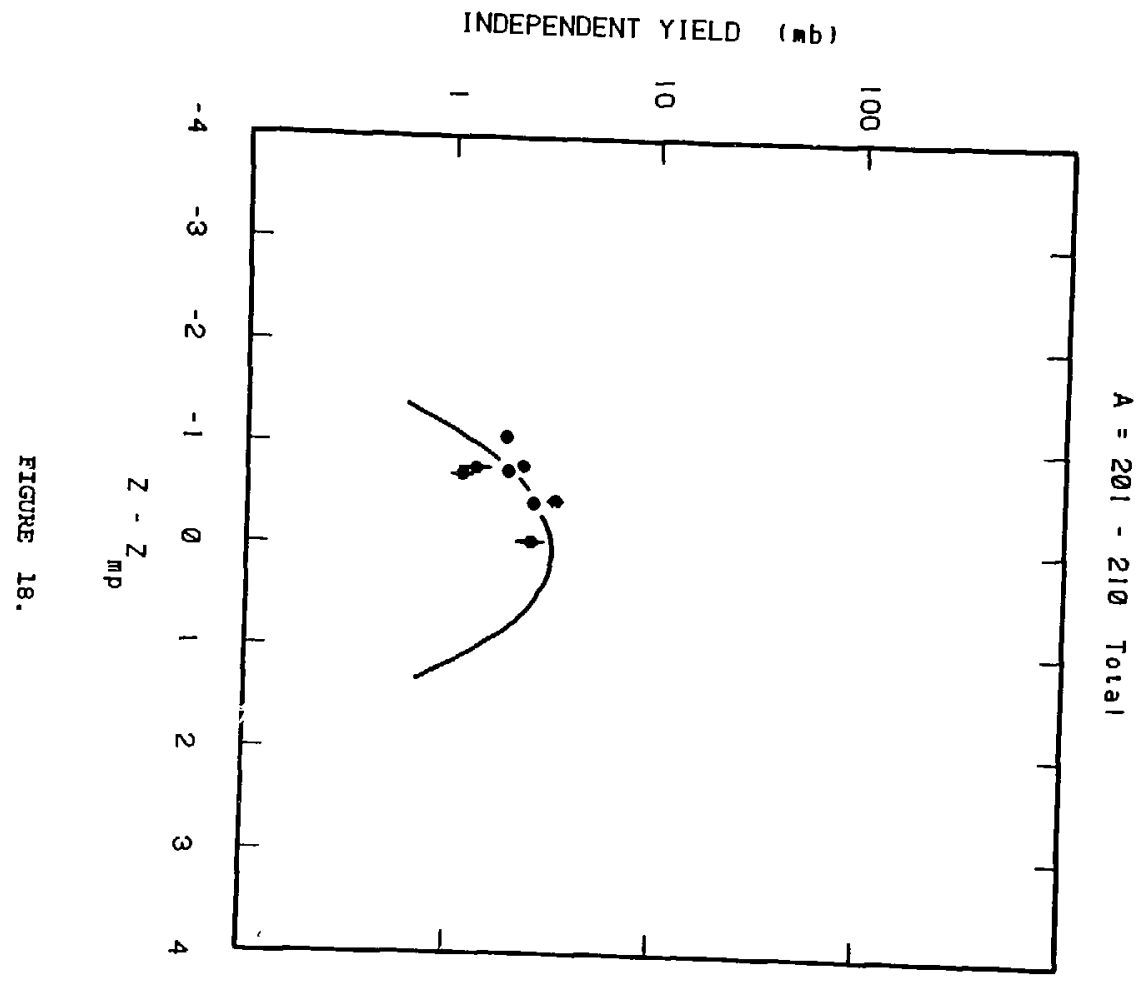




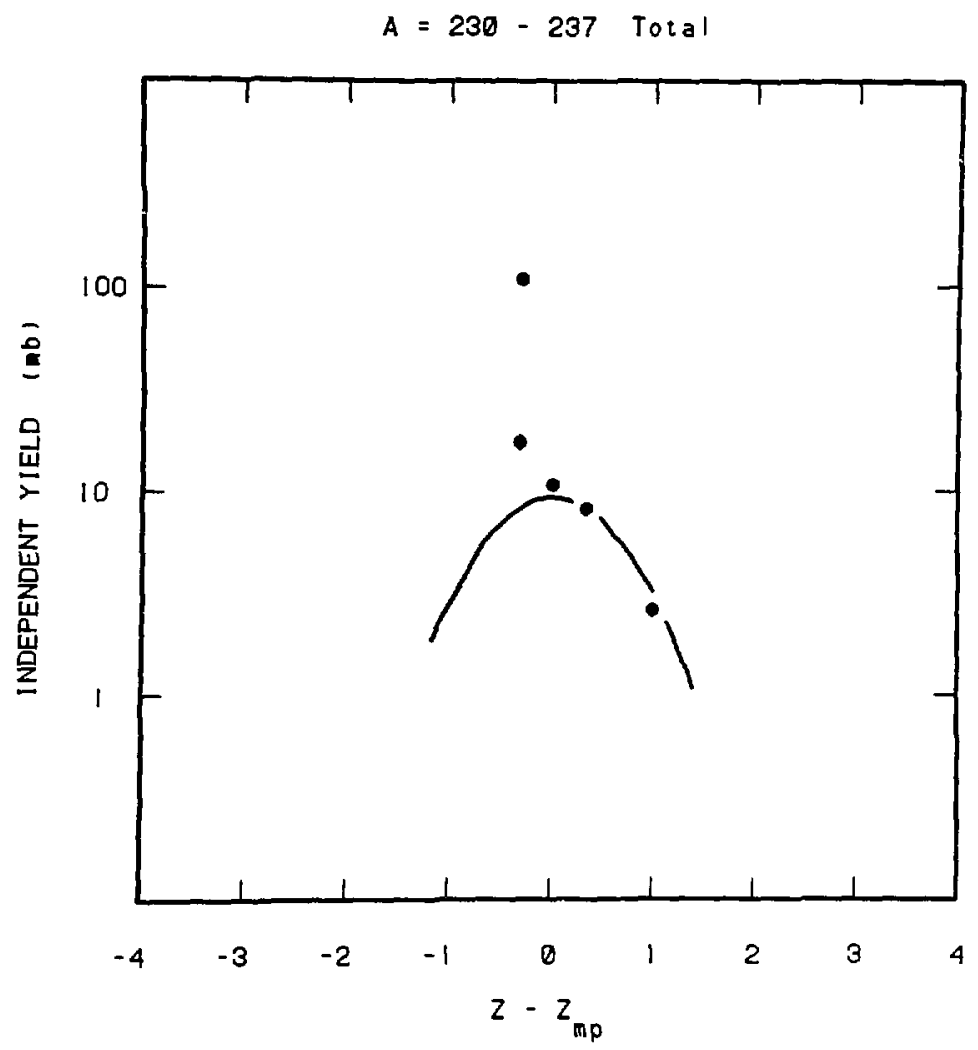

FTGURE 19. 


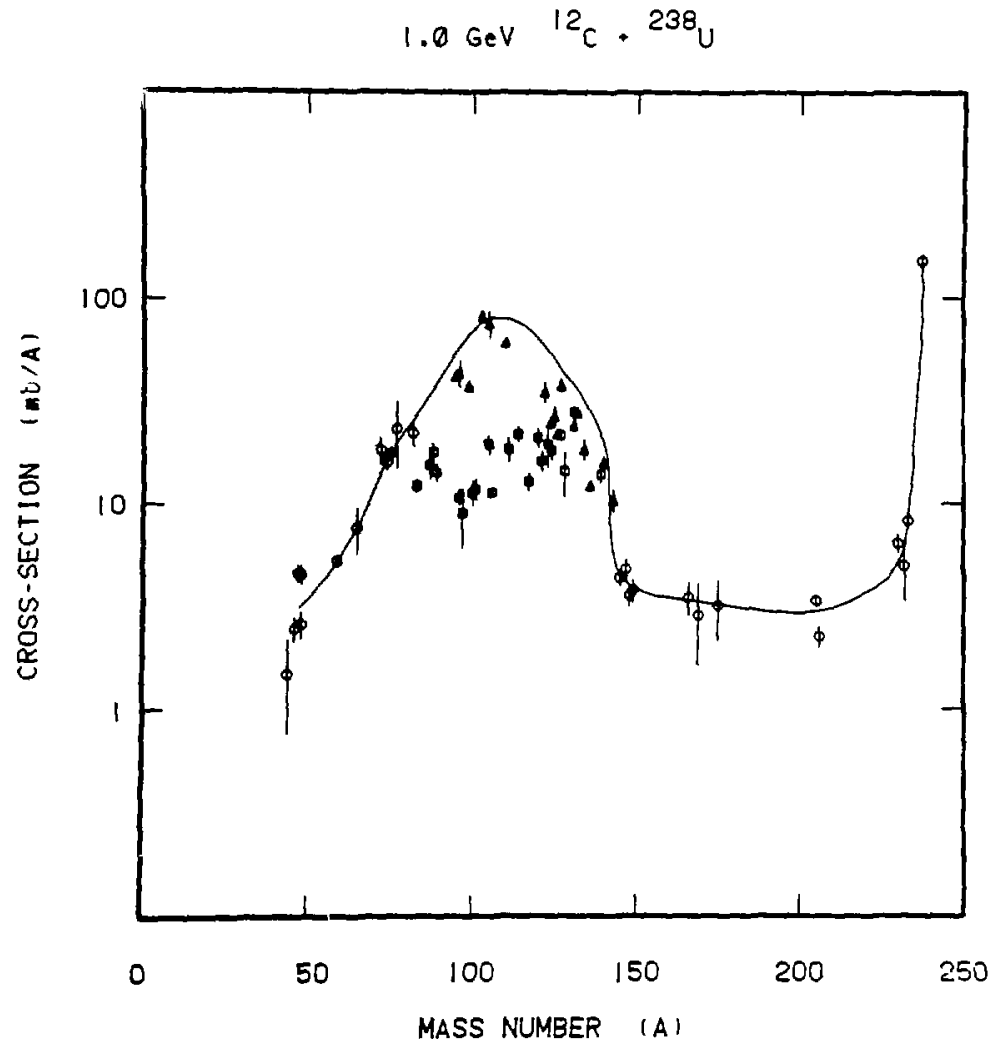

FIGURE 20. 


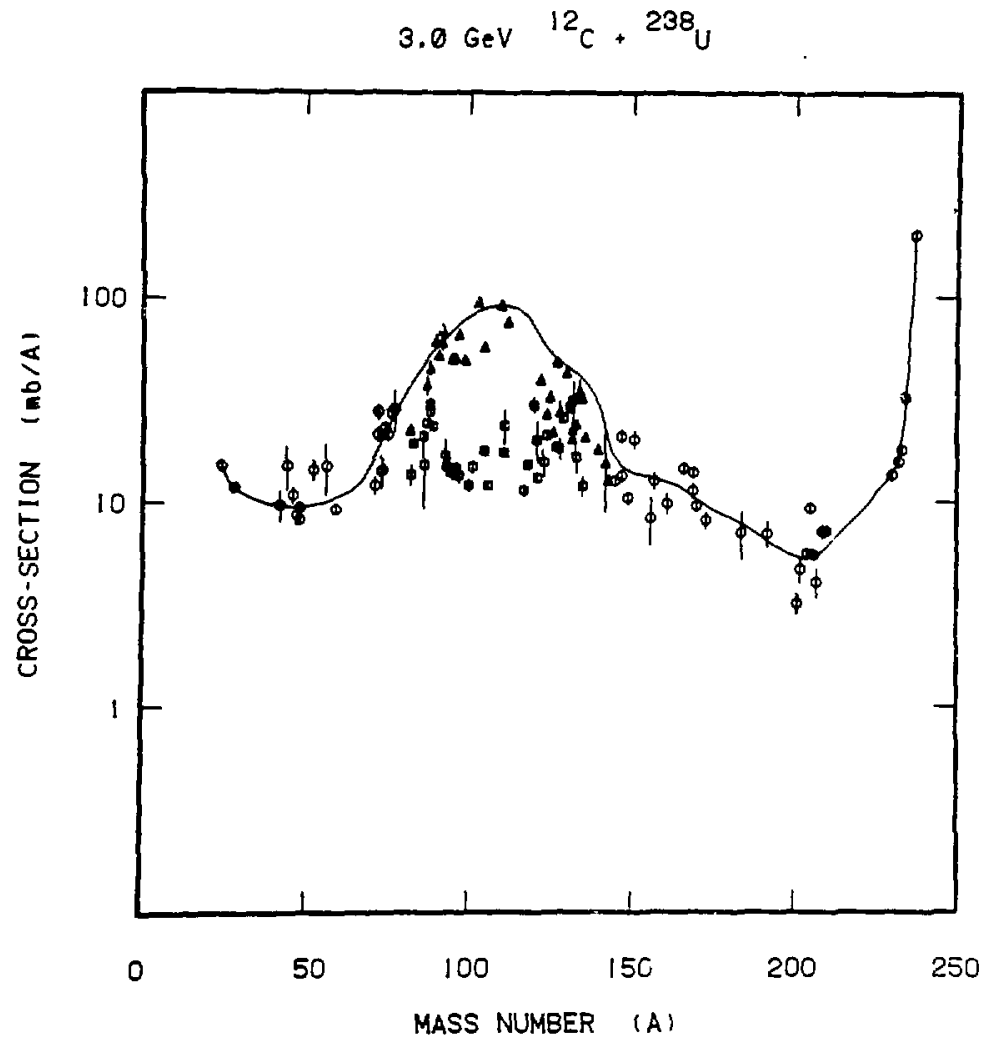

FIGURE 21 . 


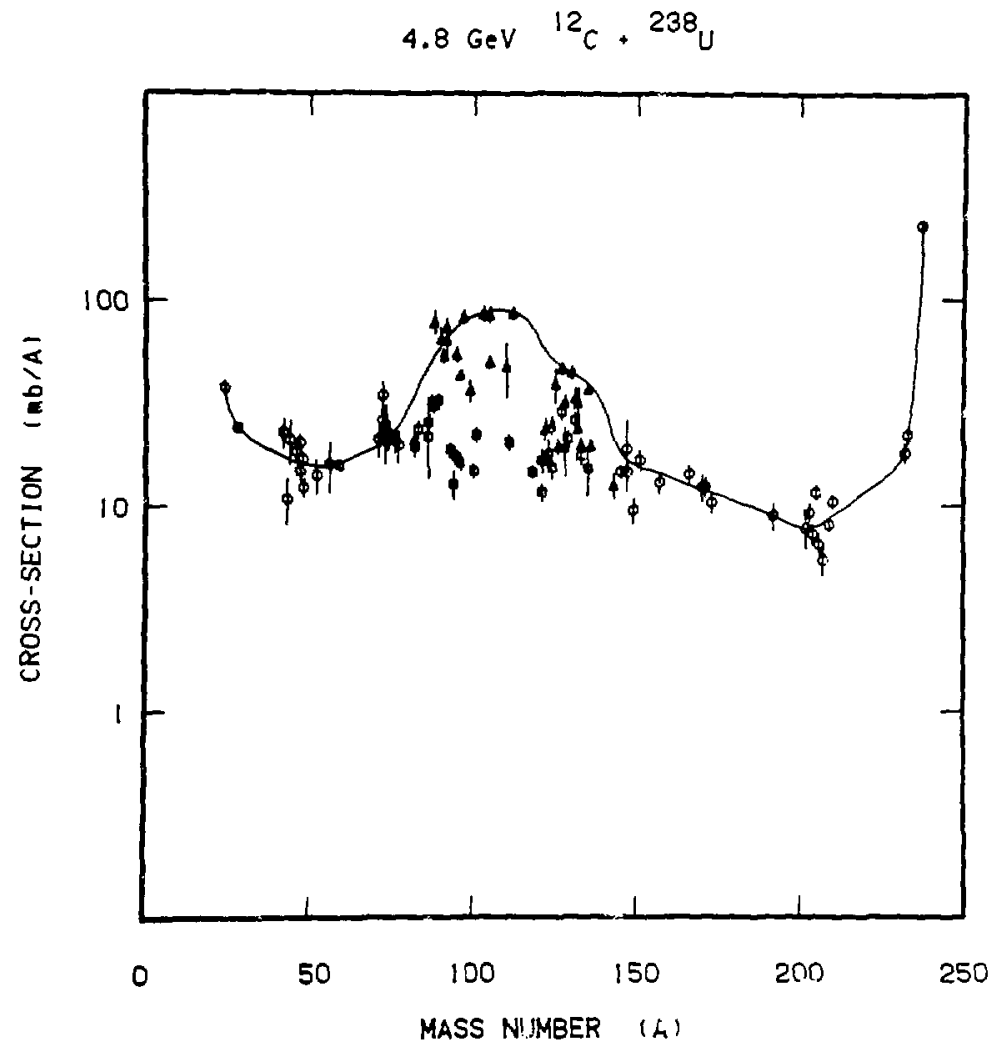

FIGURE 22. 


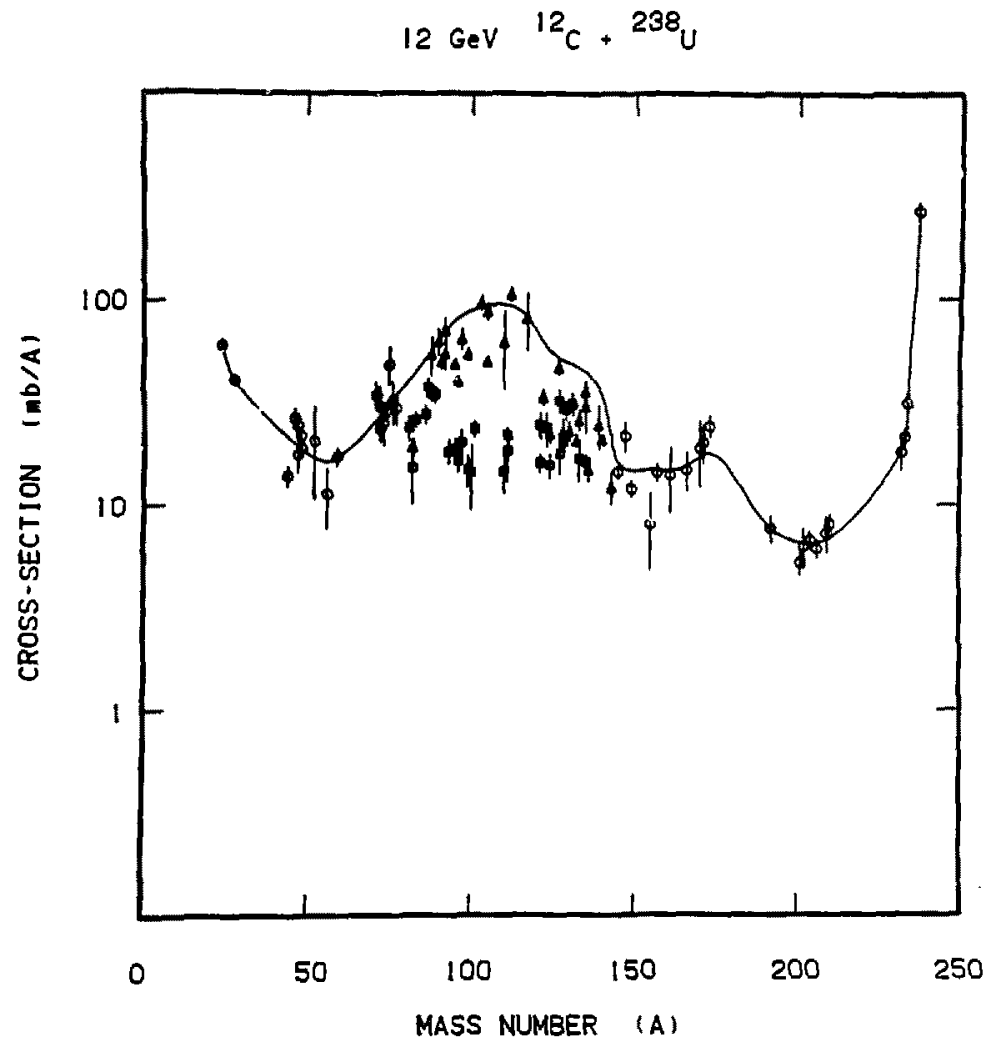

FIGURE 23. 


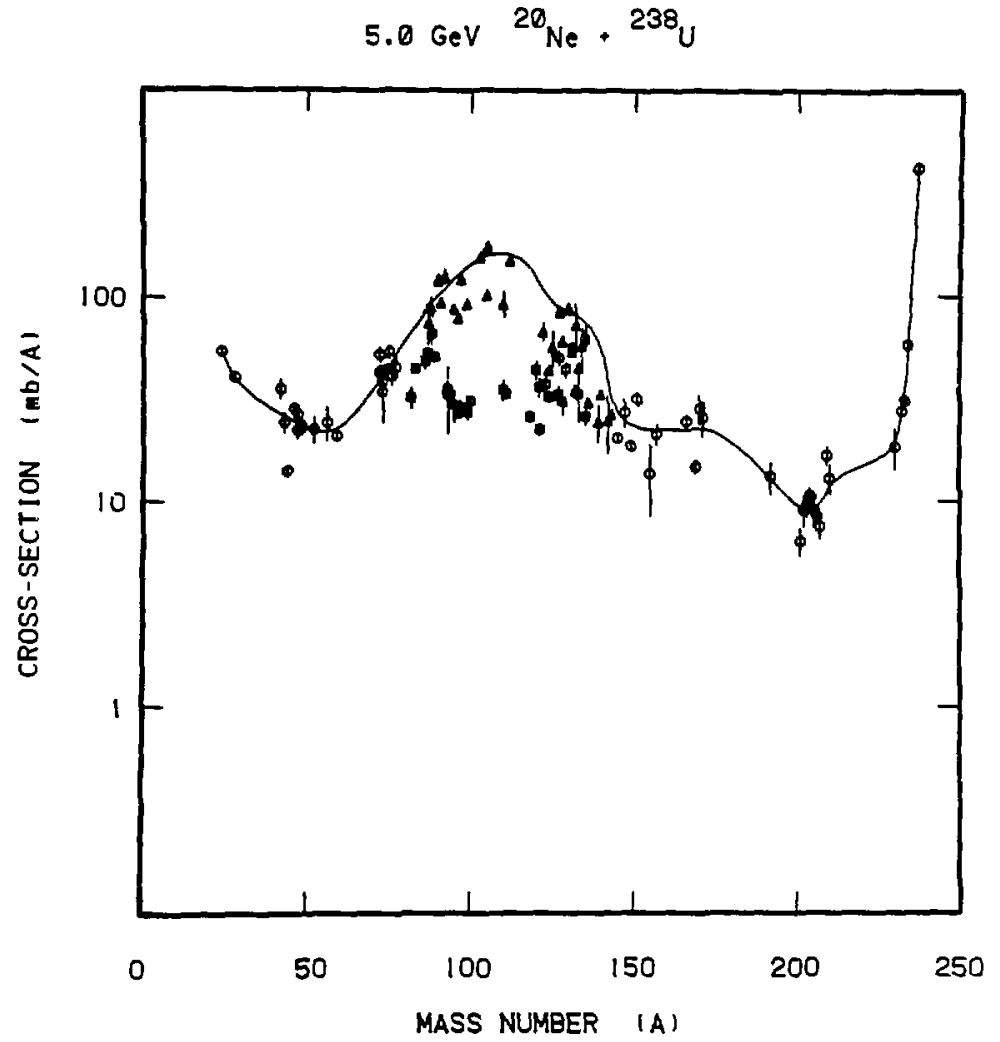

FIGURE 24. 


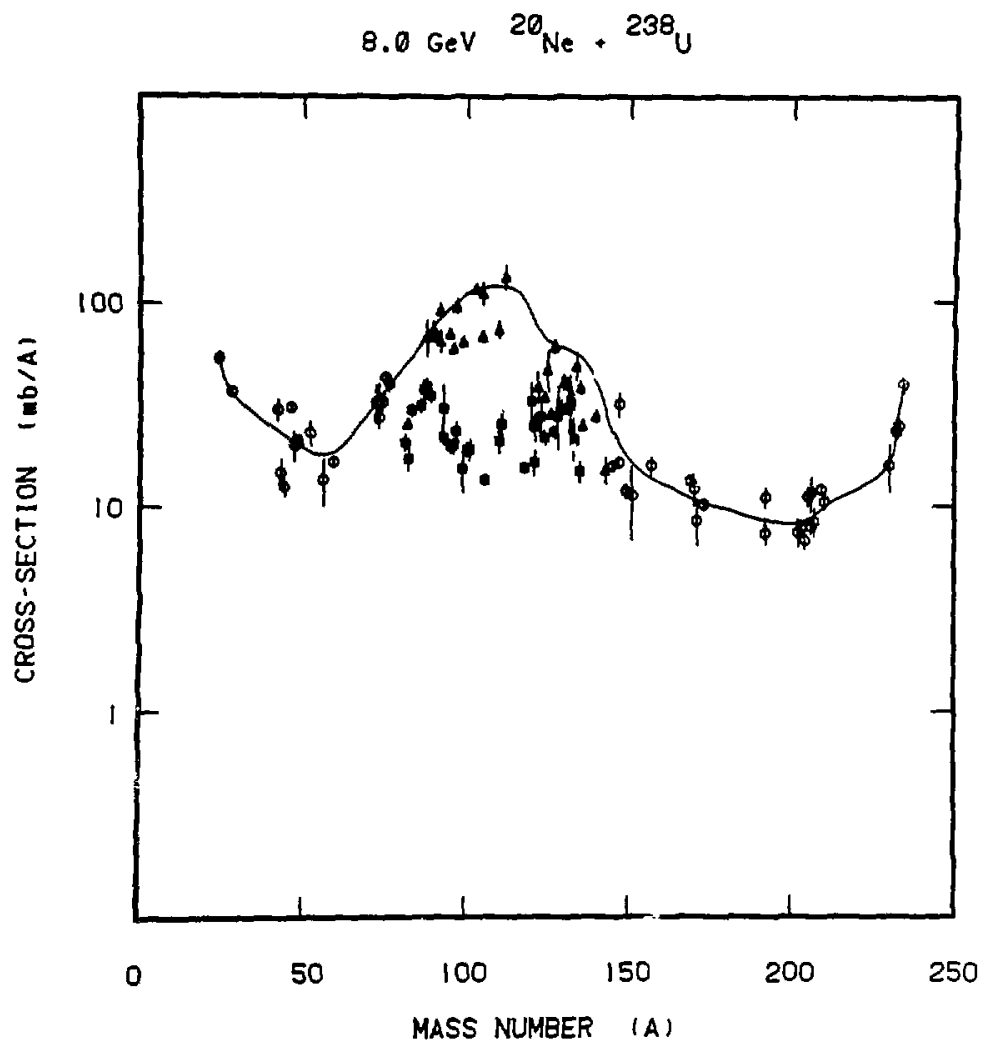

FIGURE 25. 


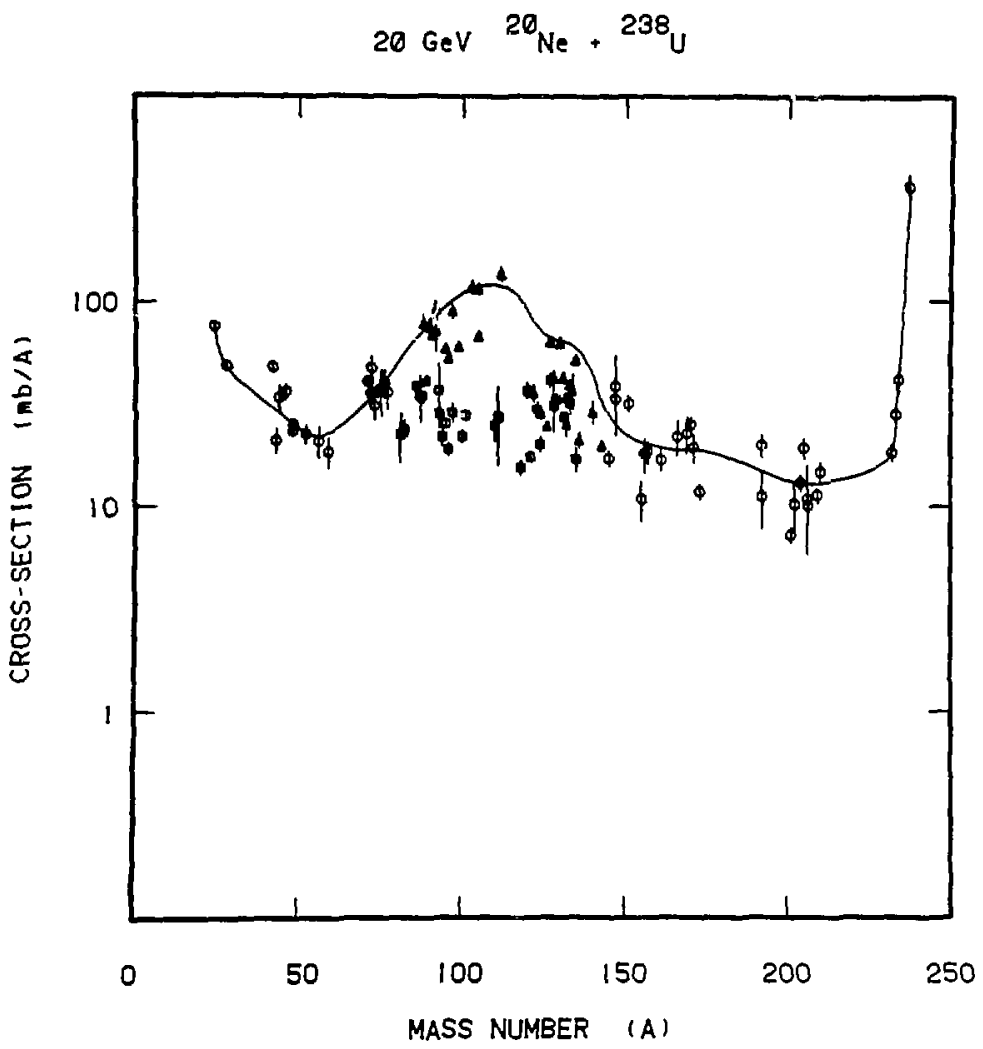

EIGURE 26. 
$42 \mathrm{GeV}{ }^{20} \mathrm{Ne} \cdot{ }^{23} 8_{\mathrm{U}}$

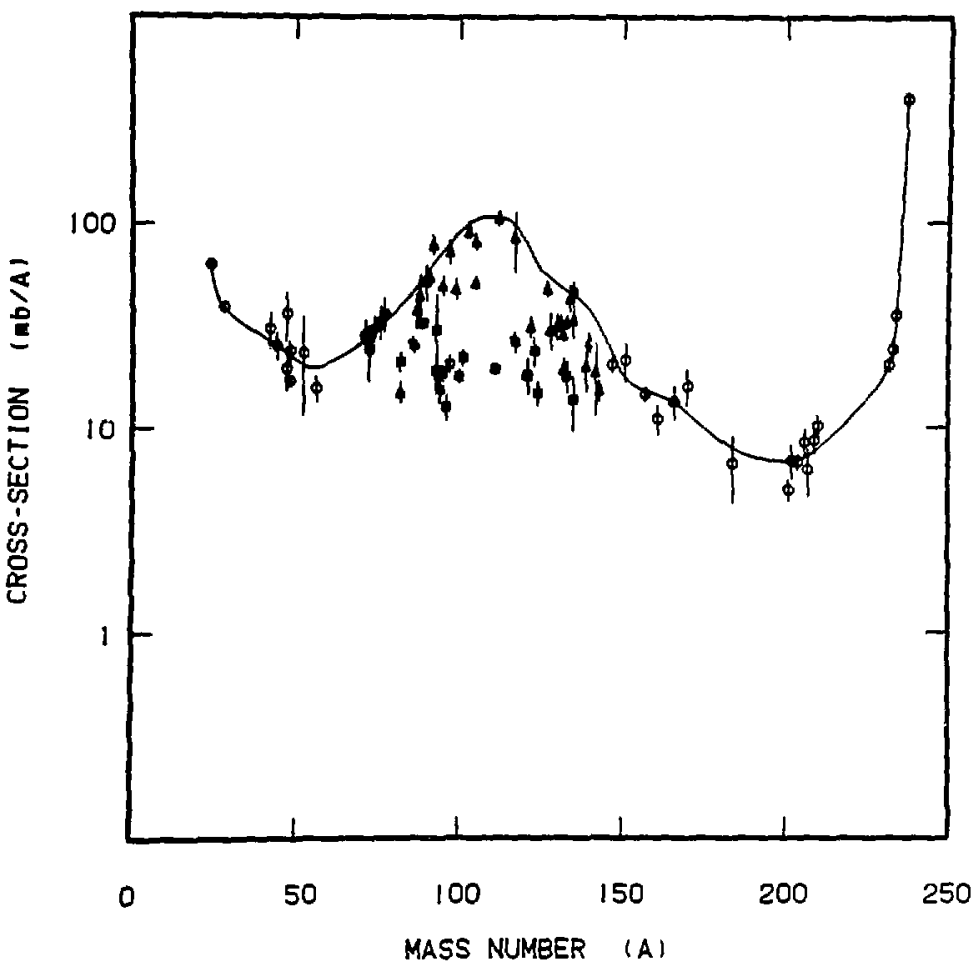

FIGURE 27. 


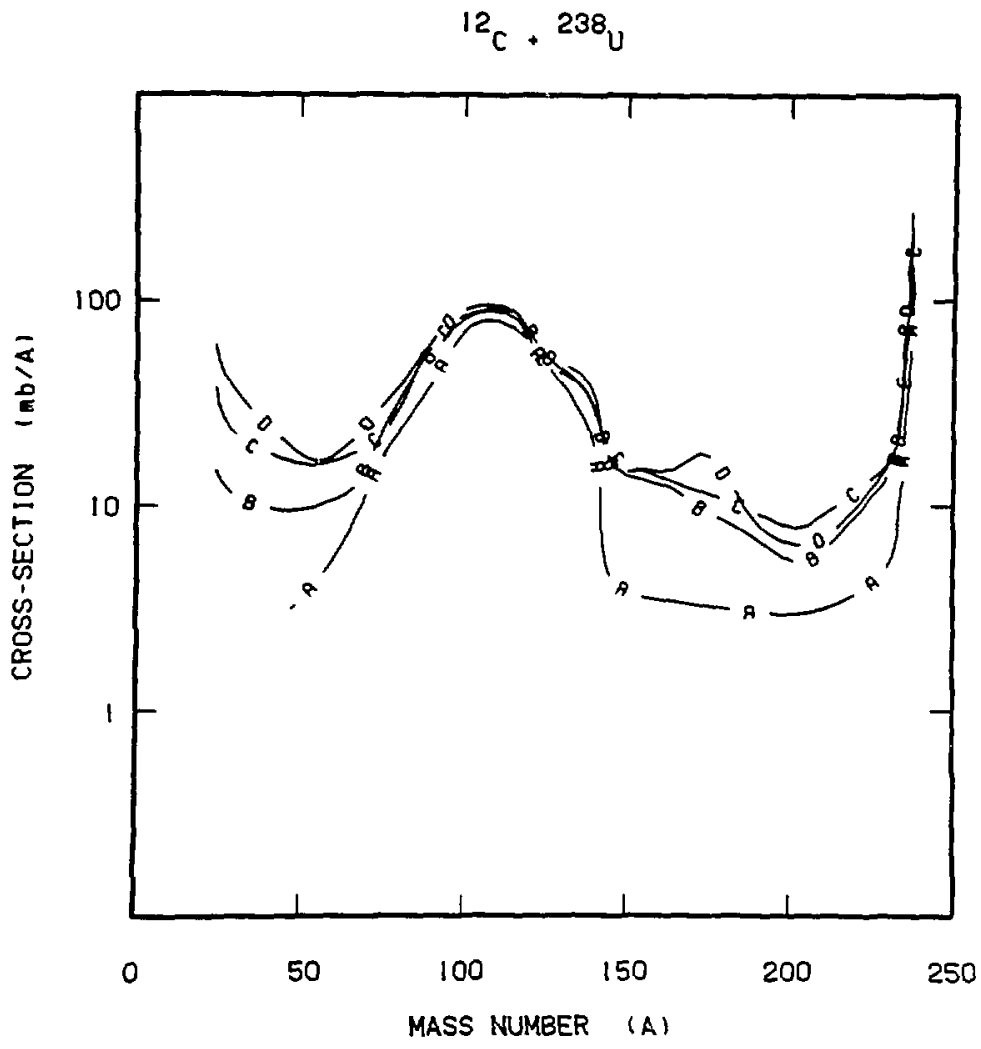

FIGURE 28, 


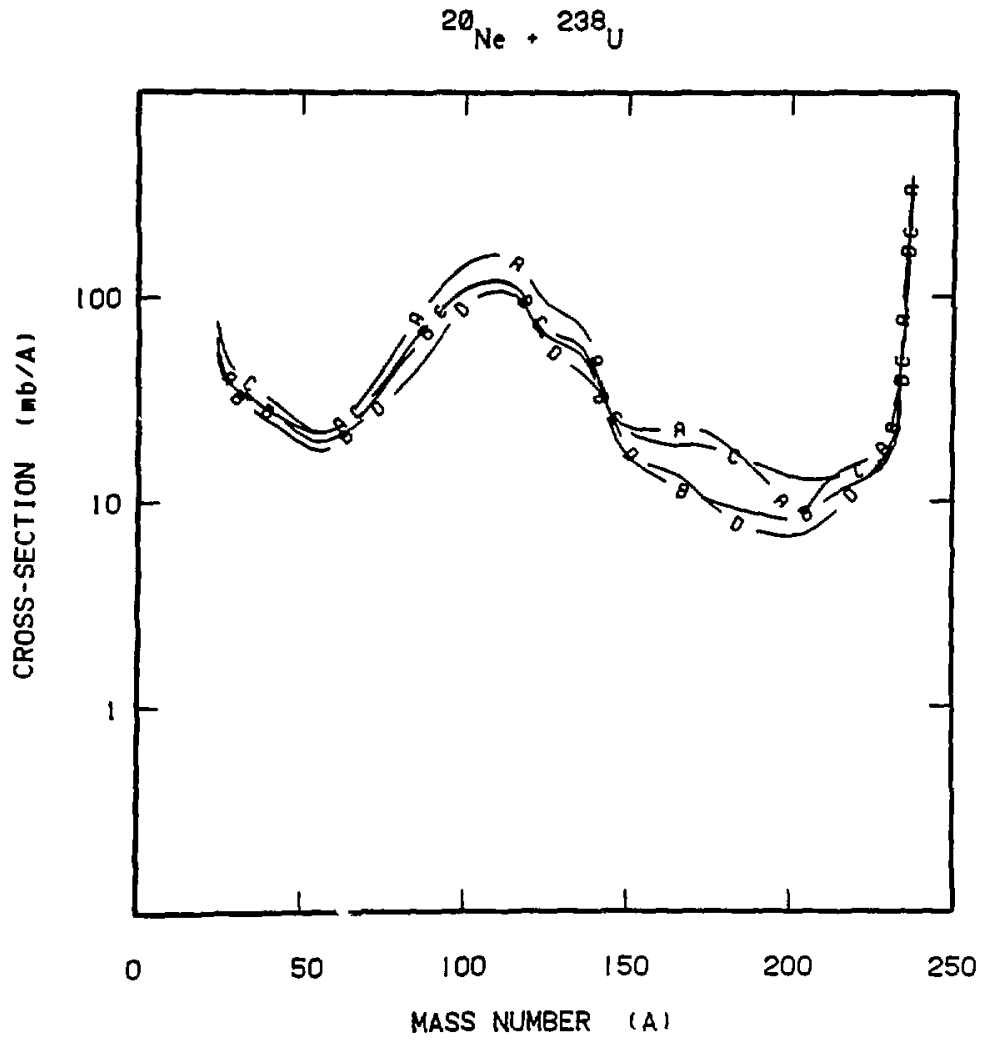

FIGURE 29. 


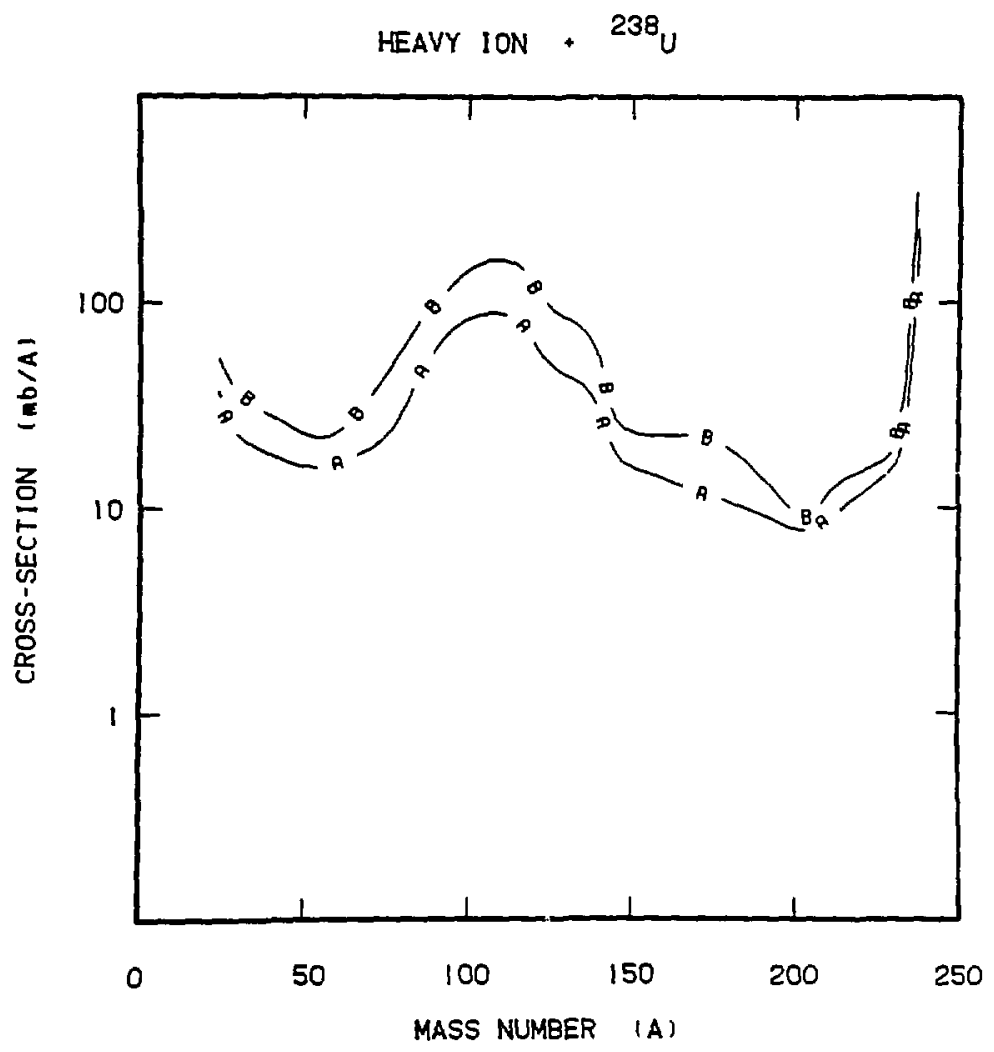

FIGURE 30. 


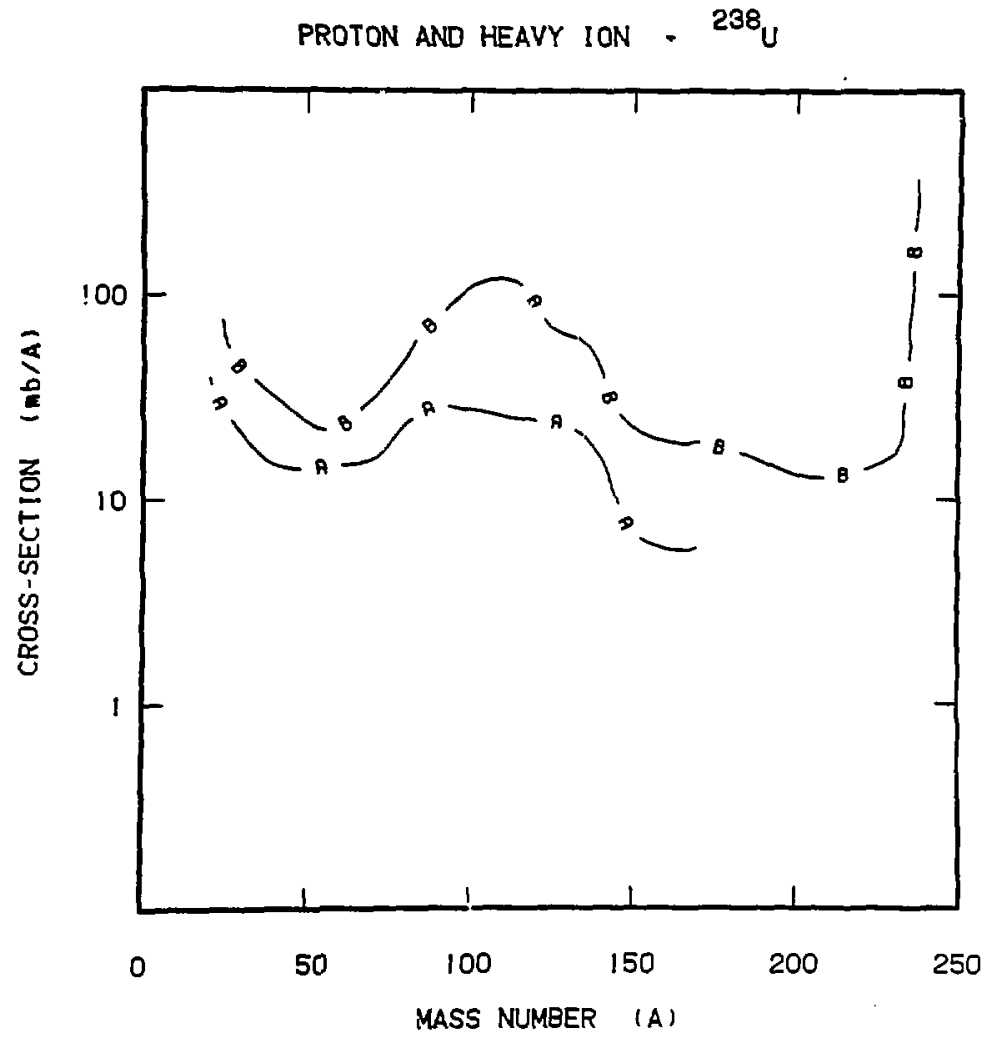

EIGURE 31. 


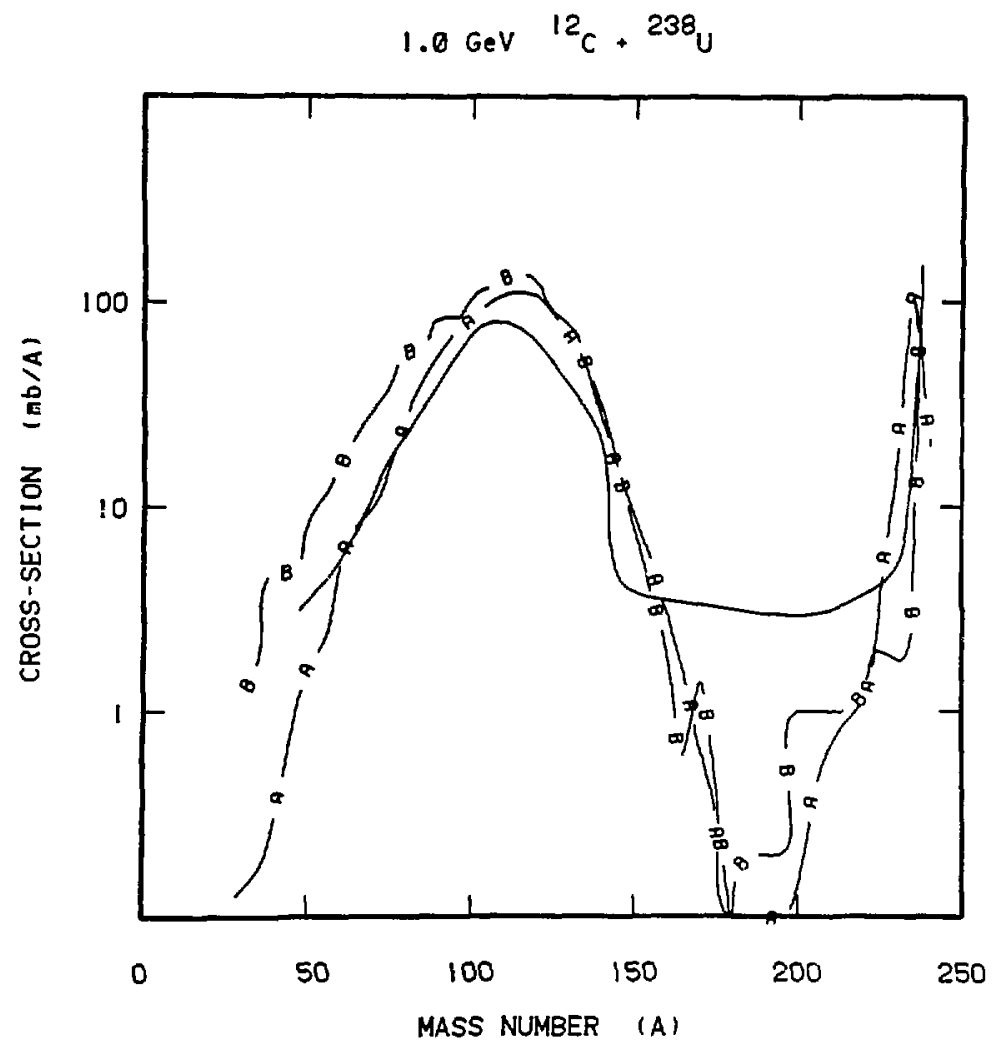

FIGURE 32. 


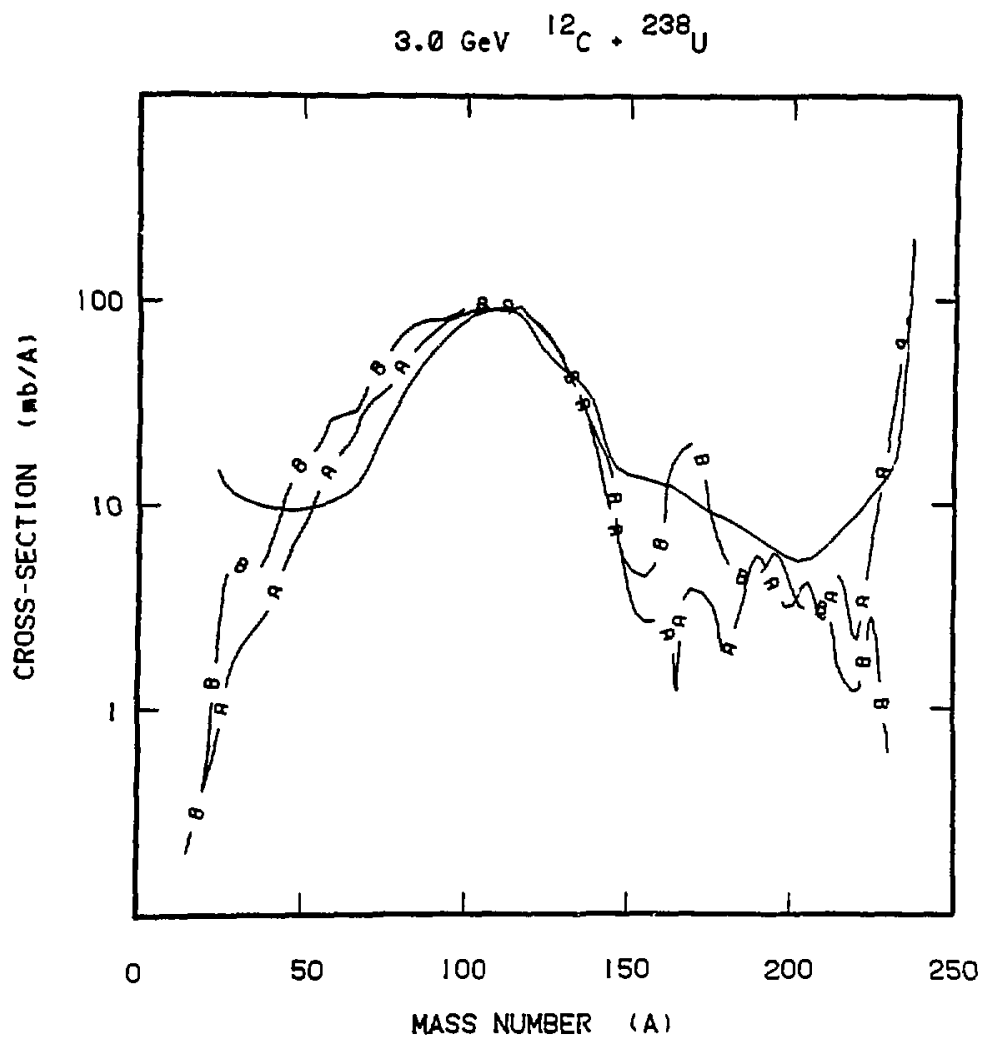

FIGURE 33. 


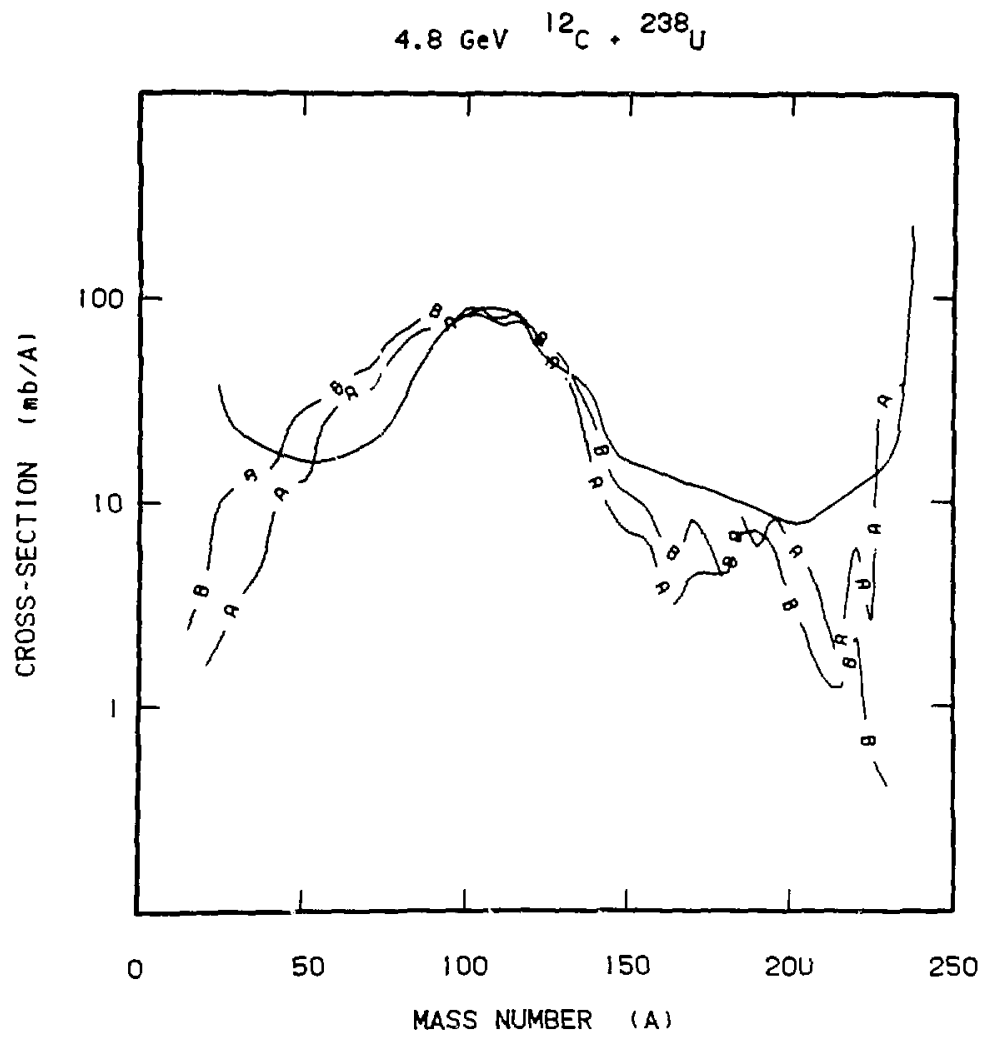

FIGURE 34. 


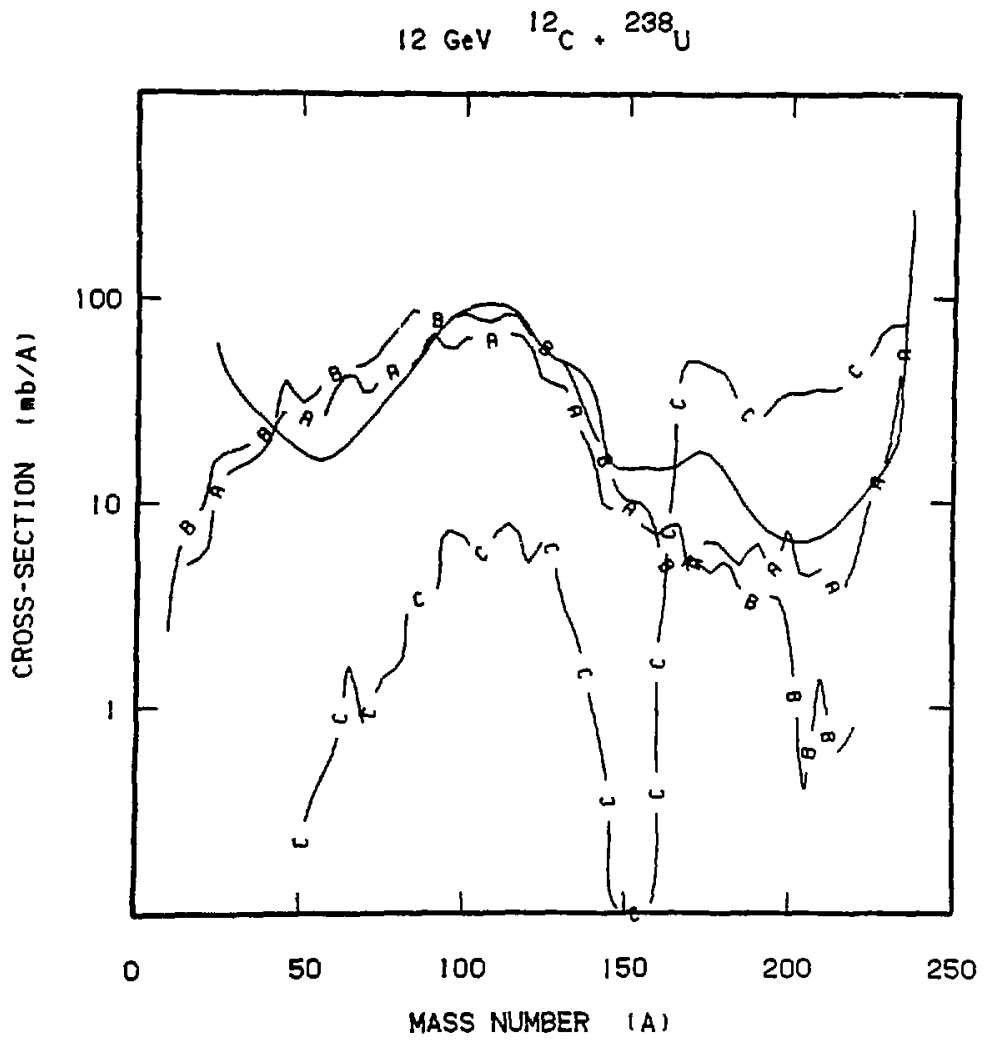

FIGURE 35. 


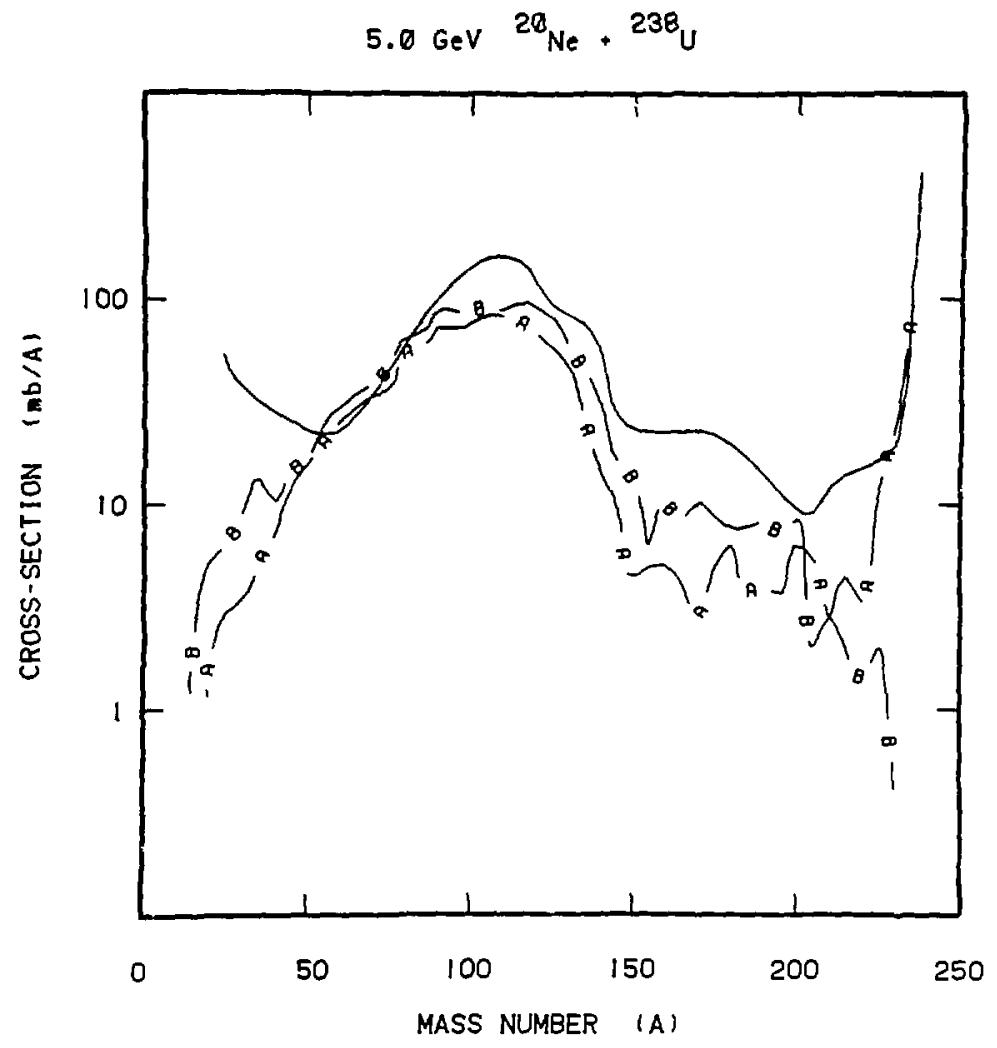

FICURE 36. 


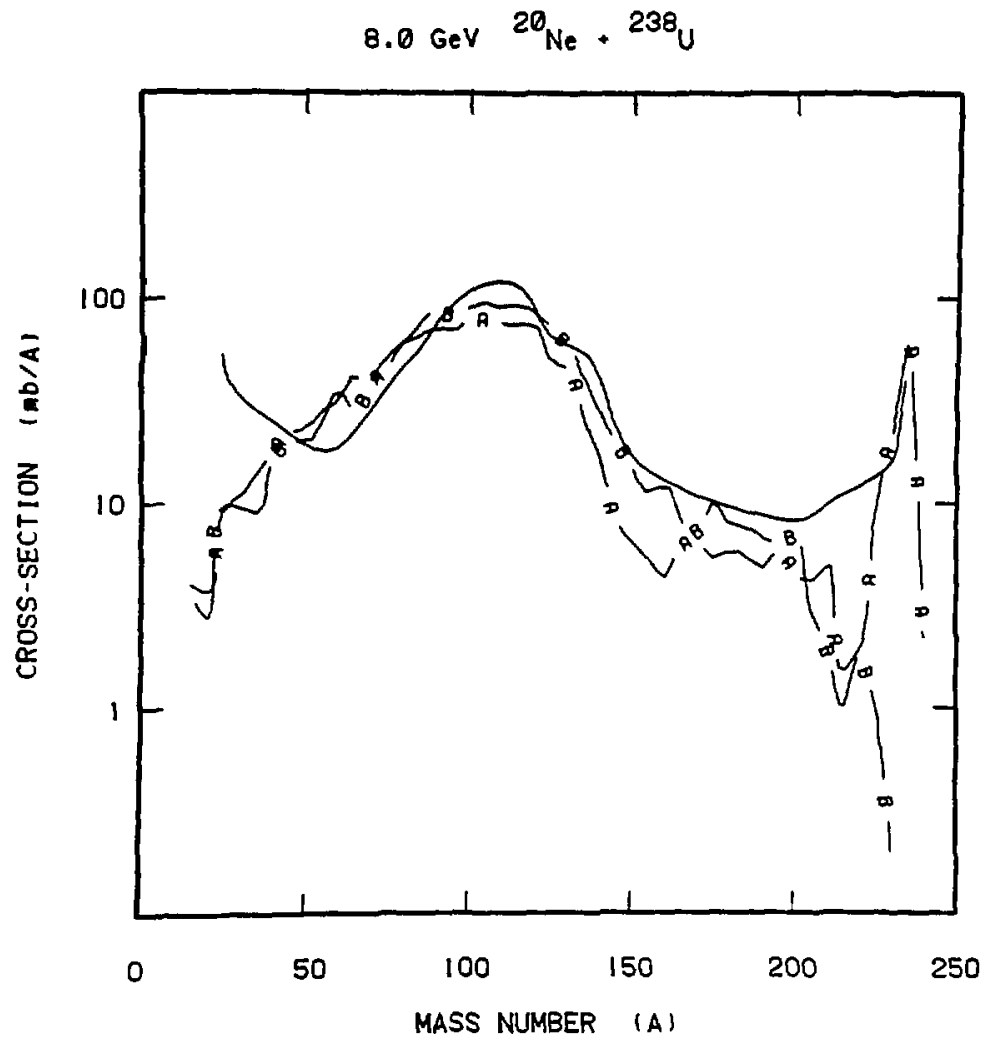

FIGURE 37. 
$20 \mathrm{GeV} 20_{\mathrm{Ne}}+{ }^{238} \mathrm{U}$

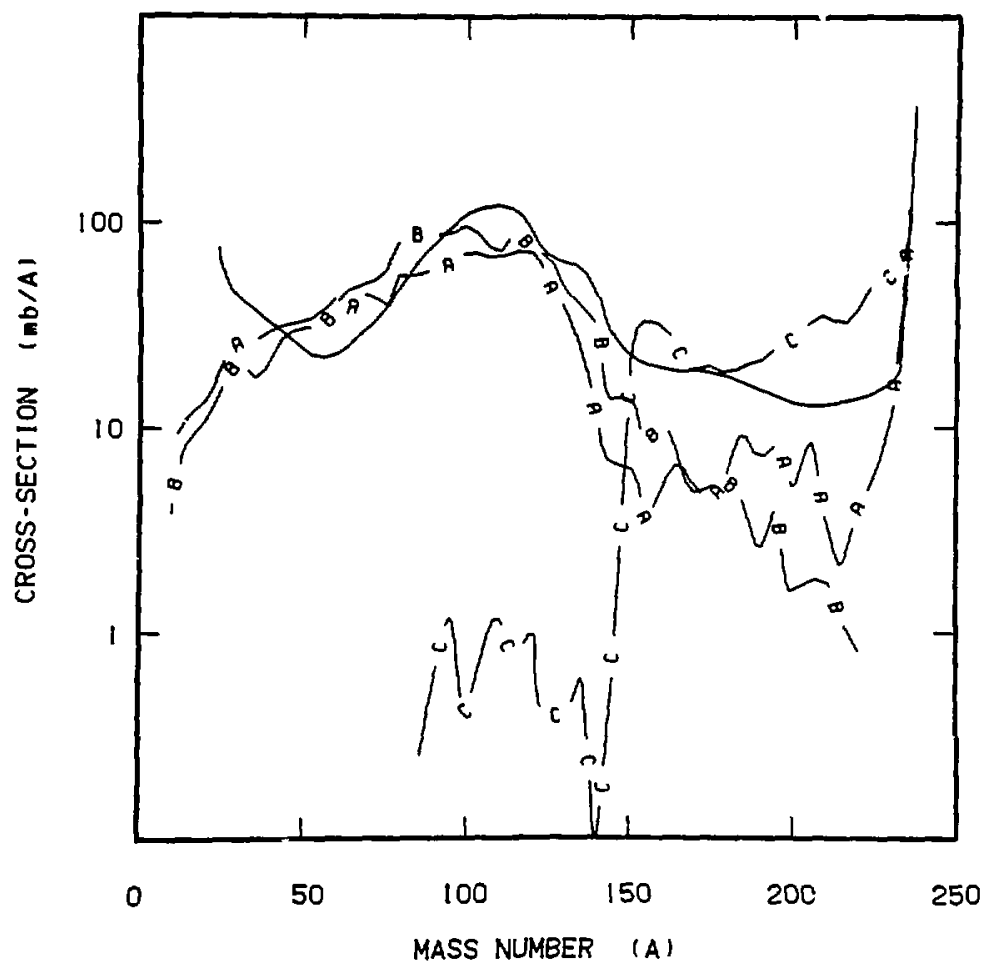

EIGURE 38. 


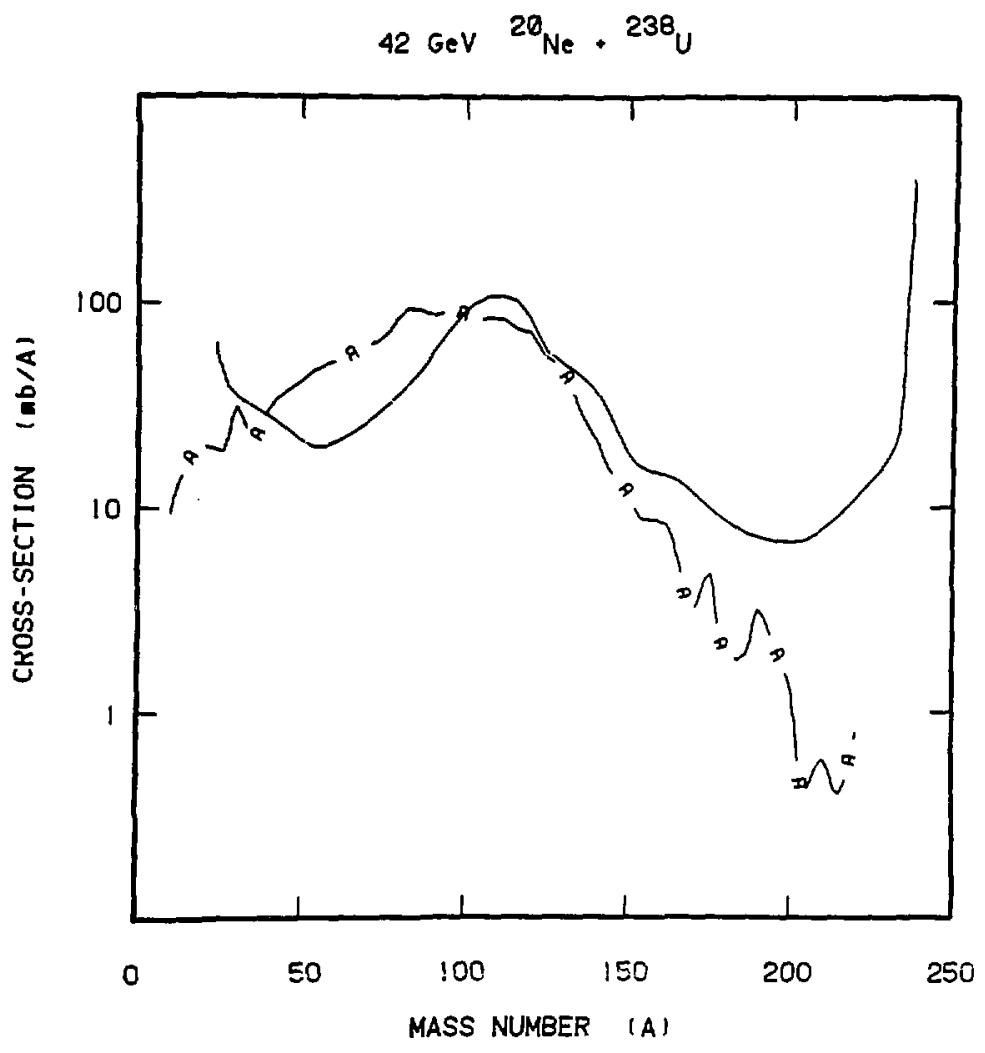

EIGURE 39. 


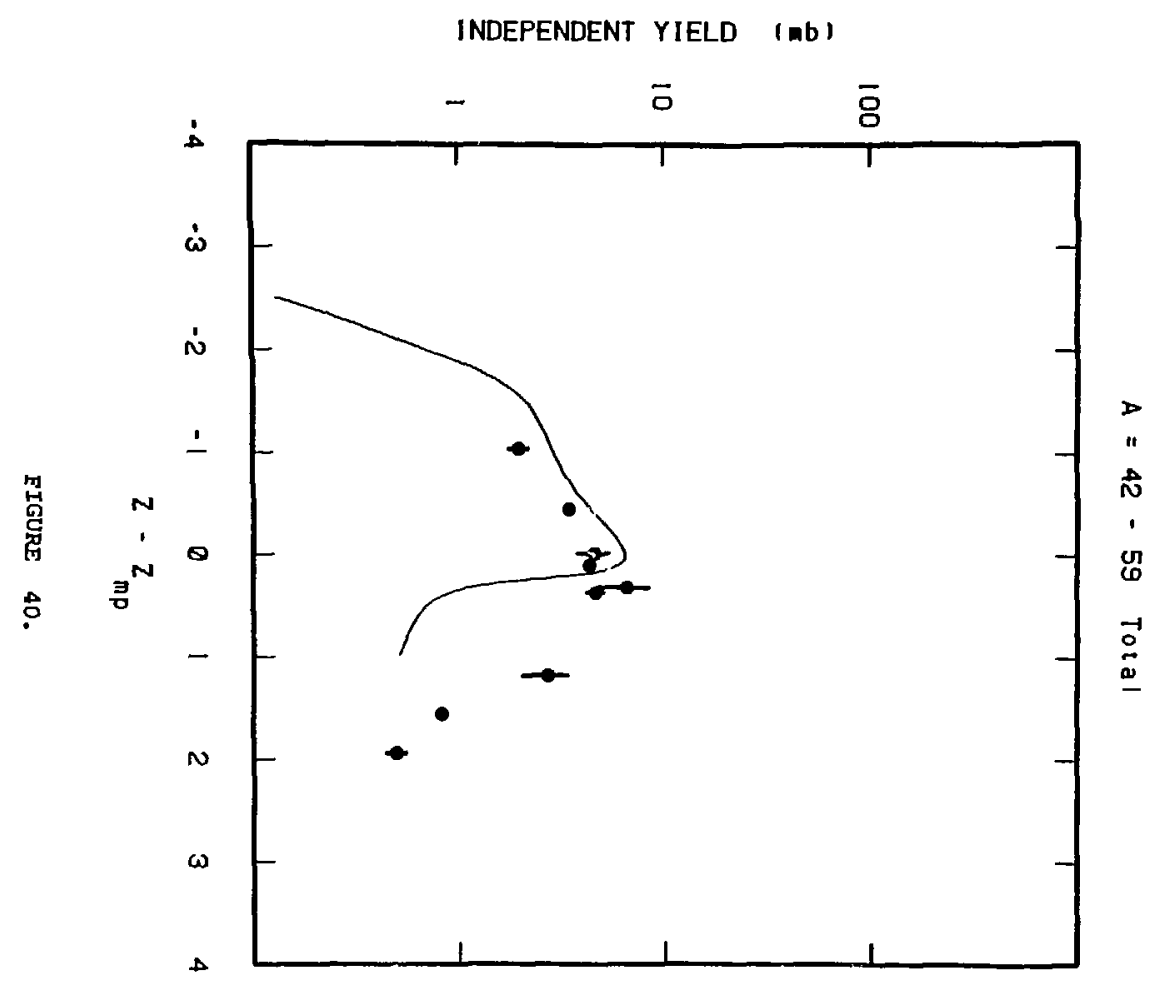




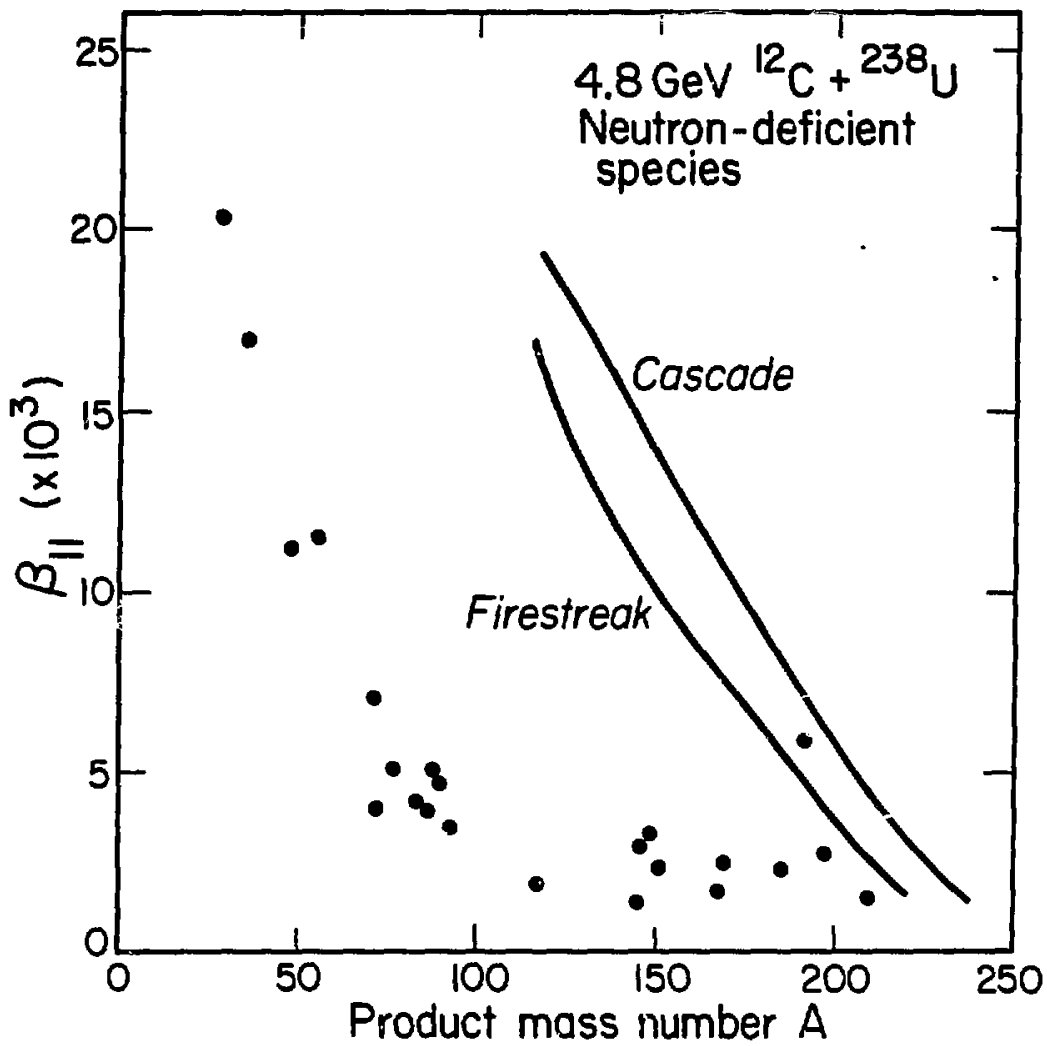

FIGURE 41.

XBL 808-1743 